\title{
EDUARDO AKISUE
}

\section{AVALIAÇÃO DA RESPOSTA INFLAMATÓRIA PERIAPICAL RESULTANTE DA INFILTRAÇÃO CORONÁRIA EM DENTES DE CÃES OBTURADOS COM DIFERENTES CIMENTOS RESINOSOS E TÉCNICAS OBTURADORAS}




\title{
Eduardo Akisue
}

\section{Avaliação da resposta inflamatória periapical resultante da infiltração coronária em dentes de cães obturados com diferentes cimentos resinosos e técnicas obturadoras}

\author{
Tese apresentada à Faculdade de \\ Odontologia da Universidade de São Paulo, para \\ obter o título de Doutor, pelo Programa de \\ Pós-Graduação em Ciências Odontológicas. \\ Área de Concentração: Endodontia \\ Orientador: Prof. Dr. Giulio Gavini
}

São Paulo 
Catalogação-na-Publicação

Serviço de Documentação Odontológica

Faculdade de Odontologia da Universidade de São Paulo

Akisue, Eduardo

Avaliação da resposta inflamatória periapical resultante da infiltração coronária em dentes de cães obturados com diferentes cimentos resinosos e técnicas obturadoras/ Eduardo Akisue; orientador Giulio Gavini. -- São Paulo, 2009.

142p. ; fig.; tab. ; $30 \mathrm{~cm}$.

Tese (Doutorado - Programa de Pós-Graduação em Ciências Odontológicas. Área de Concentração: Endodontia) -- Faculdade de Odontologia da Universidade de São Paulo.

1. Obturação do canal radicular - Infiltração coronária 2. Infiltração coronária - Periodontite periapical 3 . Endodontia

CDD 617.6342

BLACK D242

AUTORIZO A REPRODUÇÃO E DIVULGAÇÃO TOTAL OU PARCIAL DESTE TRABALHO, POR QUALQUER MEIO CONVENCIONAL OU ELETRÔNICO, PARA FINS DE ESTUDO E PESQUISA, DESDE QUE CITADA A FONTE E COMUNICADA AO AUTOR A REFERÊNCIA DA CITAÇÃO.

São Paulo,

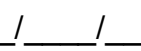

Assinatura:

E-mail: eakisue@usp.br 


\section{FOLHA DE APROVAÇÃO}

Akisue E. Avaliação da resposta inflamatória periapical resultante da infiltração coronária em dentes de cães obturados com diferentes cimentos resinosos e técnicas obturadoras [Tese de Doutorado]. São Paulo: Faculdade de Odontologia da USP; 2009.

São Paulo, / /2009

\section{Banca Examinadora}

1) $\operatorname{Prof}(a) \cdot \operatorname{Dr}(a)$.

Titulação:

Julgamento:

Assinatura:

2) $\operatorname{Prof}(a) . \operatorname{Dr}(a)$.

Titulação:

Julgamento:

Assinatura:

3) $\operatorname{Prof}(a) . \operatorname{Dr}(a)$.

Titulação:

Julgamento:

Assinatura:

4) $\operatorname{Prof}(a) . \operatorname{Dr}(a)$.

Titulação:

Julgamento:

Assinatura:

5) $\operatorname{Prof}(a) . \operatorname{Dr}(a)$.

Titulação:

Julgamento:

Assinatura: 


\section{DEDICATÓRIA}

\section{Ao Meu Pai, GOKITHI}

Exemplo de vida, fonte de inspiração, força e segurança.

"Os pais devem dar sempre para serem felizes. Dar sempre é o que faz que sejamos pais." (Honoré de Balzac)

Aquele que mostrou a importância da vida acadêmica. E apesar de tudo o melhor amigo...

... "A amizade é uma predisposição recíproca que torna dois seres igualmente ciosos da felicidade um do outro" (Platão)

Ao meu irmão, RODRIGO

"Em todo o tempo ama o amigo e na angústia nasce o irmão"

(Provérbios de Salomão)

A minha mãe, MARIA (in memorian)

"O amor de mãe é paz. Ele não precisa ser adquirido, não precisa ser merecido." (Erich Fromm)

"Em geral, as mães, mais que amar os filhos, amam-se nos filhos."

(Friedrich Nietzsche)

Mesmo estando distante sei que me acompanha e me ilumina por todo esse tempo. Você se faz presente em todos os momentos. 


\section{AGRADECIMENTOS}

Ao meu orientador Professor Doutor Giulio Gavini, pela amizade engrandecida, pela extrema capacitação e doação, e pela forma séria que norteia o meu pensamento científico.

"Nós somos aquilo que fazemos repetidamente. Excelência, então, não é um modo de agir, mas um hábito" (Aristóteles)

\section{Ao Prof. Dr. Marco Antonio Gioso}

Mesmo com os problemas recentes em pesquisas com animais, desde o início não colocou empecilhos à realização deste projeto, orientou e ajudou. Tornou-se amigo e minha referência em Odontologia Veterinária. Como da primeira vez, ainda irei bater na sua porta novamente. 


\section{Ao Prof. Dr. Celso Luiz Caldeira}

Pelo companheirismo, ensinamentos, orientações e bons momentos durante a nossa convivência nos diversos locais de trabalho.

As Profas. Dras. Silvia Vanessa Lourenço e Suzana C. Orsini Machado de Sousa Pela dedicação e tempo desprendido na digitalização, análise e escolha das figuras ilustrativas.

Aos professores Antonio Carlos Bombana, Carlos Eduardo Aun, Manoel Eduardo de Lima Machado, Abílio Albuquerque Maranhão de Moura, João Humberto Antoniazzi, José Luiz Lage-Marques, Marcelo dos Santos, Igor Prokopowistch e Marcia Martins Marques; essenciais na minha formação.

Aos colegas de doutorado, André Michelotto, Ângela Araki, Cácio Moura e Janet Chávez; e de mestrado, Rocio, Cabrales, Marina, Patricia Guerreiro e Soraia.

Aos novos amigos do Laboratório de Odontologia Comparada (LOC) da FMVZ-USP: Jonathan Ferreira, Lênin Villazmar, Fernanda Lopes, Fernanda Hofmann, Leslie Falqueiro, Marco Leon-Roman, Sérgio Camargo, Mariana Lage-Marques, João Rossi Jr, Terezinha e muitos outros. Obrigado pela constante ajuda e boas risadas no LOC II.

A Rocio, fiel companheira de horas e horas de experimento em ratos e cães. 
Ao funcionário do departamento de Cirurgia (VCl) da FMVZ-USP, Miron, guardião e o melhor amigo dos "meus" cães.

Aos técnicos da divisão de anatomia patológica do Hospital das Clínicas da FMUSP: Célio, Katsue e Lucilia.

Aos avaliadores dos cortes histológicos: Doutorandos Paulo Braz e Fabio Coracin; e Profa. Dra. Suzana C. Orsini Machado de Sousa.

Aos colegas da disciplina de Endodontia da UNISANTA, Giulio, Celso, Danilo, Érico, Jacob, Alexandre, Paulo, Kali, Chico, Maurílio, André, Guilherme, Luciana, Luciana Zaher, Giovanna, Thiago, Isabelle, Gustavo, Bruna, Marcela,

Aos colegas do curso de Especialização em Endodontia do CETAO, Celso, Érico e Carmen; e do curso CETAO-Itália, Celso, Edson e Simony.

Aos funcionários do departamento de Dentística da FOUSP, Neuza, Ana Maria, Luizinho, Arnaldo, Aldo, David, Selma, Sonia e Cleber; pelo convívio amigo e ajuda diante das dificuldades encontradas.

À Vânia e Luzia, Cláudia e Pascoal; bibliotecários da FOUSP (SDO), sempre eficientes e solícitos.

A todos que, de uma forma ou de outra, contribuíram para a realização deste trabalho. 
E não por último, a Deus, por tudo: pela família, pelos amigos, pelo trabalho e por todos os momentos da minha vida.

A vocês, muito obrigado! 
Akisue E. Avaliação da resposta inflamatória periapical resultante da infiltração coronária em dentes de cães obturados com diferentes cimentos resinosos e técnicas obturadoras [Tese de Doutorado]. São Paulo: Faculdade de Odontologia da USP; 2009.

\section{RESUMO}

Considerando-se a necessidade da obturação tridimensional e o adequado selamento marginal do sistema de canais radiculares, como fatores decisivos para o êxito da terapia endodôntica, este estudo objetivou avaliar as respostas inflamatórias periapicais resultantes da infiltração coronária em dentes de cães obturados com diferentes cimentos resinosos (AH Plus ${ }^{\circledR}$, RealSeal $^{\circledR}$ e RealSeal SE ${ }^{\circledR}$ ) e técnicas obturadoras (condensação lateral e termoplástica). Para tanto, pré-molares e incisivos centrais e laterais de 5 cães tiveram o tratamento endodôntico realizado empregando-se limas de NiTi e creme de Endo PTC associado ao hipoclorito de sódio a 1\%, estabelecendo-se como limite de instrumentação à distância de $1 \mathrm{~mm}$ a $1.5 \mathrm{~mm}$ aquém do vértice radiográfico. A seguir os condutos foram obturados de acordo com os grupos experimentais $(n=12)$ e grupos controles $(n=10)$ : GI- AH

Plus/condensação lateral, Gll- $\quad \mathrm{AH}$ Plus/termoplástificação, GIllRealSeal/condensação lateral, GIV- RealSeal/ termoplástificação, GV- RealSeal SE/condensação lateral, GVI- RealSeal SE/ termoplástificação, Grupo controle positivo e Grupo controle negativo. As cavidades coronárias ficaram expostas ao meio bucal por um período de 75 dias e, passado este período experimental, os cães foram eutanásiados por superdosagem de anestésico. Foi realizada a remoção cirúrgica das partes correspondentes aos pré-molares e incisivos da maxila e da 
mandíbula, fixação das mesmas em solução de formol a $10 \%$ por $72 \mathrm{~h}$ e desmineralização em solução de ácido fórmico a $20 \%$ + citrato de sódio a $10 \%$ pelo período mínimo de 90 dias. Posteriormente, realizou-se a rotina histológica com cortes seriados com espessura de $6 \mu \mathrm{m}$ e estes foram corados com hematoxilina e eosina (HE). Cada corte histológico foi digitalizado e analisado em relação à existência de patologia periapical por três avaliadores independentes. Os dados obtidos foram confrontados estatisticamente utilizando o teste de Kruskal-Wallis seguido do teste comparativo de Dunn, observando-se que em relação às técnicas, a termoplástificação por ondas contínuas de condensação associada à técnica de injeção mostrou melhores condições periapicais quando comparada à técnica de condensação lateral $(p=0.0055)$, sendo que a utilização desta técnica resultou em reações inflamatórias mais intensas para o cimento RealSeal SE $(p=0.002)$. Em relação aos cimentos avaliados, o RealSeal SE mostrou-se menos eficaz em evitar a percolação, produzindo maiores níveis de inflamação crônica independentemente do sistema de obturação $(p=0.0088)$.

Palavras-Chave: Obturação do canal radicular, Infiltração dental, AH Plus, Real Seal, Periodontite apical. 
Akisue E. Evaluation of periapical inflammation response from coronal leakage in dog's teeth obturated using different resin-based sealers and different obturation techniques [Tese de Doutorado]. São Paulo: Faculdade de Odontologia da USP; 2009.

\section{ABSTRACT}

Considering the need for three-dimensional obturations and adequate marginal sealing of the radicular canal system as being decisive factors for successful endodontic therapy, this study had as its objective the evaluation of periapical inflammatory responses resulting from coronary infiltration in dog's teeth obturated using different resin sealers (AH Plus, RealSeal and RealSeal SE) and different obturation techniques (lateral condensation and thermoplastic). For this study, premolars, central and lateral incisors from five dogs had endodontic treatment employing NiTi files and Endo PTC cream associated with 1\% sodium hypochlorite. The working length was established at a distance of 1.0 to $1.5 \mathrm{~mm}$ short of the radiographic apex. After this, the teeth were obturated according to their experimental groups $(n=12)$ and control groups $(n=10)$. The groups were defined as follows: GI - AH Plus/lateral condensation, GII - AH Plus/thermoplastic, GIII RealSeal/lateral condensation, GIV - RealSeal/thermoplastic, GV - RealSeal SE/lateral condensation, GVI - RealSeal SE/ thermoplastic, a positive control group and a negative control group. The coronal access were left exposed to the oral environment for a period of seventy-five days, and after this experimental period, the dogs were euthanized by anesthetic overdose. The parts corresponding to the premolars and the maxilar incisors were surgically removed. These were then submitted to a solution of $10 \%$ formol for 72 hours and then demineralized in a solution of $20 \%$ 
formic acid and $10 \%$ sodium citrate for a minimum period of ninety days. Before hand, a histological routine of serial cuts having a width of $6 \mu \mathrm{m}$ was undertaken and these were colored with hematoxilin and eosin (HE). Each histological cut was digitalized and analyzed with respect to the existence of periapical inflammation by three independent evaluators. The data obtained was statistically compared, firstly using the Kruskal-Wallis test and then the comparative Dunn test, where it was noted that in relation to the techniques, thermoplastification by continuous wave of condensation associated with the injection technique showed better periapical conditions than what was seen for the lateral condensation technique $(p=0.0055)$. On the other hand, for the sealers evaluated, the condensation technique resulted in more intense inflammatory reactions when the sealer RealSeal SE was used $(p=0.002)$. In relation to the sealers evaluated, RealSeal SE was seen to be less effective against percolation, thus producing greater levels of chronic inflammation irrespective of the obturation system employed $(p=0.0088)$.

Key words: Root canal obturation, AH Plus, Real Seal, Dental leakage, Periapical periodontitis. 



\section{LISTA DE ABREVIATURA E SIGLAS}

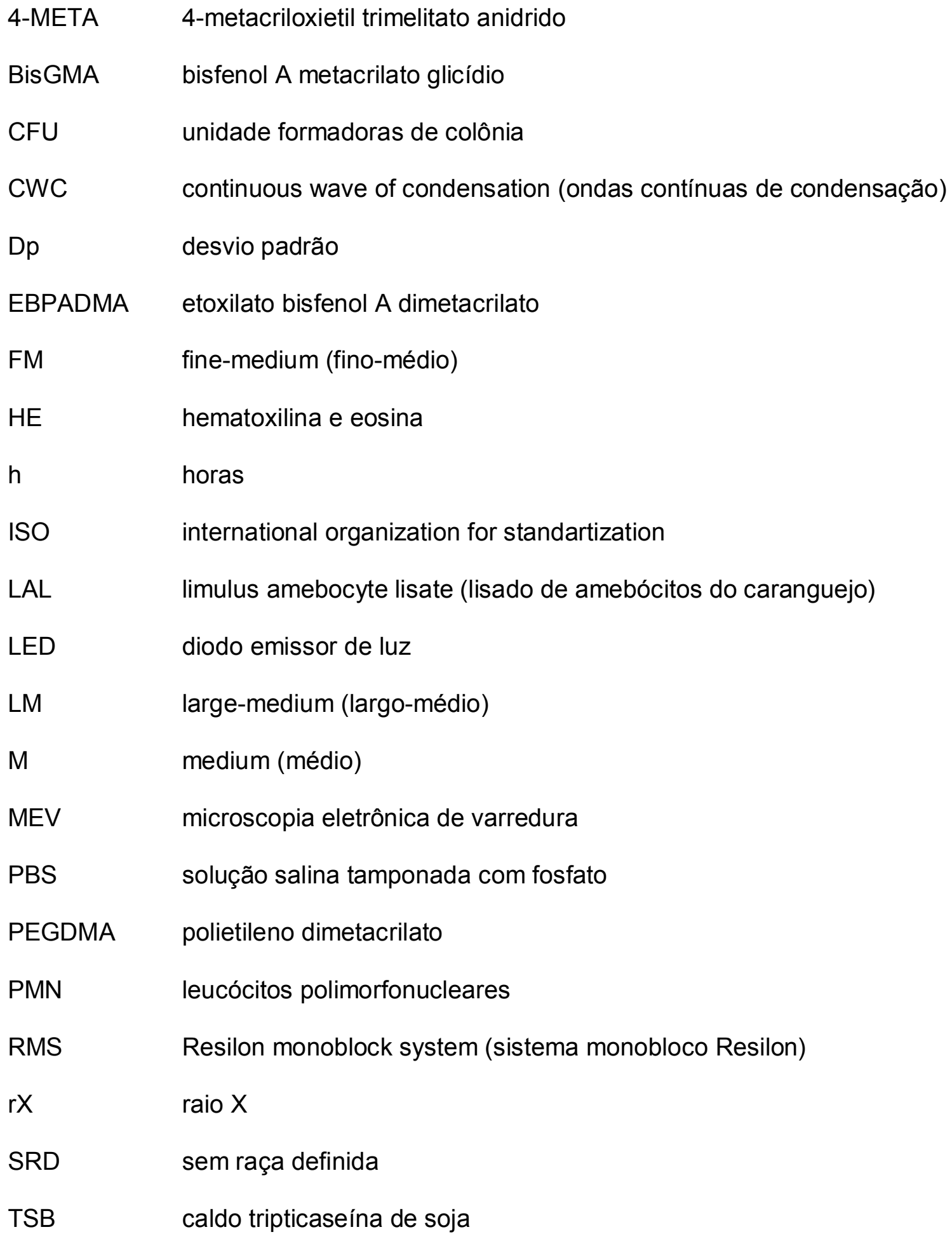


UDMA uretano dimetacrilato

UE

unidade de endotoxina 


\section{LISTA DE SÍMBOLOS}

\begin{tabular}{|c|c|}
\hline$\alpha$ & alfa \\
\hline$\beta$ & beta \\
\hline $\mathrm{cm}$ & centímetro \\
\hline $\mathrm{cm} \mathrm{H}_{2} \mathrm{O}$ & centimetros de água \\
\hline g & grama \\
\hline${ }^{\circ} \mathrm{C}$ & graus Celsius \\
\hline$=$ & igual \\
\hline $\mathrm{kg}$ & kilograma \\
\hline+ & mais \\
\hline \pm & mais ou menos \\
\hline$\mu \mathrm{m}$ & micrômetro \\
\hline $\mathrm{mg}$ & miligrama \\
\hline $\mathrm{mm}$ & milímetro \\
\hline $\mathrm{mL}$ & mililitro \\
\hline $\min$ & minuto \\
\hline$p$ & nível de significância \\
\hline $\mathrm{N}$ & Newton \\
\hline$\%$ & porcentagem \\
\hline \# & número \\
\hline
\end{tabular}




\section{SUMÁRIO}

p.

1 INTRODUÇÃO ........................................................ 17

2 REVISÃO DA LITERATURA ............................................ 20

2.1 Cimentos de uso endodônticos........................................ 24

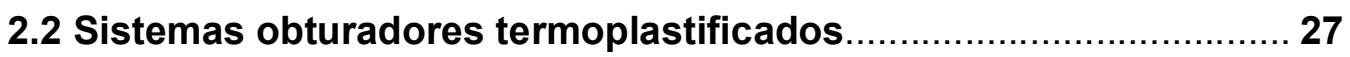

2.3 Infiltração com marcadores não biológicos ....................................32

2.4 Infiltração com marcadores biológicos ........................................... 44

2.5 Estudos de resposta inflamatória in vivo.......................................51

3 PROPOSIÇÃO.................................................... 56

4 MATERIAL E MÉTODOS .............................................. 57

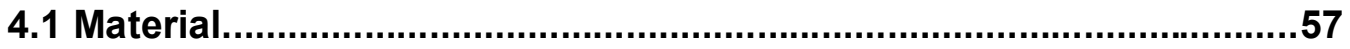

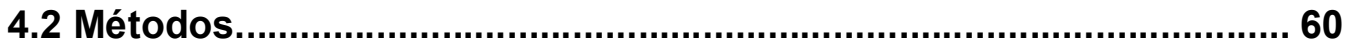

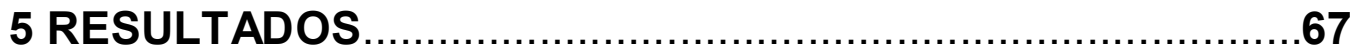

5.1 Da avaliação histopatológica das regiões periapicais.....................67

5.1.1 Análise descritiva do grupo controle positivo (CP)......................68

5.1.2 Análise descritiva do grupo controle negativo (CN).................... 70

5.1.3 Análise descritiva do grupo GI-AH Plus/condensação lateral......72

5.1.4 Análise descritiva do grupo GII-AH Plus/termoplástica.................74

5.1.5 Análise descritiva do grupo GIII-RealSeal/condensação lateral... 76

5.1.6 Análise descritiva do grupo GIV-RealSeal/ termoplástica............. 78

5.1.7 Análise descritiva do grupo GV-RealSeal SE/cond. lateral.......... 80 
5.1.8 Análise descritiva do grupo GVI-RealSeal SE/ termoplástica....... 82

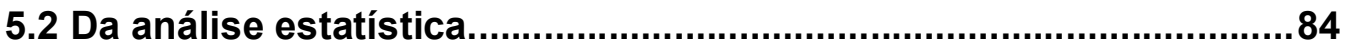

5.2.1 Em relação às técnicas de obturação.......................................... 84

5.2.2 Em relação aos cimentos endodônticos....................................... 85

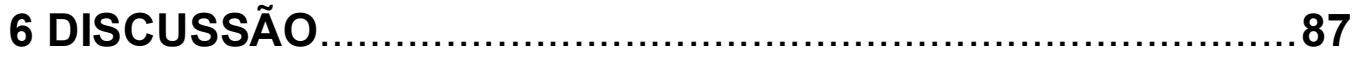

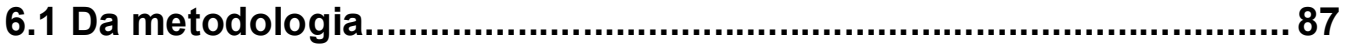

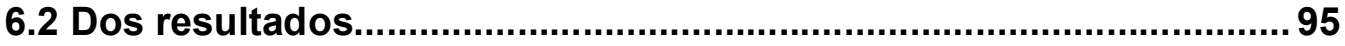

6.2.1 Em relação às técnicas de obturação...............................................95

6.2.2 Em relação aos cimentos endodônticos........................................ 98

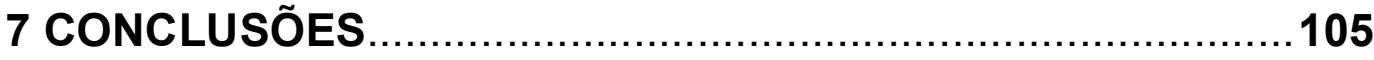

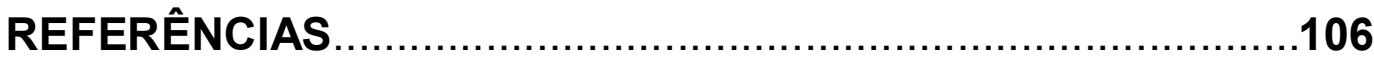

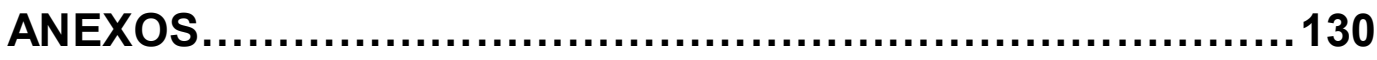

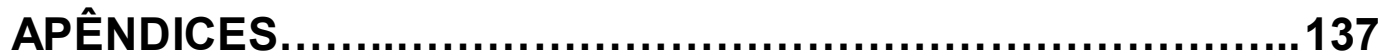




\section{INTRODUÇÃO}

A chave do sucesso na terapia endodôntica depende das diversas etapas desde a fase de cirurgia de acesso até a restauração do elemento dental, tendo como objetivo final deste tratamento a reparação da ferida endodôntica e a volta do elemento dental a normalidade fisiológica. A obturação do sistema de canais radiculares tem como objetivo o completo selamento do sistema de canais radiculares.

A partir do trabalho histórico de Ingle (1962) que atribuí cerca de $60 \%$ dos insucessos às obturações inadequadas ou incompletas do canal radicular, diversos são os trabalhos que relacionam o insucesso do tratamento com a falta de selamento do espaço endodôntico.

Falhas na obturação do conduto radicular ou nas restaurações favorecem o processo de percolação marginal.

A infiltração apical no canal radicular é descrita como o movimento de fluidos, microorganismos e suas toxinas pelo forame apical, e a infiltração coronária como o mesmo ocorrendo pela abertura cervical. Ambos proporcionam percolação pela interface entre o material obturador e a parede dentinária que pode ocasionar a chegada de microorganismos na região periapical ou que; ao recontaminar o conduto, esses produtos nutrem bactérias remanescentes da etapa de preparo do canal. Tal acontecimento passa a induzir a continuidade ou aparecimento de um processo patológico.

Para a análise da eficácia do selamento marginal, vários são os trabalhos que usam metodologias que empregam marcadores não biológicos (corantes, transporte 
de fluidos e penetração de glicose) e marcadores biológicos (bactérias e endotoxinas). Porém, a análise da resposta periapical frente ao tratamento endodôntico só pode ser avaliado de forma confiável em modelos experimentais in vivo.

Sabendo que infiltrações em tratamentos endodônticos resultam na continuidade do processo patológico, na tentativa de minimizar tais falhas atualmente tem se dado maior ênfase as técnicas de obturação termoplastificadas que proporcionam preenchimentos com maior densidade de material sólido, e também aos novos cimentos à base de resinas ou metacrilatos que incorporam a idéia da adesão dentinária concebidas para a dentística restauradora com o uso de agentes condicionantes compostos de monômeros ("primer").

Muitos são os sistemas termoplásticos que se mostram eficientes em relação à capacidade de preenchimento, porém diversos são os trabalhos científicos que comprovam a eficiência do sistema de condensação vertical aquecida ou por ondas contínuas de condensação (System $\mathrm{B}^{\circledR}$ ) associada a sistema de obturação por injeção de guta-percha Obtura $\|^{\circledR}$.

Com relação aos novos cimentos endodônticos a base de metacrilatos, poucos são os trabalhos in vivo avaliando a eficiência desses novos cimentos endodônticos resinosos com relação à percolação marginal seja utilizado com técnicas de obturação convencionais ou termoplásticas. Além disso, atualmente, novos cimentos a base de metacrilatos tem incorporado num único produto o agente condicionante (primer) que antes era utilizado previamente à aplicação do cimento.

A fim de atingir a excelência na prevenção da percolação marginal nos tratamentos endodônticos, parece pertinente a realização de pesquisas in vivo que avaliem e comparem a capacidade de selamento desses cimentos de uso 
endodôntico á base de metacrilatos associado às técnicas convencionais e termoplásticas de obturação. 


\section{REVISÃO DA LITERATURA}

Tem-se como sucesso da terapia endodôntica a reparação da ferida e o retorno do elemento dental às suas funções fisiológicas. Sabe-se que este sucesso está diretamente relacionado ao controle da infecção endodôntica, obtida pela modelagem e sanificação do conduto, sendo mantida pela adequada obturação.

As bactérias normalmente encontradas na cavidade oral são capazes de invadir o espaço endodôntico, desencadeando inflamação no tecido pulpar que pode resultar na sua mortificação, gerando alterações na região periapical (MÖLLER et al., 1981; NAIR, 2006; SIQUEIRA; ROÇAS, 2008).

Trabalho pioneiro de Kakehashi, Stanley e Fitzgerald (1965) não verificou nenhuma alteração patológica quando da exposição pulpar a cavidade oral em ratos "germ-free"; por outro lado, o mesmo procedimento em animais normais levou a formação de lesões periapicais, concluindo que a presença de microorganismos é fator fundamental para o aparecimento da lesão apical.

Clinicamente as infecções endodônticas desencadeiam processos periapicais e dependendo da interação entre a microbiota e as defesas do hospedeiro, este pode evoluir para periodontites apicais crônicas ou agudas.

Inúmeros autores têm estudado a microbiota dos canais radiculares e de lesões periapicais, constatando-se que as infecções endodônticas são polimicrobianas com predominância de anaeróbios estritos e facultativos (ABOURASS; BOGEN, 1998; BLOME et al.,2008; GOMES et al., 2004; JACINTO et al., 2007; MÖLLER et al., 1981; PETERS; WESSELINK; VAN WINKELHOFF, 2002; SIQUEIRA; ROÇAS, 2008; SUNDQVIST, 1992, 1994; SUNDQUIVST et al., 1998; 
VIANNA et al., 2005). Características semelhantes são encontradas em dentes com infecção endodôntica primária (GOMES et al.,, 2004; GOMES et al., 2008; GOMES; LILLEY;DRUCKER, 1996; SASSONE et al., 2008; SIQUEIRA et al., 2002; SIQUEIRA; ROÇAS, 2008), onde destacam-se a predominância de bactérias anaeróbias.

Entende-se por obturação o selamento marginal do sistema de canais radiculares que evita a percolação do infiltrado inflamatório, de microorganismos e seus subprodutos pelo forame apical ou de bactérias oriundas da cavidade oral pela abertura coronária.

Falhas no selamento marginal proporcionam a percolação de nutrientes que possibilitam o desenvolvimento de microorganismos oriundos da cavidade oral ou remanescentes da fase de preparo do canal radicular, resultando no surgimento ou manutenção de lesão periapical (NAIR, 2006; NAIR et al., 1990; SIQUEIRA, 2005; SIQUEIRA; ROÇAS 2008; YOSHIDA et al., 1987). Além disso, exsudatos e leucócitos provenientes da região periapical tendem a se acumular e decompor nos espaços vazios do canal radicular, resultando em metabólitos que atuam como irritantes na região periapical (COOLIDGE, 1933).

Justificando a assertiva acima, Dixon e Rickert ${ }^{1}$ (1933, apud PAIVA; ANTONIAZZI, 1991) mostraram que após o implante de tubos ocos de platina em animais de laboratório, ocorre o aparecimento de áreas de inflamação junto às extremidades desses tubos. Entretanto, ao repetirem o experimento com tubos maciços, não observaram a ocorrência de resposta inflamatória.

Com relação à dependência do sucesso da terapia endodôntica com a obturação, Dow e Ingle (1955) demonstraram in vitro a possibilidade de percolação

\footnotetext{
${ }^{1}$ Dixon CM, Rickert UG. Tissue tolerance to foreign materials. J Am Dent Assoc 1933;20(8):1458-72.
} 
apical utilizando isótopo radioativo $\left(\left(^{131}\right)\right.$ em canais que não possuíam um adequado vedamento, concluindo que in vivo, a mesma penetração poderia levar à inflamação periapical e, em conseqüência, ao insucesso endodôntico.

Ingle (1956) destacou que aproximadamente $75 \%$ dos insucessos endodônticos estão relacionados à incorreta obturação do canal radicular.

Este mesmo autor, num levantamento sobre êxitos e fracassos em Endodontia denominado Estudo de Washington, avaliou 1229 dentes tratados endodonticamente (INGLE, 1962). Controles clínicos e radiográficos efetuados dois anos após a conclusão dos tratamentos indicaram $91,54 \%$ de sucesso. Avaliando os $8,46 \%$ de insucesso (104 casos), verificaram que $63,46 \%$ estavam relacionados à percolação, distribuindo-se da seguinte forma: 58,66\% apresentavam canais parcialmente obturados, $2,88 \%$ canais não obturados e $1,92 \%$ eram casos em que o cone de prata havia sido removido acidentalmente durante o procedimento restaurador.

Outros trabalhos também mostram um alto índice de sucesso dos tratamentos endodônticos (CHEVIGNY et al., 2008; FARZANEH et al., 2004; FRIEDMAN; ABITBOL; LAWRENCE, 2003; IMURA et al., 2007; LUMLEY; LUCAROTTI; BURKE, 2008; MARQUIS et al., 2006; NG et al., 2003; NG et al., 2007; SALEHRABI; ROTSTEIN, 2004; SJÖGREN et al., 1990) e a relação do insucesso com as falhas na obturação (BARBAKOW; CLEATON-JONES; FRIEDMAN, 1980; CHEVIGNY et al., 2008; FRISK; HUGOSON; HAKEBERG, 2008; NAIDORF, 1974; OLIVER ;ABBOTT, 1997; PETERSSON et al., 1986; SAUNDERS; SAUNDERS, 1994; SMITH; SETCHELL; HARTY, 1993; SUNDQVIST et al., 1998; TOURÉ et al., 2008). 
Numa análise crítica sobre esta problemática, afere-se que a alta incidência de insucessos decorre não só da inobservância dos limites apicais da obturação, mas, principalmente, do não preenchimento do sistema de canais radiculares na totalidade de suas dimensões, pelo material obturador. Esta falha proporciona o desenvolvimento de microorganismos no interior do conduto e, conseqüentemente, o surgimento ou manutenção da lesão periapical, culminando no insucesso da terapia endodôntica.

Visando a melhoria do selamento marginal, diversas técnicas obturadoras e cimentos endodônticos têm surgido nos últimos anos.

Dentre os diversos cimentos endodônticos, os cimentos a base de resina mostram-se mais efetivos na capacidade de selamento. Ademais, a idéia da adesão dentinária vinda da dentística restauradora mostra-se uma nova opção para o alcance da excelência na prevenção da percolação marginal nas obturações endodônticas.

Devido à recente introdução no mercado, poucos são os trabalhos que mostram a relação adequada entre obturações com cimentos resinosos com propriedades adesivas e o sucesso do tratamento endodôntico (CONNER et al., 2007; COTTON et al., 2008).

Do mesmo modo, as técnicas de obturação termoplásticas, dentre elas a mais difundida e avaliada técnica da condensação vertical aquecida ou por ondas contínuas de condensação (CWC), têm-se mostrado eficientes contra a infiltração marginal resultando em sucesso do tratamento endodôntico (AQRABAWI, 2006; CHEVIGNY et al., 2008; FARZANEH et al., 2004; FRIEDMAN; ABITBOL; LAWRENCE, 2003; MARQUIS et al., 2006). 


\subsection{Cimentos de uso endodôntico}

Apesar da guta-percha ser o principal componente da obturação endodôntica, os cimentos são essenciais na adesão deste material junto à parede do canal radicular e na união dos diversos cones de guta-percha.

Os cimentos endodônticos devem possuir para isso diversas propriedades, sendo que entre elas, pode-se destacar: tempo de trabalho, estabilidade dimensional, escoamento, radiopacidade, adesividade, insolubilidade, biocompatibilidade e capacidade de selamento.

É grande o número de cimentos no mercado odontológico. Podemos classificá-los em diversos grupos de acordo com a composição: cimentos à base de óxido de zinco e eugenol, hidróxido de cálcio, resinosos, ionômero de vidro e a base de polivinilsiloxano.

A literatura tem destacado os cimentos resinosos devido às vantagens quanto ao tempo de trabalho, adesividade, biocompatibilidade e capacidade de selamento.

O cimento $\mathrm{AH} 26^{\circledR}$ (Dentsply DeTrey $\mathrm{GmbH}$, Konstanz, Alamanha) a base de resina epóxica detém boas propriedades físico-químicas, possui um tempo de trabalho de 7 horas e tempo de presa total de 32 horas. Devido ao pequeno tamanho das suas partículas, explica-se o alto grau de escoamento e adesividade.

Com o intuito de agregar o hidróxido de cálcio a uma base resinosa, foi lançado o Sealer $26^{\circledR}$ (Dentsply Ind. e Com. Ltda, Petrópolis, RJ). Com o objetivo de melhorar as propriedades deste cimento, foi realizada uma modificação visando uma melhora na expansão volumétrica após a manipulação e uma menor toxicidade, que resultou no surgimento do Sealer Plus ${ }^{\circledR}$ (Dentsply Ind. e Com. Ltda, Petrópolis, RJ). 
Apesar de tais cimentos serem amplamente utilizados na atualidade, a decomposição de um de seus componentes (hexametilenotetramina) promove o surgimento de formaldeído e amônia, substâncias reconhecidamente citotóxicas. Para minimizar esses problemas, foi desenvolvido o cimento AH Plus ${ }^{\circledR}$ (Dentsply DeTrey $\mathrm{GmbH}$, Konstanz, Alamanha) à base de resina do tipo epoxiaminas, o qual possui uma boa compatibilidade como resultado da não formação dessas substâncias indesejadas.

Devido aos bons resultados obtidos pelo AH Plus, outros cimentos a base de resina epóxica tem surgido, como por exemplo, o Acroseal ${ }^{\circledR}$ (Septodont do Brasil Ltda, Barueri, SP) que é um cimento resinoso que contém na sua composição o hidróxido de cálcio.

Baseados nos princípios de adesividade dos adesivos dentinários utilizados na dentística restauradora e após resultados promissores quanto ao adequado selamento apical promovido pelo sistema de retentores intra-radiculares FibreFill ${ }^{\circledR}$ Pentron Clinical Technologies LLC, Wallingford, CT, USA - (ECONOMIDES et al., 2004) que utilizava um cimento dual resinoso a base de metacrilatos (UDMA, PEGDMA, BisGMA e EBPADMA) para a cimentação, um agente auto-condicionante ("primer") e um material sólido composto por polímero sintético termoplástico $\left(\right.$ Resilon $^{\circledR}$ ), estudos sugeriram a utilização deste cimento resinoso (Epiphany ${ }^{\circledR}$ ) conjuntamente com o material termoplástico $\left(\right.$ Resilon $\left.^{\circledR}\right)$ na forma de cones para obturação. Esta associação demonstrou uma grande capacidade de selamento do sistema de canais radiculares in vitro e in vivo, quando comparado a outros cimentos resinosos associados ou não à técnica termoplástica (SHIPPER et al., 2004; SHIPPER; TROPE, 2004). Por motivos comerciais, esse mesmo sistema de obturação também é comercializado pela SybronEndo (SybronEndo Corp., Orange, 
CA, USA) com o nome de RealSeal ${ }^{\circledR}$, sendo constituído igualmente de um primer auto-condicionante, um cimento resinoso dual e cones de polímero sintético termoplástico Resilon.

Para diminuir os passos operatórios durante a utilização do cimento Epiphany, foi lançado em 2007 os cimentos Epiphany SE ${ }^{\circledR}$ (Pentron Clinical Technologies LLC, Wallingford, CT, USA) e RealSeal $\mathrm{SE}^{\circledR}$ (SybronEndo Corp., Orange, CA, USA), cimentos endodônticos autocondicionantes "self-etched" que eliminam a utilização do agente condicionador "primer", pois este se encontra incorporado na composição do cimento dual resinoso.

Diante dos resultados promissores do principio da adesividade dentinária em obturações endodônticas, diversos cimentos resinosos têm sido introduzidos no mercado.

O EndoRez ${ }^{\circledR}$ (Ultradent Corp., South Jordan, UT, USA) é um cimento que possui na sua composição um metacrilato (UDMA), possui a propriedade de hidrofilia e é recomendado segundo o fabricante para ser utilizado com a técnica de cone único (KARDON et al., 2003)

Seguindo a mesma idéia lançada pelos cimentos Epiphany $\mathrm{SE}^{\circledR}$ e RealSeal $\mathrm{SE}^{\circledR}$, surgiu o cimento resinoso de dupla polimerização MetaSEAL ${ }^{\circledR}$ (Parkell Inc., Edgewood, NY, USA) composto de monômero 4-META que confere a capacidade de adesividade dentinária. 


\subsection{Sistemas obturadores termoplastificados}

A guta-percha tem sido aceita como o melhor material obturador para canais radiculares (GROSSMAN, 1981; PAIVA; ANTONIAZZI, 1991) e conseqüentemente considerada agente de escolha pela maioria dos endodontistas. Desde sua introdução na Endodontia por Bowman em 1867, este material é utilizado de diferentes formas, sendo a mais comum, o emprego de cones nas técnicas de condensação vertical ou lateral, conjuntamente a um cimento obturador.

Em 1874, Howard sugeriu inicialmente a sua plastificação pelo clorofórmio, objetivando com tal procedimento, melhorar a adaptação do cone na região apical.

Schilder em 1967 apresentou a técnica de obturação do sistema de canais radiculares pelo emprego da guta-percha aquecida acreditando que esta oferece melhor selamento apical, melhorando a adaptação do material de repleção e o preenchimento de condutos. A técnica utiliza condensadores manuais aquecidos que plastificam o cone de guta-percha em diversas etapas desde o terço cervical até o terço apical; e posteriormente, pequenas porções de guta-percha são levadas aquecidas e condensadas a frio nos diversos terços, de apical a cervical, até o completo preenchimento do canal radicular. Segundo o autor, tal assertiva pode ser comprovada radiograficamente pelo preenchimento de múltiplas ramificações laterais e foraminas apicais.

A partir desta técnica, diversos sistemas obturadores termoplásticos foram desenvolvidos.

Yee et al. (1977) avaliaram a percolação apical entre a obturação por condensação lateral, técnica termoplástica de Schilder, e sistema termoplástico por 
injeção de guta-percha. Os autores mostraram boa qualidade do selamento apical quando da utilização do sistema de guta-percha injetável, comparada à técnica convencional e à técnica de Schilder, parecendo ser então, promissora no uso in vivo.

Torabinejad et al. (1978) avaliaram a adaptação da guta-percha na parede dentinária através da Microscopia Eletrônica de varredura em 40 dentes obturados pelas técnicas: injeção de guta-percha termoplastificada, condensação lateral, condensação vertical de guta-percha aquecida e cloropercha. Os resultados mostraram que a técnica de injeção de guta-percha termoplastificada proporciona obturação semelhante as técnicas convencionais.

Marlin et al. (1981) estudaram clinicamente a utilização de uma nova técnica de obturação por sistema de injeção de guta-percha termoplastificada. O sucesso de 125 casos obturados com este sistema foi avaliado após 6 e 12 meses. Os resultados mostraram o bom desempenho clínico deste sistema pois, dos 56 casos iniciais com lesões periapicais sugestivas radiograficamente, 54 tiveram uma resolução parcial ou completa; quanto aos 69 dentes iniciais sem alterações periapicais, radiograficamente, 67 mantiveram-se inalterados.

Com base nesses trabalhos (MARLIN et al., 1981; TORABINEJAD et al., 1978; YEE et al., 1977), a Unitek Corporation lançou um sistema de guta-percha aquecida injetável denominado Obtura $\|^{\circledR}$. Nele a guta-percha é termoplastificada numa câmara aquecedora no interior da pistola numa temperatura previamente definida na unidade controladora do sistema, e em seguida pela pressão determinada no acionamento do gatilho, ela é direcionada à uma agulha que a aplica no interior do canal radicular. 
Johnson (1978) introduziu o Thermafil ${ }^{\circledR}$ (Dentsply Tulsa Dental Corp., Tulsa, OK, USA); constituído de carregadores na forma de limas endodônticas envoltos por uma camada de guta-percha termoplastificável que, após a escolha do diâmetro adequado pelo uso de um calibrador, são aquecidos num forno próprio e introduzidos nos canais radiculares em movimento único até o comprimento real de trabalho. Tal sistema é denominado de obturação termoplastificada com núcleo sólido.

Wolcott et al. (1997) compararam a efetividade de duas técnicas de obturação (Thermafil e condensação lateral) em canais simulados. Os autores concluíram que ambas foram efetivas no preenchimento de canais laterais, porém quanto a repleção do canal principal, o sistema Thermafil foi melhor.

Utilizando o mesmo princípio do Obtura II, Michanowicz e Czonstkowsky (1984) analisaram a infiltração apical em dentes obturados pela condensação lateral ou pelo sistema de injeção de guta-percha termoplastificada a baixa temperatura $\left(70^{\circ} \mathrm{C}\right)$. Os autores mostraram que a guta-percha injetável promove bom selamento apical, principalmente quando utilizado conjuntamente a um cimento obturador. Com isso, a Hygenic Corporation lançou o sistema Ultrafi ${ }^{\circledR}$, salientando como vantagem, rápido e completo preenchimento do canal radicular pela guta-percha.

Greene, Wong e Ingram (1990) compararam o selamento apical produzido por quatro técnicas de obturação (condensação lateral, sistema Canal Finder, Ultrafil e Técnica de Schilder) pela infiltração do azul de metileno a $0.25 \%$ em 40 dentes. Os resultados estatísticos mostraram não haver diferença significante entre as quatro técnicas empregadas.

Baseado nos seus estudos de 1980, McSpadden em 1991 propôs a obturação do canal radicular por um sistema de guta-percha termoplastificada 
denominada Multiphase ${ }^{\circledR}\left(\right.$ Alphaseal $\left.^{\circledR}\right)$. O sistema emprega dois tipos de guta-percha ( $\alpha$ : termoplastificada em baixa temperatura e $\beta$ : termoplastificada em alta temperatura) que são levadas ao interior do canal por meio de compactadores de ação reversa.

Kataia e El-Sayed (1994) compararam a qualidade do selamento apical das técnicas de condensação lateral e sistema Multiphase (Alphaseal) através da infiltração de azul de metileno em 30 dentes. A análise dos resultados comprovou que o sistema Multiphase proporciona menor percolação em relação à técnica de condensação lateral.

Gilhooly et al. (2000) analisaram a infiltração apical em 108 canais radiculares curvos obturados por condensação lateral e pelo sistema termoplástico de gutapercha tipo a e $\beta$ (Alphaseal). Os autores mostraram que sob condições laboratoriais, o sistema de termocompactação promove melhor selamento apical; contudo, radiograficamente, observaram falhas de preenchimento quando comparada com os condutos obturados pela condensação lateral.

Tendo como base os aparatos anteriormente idealizados por McSpadden (1991), destacamos também o sistema Microseal ${ }^{\circledR}$ (SybronEndo Corp., Orange, CA, USA) que possui um termocompactador de niquel-titânio que é introduzido no canal radicular envolto por uma camada de guta-percha, associado à um cone de gutapercha previamente posicionado no comprimento de trabalho. O compactador assemelha-se a uma lima tipo Hedstroem invertida e seu acionamento baseia-se no princípio de rotação reversa que ao gerar atrito produz calor, plastificando o cone de guta-percha, unindo-o a guta-percha termoplastificada e compactando esta associação em direção ao terço apical (KORZEN, 1997). 
A partir do aparelho Touch'n Heat (SybronEndo Corp., Orange, CA, USA) utilizado para termoplastificação da guta-percha, Buchanan (1996) desenvolveu o aparato System $B^{\circledR}$ (SybronEndo Corp., Orange, CA, USA) baseado no conceito de Schilder e constituído de unidade geradora de calor que, através de um cabo o conduz para a ponta condensadora. Quando levado ao interior do canal radicular, esta plastifica e condensa simultaneamente o cone de guta-percha, permitindo a realização da técnica de condensação vertical aquecida ou "Ondas Contínuas de Condensação". O aquecimento e a compactação do material nos terços cervical e médio viabilizam o selamento de canais laterais, e na região apical, possibilita melhor adaptação do cone à parede dentinária, resultando num adequado selamento desta área.

Recentemente a partir de estudos preliminares de Pagavino et al. (2006) onde utilizaram o aparelho Endo Twinn que causa uma termoplastificação semelhante ao Touch'n Heat acrescida de vibração, surge a sua evolução, o sistema de obturação DownPak (Hu-Friedy Mfg. Inc., Chicago, IL, USA) constituído pela mesmo sistema de termoplastificação, associado à vibração de $100 \mathrm{~Hz}$.

Com os diversos trabalhos mostrando a efetividade da associação System B/Obtura II em obturações, várias companhias lançaram unidades com características semelhantes a este conjunto, onde temos a obturação do conduto radicular pelas técnicas de ondas continuas de condensação e injeção de material termoplástico. Dentre os sistemas atualmente disponíveis podemos citar: Elements Obturation Unit (SybronEndo Corp., Orange, CA ,USA), E\&Q System (Meta Biomed Co. Ltd., Chungbuk, Coréia), BeeFill (VDW GmbH, Munique, Alamanha) 


\subsection{Infiltração com marcadores não biológicos}

McRobert e Lumley (1997) avaliaram a capacidade de selamento de três técnicas de obturação do terço cervical e médio (backfilling). Dez dentes foram obturados pela técnica de condensação lateral (grupo controle) e 30 tiveram os últimos $3 \mathrm{~mm}$ apicais obturados pela técnica do sistema System B. Os 30 dentes do grupo experimental foram divididos em 3 grupos de acordo com a técnica de obturação do terço médio e cervical: GI - System B, GII - Obtura II e GIII Alphaseal. Após a obturação os dentes foram imersos em tinta da Índia por 65 horas, seccionados longitudinalmente e analisados com relação a percolação coronária. A diferença entre o GI e Gll não foi significante ( $p>0.05)$ e quando esses dois grupos (Gl e GII) foram comparados com o GIII e o grupo de condensação lateral, ambos mostraram uma menor infiltração $(p<0.001)$.

Oliver e Abbott (1998) compararam a infiltração coronária e apical em dentes obturados com os cimentos Ketac-Endo e AH26. Os dentes foram imersos em solução de azul de metileno a $2 \%$ sob vácuo de $660 \mathrm{~mm}$ de mercúrio durante 5 minutos, e após este período, foram seccionados longitudinalmente para a análise da infiltração do corante. Os níveis de infiltração foram: Ketac-Endo, infiltração apical de 1.08mm e infiltração coronária de 6.29mm; para o AH26, infiltração apical de 0.75mm e infiltração coronária de $6.67 \mathrm{~mm}$; para o AH26. Este estudo demonstrou não haver diferença significante no selamento apical e coronário obtido com os dois cimentos, embora o selamento apical em cada material fosse melhor que o selamento coronário. 
Kytridou, Gutmann e Nunn (1999) avaliaram a adaptação e selamento de duas técnicas termoplásticas diferentes, sistema Thermafil e sistema de "ondas contínuas de condensação" (System B) pela imersão dos espécimes em tinta da Índia e análise da infiltração linear após diafanização nos períodos de 24h, 10 dias e 67 dias. Os autores concluíram que o sistema Thermafil mostrou uma maior extrusão de material e uma percolação apical significativamente maior em longo prazo (67 dias).

Avaliando o selamento apical e coronário proporcionado por duas novas técnicas de obturação; Davalou, Gutmann e Nunn (1999) estudaram a infiltração apical da tinta da Índia nas técnicas sistema System B associado ao Obtura II e na técnica com o sistema Microseal após diafanização. Os resultados mostraram que todas as técnicas promoveram de mínima a nenhuma penetração do corante tinta da Índia. Os autores concluíram que essas novas técnicas e materiais promovem um adequado selamento apical e coronário, resultando num alto grau de aceitabilidade.

Akisue e Gavini (2001) quantificaram a percolação apical do corante azul de metileno em duas técnicas de obturação termoplastificada: G1-sistema Microseal e G2-Combinação dos sistemas System B e Obtura II. As hemi-secções de todos os espécimes foram submetidas à observação no perfilômetro medindo-se a penetração linear do corante. Os dados obtidos em cada grupo foram confrontados estatisticamente. Os resultados mostraram menor penetração do corante no grupo G2 ocorrendo diferença significante ao nível de 5\%.

Pommel e Camps (2001) analisaram a infiltração apical de cinco técnicas de obturação (System B, Thermafil, cone único, condensação lateral e condensação vertical) pelo método de avaliação da movimentação da bolha de ar contida num tubo capilar preenchido com solução PBS e mantida com pressão de $15 \mathrm{~cm}$ de água 
(filtração de fluido). Após $24 \mathrm{~h}$ a técnica do cone único mostrou o maior índice de infiltração ( $p=0.0001)$. Na avaliação realizada após um mês, as técnicas System $B$, Thermafil e condensação vertical apresentaram menor infiltração em relação às demais (condensação lateral e cone único).

De Moor e Hommez (2002) avaliaram a capacidade do selamento apical e coronário, utilizando cimento a base de resina epóxica $(\mathrm{AH} 26)$ e diferentes técnicas de obturação. Os espécimes foram divididos em 10 grupos de 75 dentes. Os canais foram preparados e obturados usando as técnica de condensação lateral fria, condensação vertical e condensação híbrida de guta-percha, Thermafil e Soft-core. Após o preenchimento do canal, cada grupo foi dividido em 5 grupos sendo mantido cada um pelos períodos de: 1 dia, uma semana, 4 meses, 6 meses e 12 meses. Posteriormente, os dentes foram imersos em tinta da Índia por 90 horas, cortados longitudinalmente e a extensão máxima da infiltração foi medida. Foi observado que ocorreram infiltrações em qualquer que seja a técnica combinada com o AH26. A técnica de condensação híbrida de guta-percha foi superior as demais técnicas de obturação em relação à infiltração apical. A infiltração coronária foi significantemente maior durante os 4 primeiros meses no sistema Thermafil comparado com as 3 técnicas de condensação. A infiltração coronária foi significantemente maior em todo período no sistema Soft-core. Não houve diferenças significantes entre Thermafil e o Soft-core.

Schafer e Olthoff (2002) verificaram o selamento apical proporcionado pelas técnicas de obturação por condensação lateral e Thermafil quando associadas aos cimentos Roeko Seal, AH Plus e AH26. A análise da infiltração foi realizada pela verificação da penetração linear da tinta da Índia nas raízes obturadas. Concluíram que não houve diferença estatisticamente significante entre os três cimentos 
analisados e que ambas as técnicas mostraram capacidade de selamento semelhante.

Brosco (2002) analisou o selamento apical em canais radiculares obturados pelas técnicas: 1- condensação lateral, 2- condensação por ondas contínuas (System B), 3 - Ultrafil, 4 - JS QuickFill e 5 - Microseal. Após instrumentação, obturação e impermeabilização, os dentes foram imersos em solução de azul de metileno a $2 \%$, a $37^{\circ} \mathrm{C}$, por 72 horas. A infiltração apical foi avaliada por meio de estereomicroscópio. A análise dos dados mostrou que o sistema Microseal apresentou selamento apical semelhante ao do System B, sendo estes superiores aos demais grupos.

Cobankara et al. (2002) analisaram a infiltração apical de quatro cimentos endodônticos (AH Plus, RoekoSeal, Ketac-Endo e Sultan) pelo método de transporte de fluído nos períodos de 7, 14 e 21 dias. Como resultados, os autores mostraram que o cimento Sultan proporcionou maiores índices de infiltração; e que após os 21 dias, o cimento RoekoSeal possui uma melhor capacidade de selamento quando comparado aos demais cimentos. Com relação aos períodos, a análise estatística revelou menores infiltrações após 21 dias $(p<0.05)$

Miletic et al. (2002) empregaram neste trabalho cinco cimentos obturadores (AH26, AHPlus, Apexit, Diaket e Ketac-Endo) para comparar a capacidade de selamento. Um sistema de modelo de transporte de fluido foi utilizado para detectar a infiltração, onde o forame apical era conectado com um tubo e uma bolha de ar era deslocada dentro de um capilar cada vez que ocorria a infiltração. Sessenta dentes unirradiculares foram preparados, obturados com técnicas de condensação lateral e os cimentos citados sendo os espécimes armazenados por um ano. Os resultados 
mostraram que os cimentos Apexit e Diaket apresentaram infiltração superior aos cimentos AHPlus e Ketac-Endo e AH26.

Economides et al. (2004) avaliaram a infiltração apical em dentes com ou sem a presença da camada de magma dentinário obturados com dois cimentos, Fibrefill (cimento resinoso) e CRCS (cimento a base de hidróxido de cálcio), pelo método de transporte de fluido. A infiltração foi analisada nos períodos de 7 dias, 1 mês e 2 meses. Os resultados mostraram menores infiltrações no grupo do Fibrefill, independentemente da remoção ou não da camada de magma. Não houve diferença estatisticamente significante entre os grupos com o mesmo material com e sem a remoção do magma dentinário, mas a infiltração foi menor quando da remoção desta camada.

Kardon et al. (2003) estudaram a capacidade de selamento de um novo cimento resinoso (EndoRez) pelo método de transporte de fluido em $\mathrm{mm} / \mathrm{h}$. A infiltração no grupo obturado com EndoRez + guta-percha (G1) foi maior em relação aos grupos obturados com AHPlus + guta-percha (G2) e AHPlus + guta-percha com condensação vertical com calor (G3) com $p=0.01$. Não houve diferença significante entre os grupos G2 e G3.

Wu, van der Sluis e Wesselink (2004) compararam pelo método do transporte de fluído, a capacidade de selamento da obturação dos terços médio e cervical ("backfill") quando da utilização de diferentes cimentos (RoekoSeal, Pulp Canal Sealer EWT e AH 26) e de um grupo sem cimento. Houve diferença entre os 4 grupos $(p=0.038)$. Concluíram os autores que o cimento AH 26 mostrou um menor transporte de fluido em comparação aos grupos sem cimento $(p=0.006)$ e sealer EWT $(p=0.017)$. 
Orucoglu, Sengun e Yilmaz (2005) estudaram pelo método computadorizado da filtração de fluido, a infiltração em dentes obturados com os cimentos AH Plus, Diaket e EndoRez. O deslocamento da bolha de ar dentro do capilar do modelo de transporte de fluido foi analisado por leitura a laser e analisado pelo programa Fluid Filtration'03 (Konya, Turkey) e convertido em $\mu \mathrm{l} / \mathrm{cmH}_{2} \mathrm{O} / \mathrm{min}^{-1}$. Os resultados mostraram que o cimento Diaket apresentou melhores resultados em comparação aos demais cimentos $(p<0.05)$ e que esta nova metodologia é confiável porém, necessita de mais testes.

Taranu et al. (2005) avaliaram a infiltração linear apical do corante azul de metileno em obturações realizadas com os cimentos GuttaFlow®, Epiphany e RelyX Unicem ${ }^{\circledR}$ após o período de 90 dias. Como resultados, o cimento GuttaFlow apresentou o menor índice de infiltração $(2.2 \pm 0.42 \mathrm{~mm})$; sendo estatisticamente significante quando comparado com os cimentos Epiphany $(5.5 \pm 3.1 \mathrm{~mm})$ e RelyX Unicem (3.0 $\pm 1.82 \mathrm{~mm})$.

Medina et al. (2006) investigaram pelo método do movimento de fluído, a infiltração em dentes obturados com 2 cimentos e 2 técnica de obturação, a saber: G1- cimento GuttaFlow de acordo com o fabricante (técnica do cone único), G2cimento AHPlus e técnica de ondas contínuas de condensação, G3- cimento RoekoSeal e técnica de ondas continuas de condensação e G4- cimento AHPlus e técnica do cone único. Não houve diferença estatisticamente significante entre os grupos experimentais $(p=0.8710)$, sendo que o sistema GuttaFlow apresentou propriedades de infiltração similar as demais técnicas convencionais de obturação.

Cobankara et al. (2006) analisaram in vitro a infiltração apical em dentes obturados por quatro cimentos endodônticos (Rocanal2, AH Plus, Sealapex e RC Sealer) utilizando o método computadorizado da filtração de fluído. As análises de 
infiltração foram realizadas nos períodos de 7, 14 e 21 dias. Como resultado obtiveram que a infiltração diminuía com o decorrer do tempo e que o cimento Sealapex apresentou uma menor infiltração em comparação aos demais cimentos.

Shemesh, Wu e Wesselink (2006) compararam dois métodos de análise de infiltração (transporte de fluido e penetração de glicose) em dentes obturados com os cimentos AH26 e Epiphany na presença ou não da camada de magma dentinário. Como conclusão, a metodologia de penetração de glicose mostrou-se mais sensível na mensuração da infiltração, sendo que as obturações com Epiphany tiveram maiores índices de penetração de glicose. Quando da análise pela metodologia de transporte de fluído, não houve diferença entre os dois cimentos analisados.

Onay, Ungor e Orucoglu (2006) avaliaram in vitro o selamento apical do novo sistema de obturação resinoso Epiphany/Resilon pelo método computadorizado de filtração de fluído. Os dentes foram preparados e obturados por diversas combinações de material sólido (guta-percha ou Resilon) associado aos cimentos (AH Plus ou Epiphany) utilizando-se a técnica de condensação lateral, descritos a seguir: Grupo 1 - AH Plus + guta-percha, Grupo 2 - AH Plus + Resilon, Grupo 3 Epiphany + Resilon, Grupo 4 - Epiphany + guta-percha. Como resultados, a infiltração em ordem crescente foi G4, G1, G3 e G2; havendo diferença significante somente entre os grupos G2 e G4 (p>0.05). Não houve diferença entre o grupo G3 (Epiphany/Resilon) e os demais grupos.

Biggs et al. (2006) utilizando o modelo da filtração de fluído, compararam a capacidade de selamento do sistema Resilon/Epiphany (RS) e da guta-percha (GP) conjuntamente com os cimentos Roth $(R)$ e AH Plus $(A H)$. Os seguintes grupos foram analisados: G1 - RS+condensação lateral, G2 - GP+R+condensação lateral e espera de três semanas, G3 - GP+R+condensação lateral (infiltração imediata), G4 - 
RS+cone único, G5 - RS sem a utilização do "primer" e do cimento, G6 - GP+AH, G7 - GP+AH após 8 horas e G8 - controle negativo. Não houve influencia do tempo na infiltração e os autores concluíram que não houve diferença entre o sistema Resilon/Epiphany e AH Plus/guta-percha ou Roth/guta-percha.

Empregando o método anteriormente usado por Orucoglu, Sengun e Yilmaz (2005), Sagsen et al. (2006) compararam a infiltração apical em dentes obturados com AH Plus/guta-percha, Sealapex/guta-percha e sistema Resilon/Epiphany. Os resultados mostraram que o sistema Resilon/Epiphany foi melhor que os demais grupos $(p<0.05)$ e que não houve diferença entres os grupos que utilizaram os cimentos AH Plus e Sealapex.

Stratton, Apicella e Mines (2006) pela metodologia da filtração de fluido, analisaram a capacidade de selamento da guta-percha associada ao cimento $\mathrm{AH}$ Plus ou do sistema Epiphany/Resilon quando da utilização de três tipos de irrigação final (solução de hipoclorito de sódio a $5.25 \%$, solução de clorexidina a $0.012 \%$ e a 2\%). A análise ANOVA indicou uma menor infiltração quando do uso do sistema Epiphany/Resilon $(p<0.05)$ quando comparado ao cimento $A H$ Plus. Não houve diferença estatisticamente significante entre as soluções irrigantes utilizadas para cada tipo de obturação.

Hanson, Rutledge e Jeansonne (2006) utilizando a metodologia de percolação de corante tinta da Índia, compararam a capacidade de selamento apical de dentes obturados com guta-percha ou Resilon associados a dois cimentos (AHPlus e Real Seal) e utilizando as técnicas de ondas continuas de condensação (CW) ou do cone único (SC). Como resultado, os autores mostram não haver diferença estatisticamente significante entre os grupos de guta-percha e Resilon quando do uso da técnica CW, porém, ambos foram melhores que a técnica SC com Resilon. 
Os resultados deste estudo indicam que o uso de guta-percha com a técnica do cone único é tão efetivo quanto à técnica de condensação lateral. Entretanto, o Resilon necessita de deformação plástica para promover um efetivo selamento apical.

Tunga e Bodrumlu (2006) compararam a infiltração de 3 materiais obturadores ( $\mathrm{AH}$ Plus/guta-percha, AH26/guta-percha e Epiphany/Resilon) pela metodologia de transporte de fluído. Como resultados, obtiveram maiores índices de infiltração no grupo obturado com o material AH26/guta-percha e menores índices no grupo obturado com o material Epiphany/Resilon, sendo as diferenças entre os grupos estatisticamente significantes $(p<0.05)$

Lin, Jhugroo e Ling (2007) analisaram a infiltração em dentes obturados com o sistema Real Seal/Resilon após retratamento pelo método de filtração de glicose. Três grupos experimentais foram avaliados: G1 - Não sofreram retratamento (controle), G2 - Retratados manualmente e obturados novamente com o mesmo sistema e G3 - Retratados por instrumentação rotatória e re-obturados. Adicionalmente, os autores complementaram a analise com microscopia eletrônica de varredura (MEV) das interfaces dentina/cimento de todos os grupos estudados. Os autores concluíram não haver diferença estatisticamente significante entre os grupos utilizados $(p<0.05)$ e mostraram pela metodologia MEV a penetração de novo cimento na superfície dentinária após o retratamento.

Wedding et al. (2007) utilizando o método de filtração de fluido, avaliaram a infiltração em dentes obturados com guta-percha associada ao cimento AH26 (grupo 1) ou obturados com o sistema Epiphany/Resilon (grupo 2) nos períodos experimentais de $1,7,30$ e 90 dias. O estudo demonstrou que o sistema Epiphany/Resilon proporcionou menores índices de infiltração nos períodos 
experimentais de um dia $(p<0.0014), 7$ dias $(p<0.0002), 30$ dias $(p<0.0015)$ e 90 dias $(p<0.0170)$; concluindo ser o sistema Epiphany/Resilon um possível substituto da guta-percha na obturação de canais radiculares.

Veríssimo, do Vale e Monteiro (2007) compararam o nível de infiltração apical do corante tinta da Índia em dentes obturados com guta-percha e cimento AH Plus ou pelo sistema Resilon/Epiphany variando se a técnica de obturação entre condensação lateral e técnica híbrida. Não houve diferença entre as técnicas de obturação ( $p>0.05)$, porém, houve diferença entre os cimentos estudados $(p<0.05)$ aonde o sistema Resilon/Epiphany mostrou menores índices de infiltração quando comparado à guta-percha associada ao cimento AH Plus. Em relação ao Resilon/Epiphany, a infiltração ficou confinada no terço apical e a técnica híbrida pode ser utilizada para plastificar este material satisfatoriamente.

Paqué e Sirtes (2007) compararam o selamento apical em longo prazo (16 meses) dos sistemas Resilon/Epiphany e da associação guta-percha/AHPlus utilizando as técnicas de condensação lateral ou vertical. Após 7 dias da etapa de obturação, os dentes foram desobturados até restarem $4 \mathrm{~mm}$ apicais com o material obturador. Os espécimes foram então avaliados pelo método de filtração de fluído imediatamente após a desobturação e novamente após 16 meses, ficando os dentes armazenados em solução fisiológica a $37^{\circ} \mathrm{C}$. Os autores mostraram que após 16 meses, os dentes obturados com a associação guta-percha/AH Plus mantiveram a capacidade de selamento apical e, contrariamente, os espécimes obturados com o sistema Resilon/Epiphany perderam a capacidade de selamento após o mesmo período.

Utilizando a mesma metodologia de Lin, Jhugroo e Ling (2007) e Shemesh, Wu e Wesselink (2006); os pesquisadores Shemesh et al. (2007) mediram a 
penetração de glicose e o transporte de fluido em dentes obturados com Resilon/Epiphany ou guta-percha/AH Plus e na estrutura dentinária coronária (dentina). Diante a metodologia de penetração de glicose, os dois grupos obturados apresentaram significante penetração em comparação ao grupo da estrutura dentinária $(p<0.05)$, não havendo diferença entre os sistemas de obturação. Pela metodologia de filtração de fluido, os dois grupos obturados também mostraram significante infiltração, porém, sem diferença estatisticamente significante entre ambos.

Raina et al. (2007) avaliaram a capacidade de selamento em dentes obturados com o sistema Resilon/Epiphany ou com o conjunto guta-percha/AH Plus. Após o período de presa, os dentes íntegros foram analisados quanto à infiltração utilizando o modelo de filtração de fluído. Posteriormente, os dentes sofreram ressecções e avaliações de infiltração milímetro a milímetro seguindo a mesma metodologia, sendo o primeiro corte $3 \mathrm{~mm}$ aquém do ápice e o último a $11 \mathrm{~mm}$ aquém do ápice. Os resultados obtidos mostraram não haver diferença estatisticamente significante nos níveis entre 0 e $8 \mathrm{~mm}$, só havendo diferença significante nos níveis de 9 e $10 \mathrm{~mm}$. Os autores concluem que o sistema Resilon/Epiphany selam o conduto radicular tão bem quanto o conjunto gutapercha/AH Plus.

Kaya, Kececi e Belli (2007) compararam a infiltração pelo método de penetração de glicose em dentes obturados com os materiais Resilon ou gutapercha e diversos cimentos endodônticos (Epiphany, Ketac Endo ou AH Plus) sob duas técnicas de obturação (condensação lateral ou associação System B/Obtura II). A concentração de glicose foi medida nos períodos de 1, 8, 15, 22 e 30 dias. Após o período experimental todos os grupos apresentaram penetração de glicose, sendo 
que as combinações de guta-percha/AH Plus apresentaram padrões similares de penetração de glicose quando comparados às combinações de Resilon/Epiphany.

Bodrumlu, Tunga e Alaçam (2007) analisando a infiltração pela metodologia de transporte de fluido em dentes preparados para receber retentor intra-radicular em dois tempos (imediato e tardio) e obturados com guta-percha/AH Plus ou Resilon/Epiphany, mostraram não haver diferença de infiltração em preparos imediatos $(p>0.05)$; porém em preparos tardios, o selamento proporcionado pelo cimento Epiphany mostrou ser mais eficiente $(p<0.05)$.

Oddoni et al. (2008) avaliaram a capacidade de selamento coronário e apical das associações AH Plus+Guta-percha e Epiphany+Resilon frente à metodologia de infiltração com corante azul de metileno pelo período de 48 horas. Os resultados mostraram não haver diferença na análise da infiltração coronária, porém, em relação à infiltração apical, o sistema Epiphany+Resilon promoveu um melhor selamento $(p<0.05)$.

Bouillaguet et al. (2008) analisaram a capacidade de selamento em curto (6, 12 e 24 horas) e longo prazo (após um ano de estocagem) dos cimentos AH Plus (AH), Pulp Canal Sealer (PCS), GuttaFlow (GF) e Epiphany (EP), utilizando a metodologia de movimentação de fluído. Após 24 horas, PCS e AH apresentaram maiores movimentações de fluído em comparação aos cimentos GF e EP. Após um ano, o PCS apresentou maiores níveis de movimentação quando comparado aos outros materiais. Concluíram que os cimentos GF e EP permitiram menores movimentações de fluído pelos canais obturados nos períodos analisados.

Nagas et al. (2008) compararam o selamento proporcionado pelo sistema Resilon/Epiphany obturados por diferentes técnicas (cone único, condensação lateral e System B) quando utilizados com diferentes unidades de fotopolimerização 
(Halogeno, LED, arco de plasma). Os dentes obturados foram analisados pelo método de filtração de fluídos nos períodos de um dia e uma semana. Os resultados mostraram que a infiltração aumenta com o tempo $(p<0.001)$ e que entre as técnicas de obturação não houve diferença significante $(p=0.433)$. Com relação ao tipo de fotopolimerização, diferenças significantes foram encontradas $(p<0.001)$ sendo nos seguintes valores: sem polimerização > plasma > LED > Halogena.

\subsection{Infiltração com marcadores biológicos}

Barthel et al. (1999) avaliaram a capacidade de selamento coronário de três cimentos endodônticos frente à infiltração bacteriana por Staphylococcus epidermides e por fucsina básica. Os condutos foram obturados com os cimentos (AH26, Ketac-Endo e Roth's 801) e expostos a bactéria por 38 dias e a fucsina por 48h após o período experimental utilizando a bactéria. Com relação à infiltração bacteriana, não se observou diferença significante, entretanto, quando da análise da infiltração do corante, o cimento AH26 obteve maior índice de infiltração que o cimento Ketac-Endo. Os resultados deste estudo sugeriram que o tamanho molecular dos marcadores de infiltração não é um parâmetro relevante na determinação da capacidade de selamento.

Siqueira et al. (1999) analisaram a infiltração coronária de saliva humana em canais obturados com dois cimentos endodônticos a base de hidróxido de cálcio (Sealapex e Sealer26). Resultados mostraram que 35\% dos espécimes obturados com o cimento Sealer26 tiveram infiltração em 60 dias, sendo que o mesmo índice 
para o cimento Sealapex foi de $80 \%$. Como resultado, mostrou-se que o cimento Sealer26 apresentou menor infiltração quando comparado ao Sealapex $(p<0.01)$.

Siqueira et al. (2000) avaliaram a infiltração coronária por saliva em canais obturados por três técnicas: condensação lateral, sistema Thermafil e sistema System B. Os dentes foram montados no modelo experimental de dupla câmara e expostos a saliva humana durante 60 dias. Posteriormente, os tempos necessários para a ocorrência da contaminação do meio de cultura TSB eram tabulados. Os resultados mostraram que nenhuma das técnicas evitou a infiltração coronária nos períodos de 30 e 60 dias; e que mesmo não havendo diferença estatisticamente significante ( $p>0.05)$, o sistema System B mostrou menor índice de infiltração.

Cerutti e $\operatorname{Re}(2000)$ analisaram in vitro a penetração coronária por bactérias $S$. mutans em 5 técnicas obturadoras: G1 - técnica de Schilder, G2 - condensação lateral a frio, G3 - sistema System B, G4 - sistema Thermafil e G5 - sistema Microseal. Os autores ficaram surpresos com o alto índice de infiltração bacteriana, sendo os menores índices de contaminação observados nos grupos G2 (27\%) e G5 (45\%) e os maiores nos grupos G1 e G4 (67\% e 65\% respectivamente).

Timpawat, Amornchat e Trisuwan (2001) compararam a infiltração coronária por bactéria Endodontalis faecalis em canais obturados utilizando três cimentos endodônticos (AHPlus, Apexit e Ketac-Endo) e técnica da condensação lateral. Os dentes obturados foram colocados num modelo experimental de duas câmaras contendo o agente contaminante e o meio de cultura respectivamente, sendo posteriormente observados nos períodos de 30 e 60 dias. Em ambos os períodos, o cimento Apexit apresentou maiores índices de infiltração. Concluíram os autores que os cimentos a base de resina epóxica possuem uma melhor adaptação a parede dentinária quando da utilização de bactérias como marcadores de infiltração. 
Gilbert, Witherspoon e Berry (2001) avaliaram a capacidade de selamento das técnicas de obturação Thermafil, condensação lateral e condensação vertical (CWC) utilizando as metodologias in vitro de infiltração coronária da bactéria Proteus vulgaris e infiltração de tinta da Índia. Os resultados mostraram menor infiltração bacteriana nos dentes obturados pela técnica da condensação vertical (CWC). Não houve diferença entre as técnicas de obturação diante da infiltração de corante.

Jacobson et al. (2002) analisando a infiltração coronária por bactérias Klebsiella pneumoniae em dentes obturados com o sistema System B (CWC) associado ao sistema Obtura II ou obturados pela técnica de condensação lateral, mostrou que embora o número de dentes infiltrados para ambos os grupos foram iguais, a infiltração coronária ocorreu num tempo menor no grupo que utilizou a técnica de condensação lateral, sendo esta diferença estatisticamente significante $(p<0.05)$

Miletic et al. (2002) avaliaram a infiltração in vitro de uma combinação de bactérias e de Candida albicans em dentes obturados com os cimentos $\mathrm{AH} 26$ e $\mathrm{AH}$ Plus pelo período de 90 dias. Infiltrações ocorreram entre 14 e 87 dias. Espécimes obturados com AH26 tiveram infiltração bacteriana em $45 \%$ e fungica em $60 \%$ dos casos. Os dentes obturados com AH Plus tiveram infiltração bacteriana e fungica em $50 \%$ e $55 \%$ respectivamente. Os resultados mostraram não haver diferença estatisticamente significante entre os dois cimentos utilizados.

Akisue (2003) avaliou a capacidade do selamento apical do sistema termoplástico de obturação por ondas contínuas de condensação (SystemB), para isto, os espécimes foram divididos em 2 grupos experimentais: G1 -obturados pela condensação lateral; G2 - obturados pelo System B. Utilizou-se a endotoxina pura de E. coli como marcador da infiltração no sentido ápico-cervical. Após o período 
experimental de 30 dias, realizou-se avaliação e quantificação da infiltração pelo método de leitura óptica por absorbância com o uso do teste LAL KTA2 turbidimétrico. Concluiu o autor que o grupo G2 (System B) apresentou os melhores resultados, com média de infiltração da endotoxina de 0,28432 UE/mL contra 0,36825 UE/mL dos espécimes obturados pela técnica de condensação lateral (G1), sendo esta diferença significante ao nível de $5 \%$.

Shipper et al. (2004) analisaram a infiltração bacteriana com S. mutans e E. faecalis em dentes obturados com guta-percha ou com o polímero sintético Resilon associados aos cimentos AH26 ou Epiphany e utilizando duas técnicas de obturação (System B/Obturall e condensação lateral) durante o período de 30 dias. Os resultados mostraram que os grupos que utilizaram Resilon tiveram uma mínima infiltração com valores menores de $15 \%$, sendo estes números significantemente menores que aos das infiltrações nos grupos que utilizaram guta-percha que obtiveram valores maiores de $70 \%(p<0.05)$.

Shipper e Trope (2004) compararam a infiltração coronária por bactéria Streptococcus mutans pelo período de 30 dias em técnicas convencionais e novas técnicas de obturação (condensação lateral, condensação vertical, Obtura II, SimpliFill + Obtura II, Fibrefill, SimpliFill + Fibrefill). Ocorreu diferença significante quando comparados todos os grupos, sendo que a infiltração ocorreu num tempo menor nas técnicas de condensação lateral e vertical $(p<0.0001)$. A combinação da obturação apical com SimpliFill e da parte coronária com Fibrefill mostrou ser a melhor técnica de obturação.

Sevimay e Kalayci (2005) analisaram a adaptação e o selamento apical de obturações quando da utilização de dois cimentos resinosos (AH Plus e EndoRez). A média de infiltração foi de $2,87 \pm 0,43 \mathrm{~mm}$ para o cimento AHPlus enquanto que para 
o cimento EndoRez foi de 4,54 $\pm 0,36 \mathrm{~mm}$. Concluíram os autores que o cimento AHPlus obteve uma melhor capacidade de selamento e uma melhor adaptação em comparação ao cimento EndoRez $(p<0,01)$.

Yücel et al. (2005) estudando a percolação de Enterococcus faecalis em dentes obturados com quatro cimentos diferentes (AH26, AH Plus, Sealapex e Ketac Endo) utilizando a técnica da condensação lateral. Os autores observaram não haver diferença estatisticamente significante entre os cimentos utilizados nos períodos experimentais de 30 e 60 dias $(p>0.05)$.

Williamson et al. (2005) avaliaram a penetração da endotoxina em canais radiculares usando um modelo de duas câmaras. Quarenta e quatro dentes obturados pela técnica da condensação lateral ou pela técnica termoplastificada (System B) utilizando-se os cimentos Roth's 801 ou AH 26. O teste QCL-1000 LAL foi usado para medir a endotoxina em $0,1,7,14$ e 21 dias. Grupos obturados com a associação sistema termoplástico (System B) / cimento Roth’s 801 permitiu mínima penetração apical da endotoxina. Os resultados também sugerem que o cimento Roth's 801 pode ter um papel na inibição da penetração de endotoxinas.

Farmakis et al. (2006) analisaram a infiltração coronária in vitro de bactérias P. vulgaris em dentes obturados pela técnica de condensação lateral utilizando os cimentos EndoRez, TopSeal e RSA. A infiltração foi verificada após 60 dias e quantificada em CFU/ mL. Como resultados, o cimento EndoRez apresentou 3 amostras positivas num período médio de 31 dias e concentração média de $4.5 \times 10^{5}$ CFU/mL, o cimento TopSeal apresentou 4 amostras positivas num período médio de 26 dias e concentração média de $2.6 \times 10^{5} \mathrm{CFU} / \mathrm{mL}$ e o cimento RSA não resultou em amostras positivas. A analise estatística não revelou diferença entre os grupos $(p>0.05)$. 
De Deus et al. (2006) avaliaram o selamento de quatro cimentos endodônticos (Pulp Canal Sealer, EndoRez, Sealapex e AH Plus) em obturações com duas espessuras de linha de cimentação. Oitenta e dois dentes foram preparados com brocas de Gates \#6 (1.5 mm de diâmetro) e obturados com cilindros de guta-percha de 1 e 1.5mm de diâmetro, sendo 36 para cada grupo experimental de infiltração e 5 de cada grupo separados para controle da espessura de cimento em microscópio óptico. Os espécimes dos grupos experimentais foram montados no modelo de dupla câmara, tendo como marcador um composto microbiano que era avaliado diariamente durante 12 semanas. O cimento AH Plus revelou os melhores resultados em relação à capacidade de selamento. Quanto à linha de cimentação, uma maior espessura de cimento influencia negativamente no selamento marginal, exceto para o grupo AH Plus.

Utilizando o clássico modelo experimental de duas câmaras, Pitout et al. (2006) compararam a infiltração bacteriana (E. faecalis) em dentes obturados com Resilon ou guta-percha utilizando as técnicas de condensação lateral ou termoplástica utilizando o System B. Após o período experimental de 3 meses, uma análise de infiltração com corante tinta da Índia foi realizada nos mesmos espécimes. Não se observou diferença entre os dois cimentos quando do uso das técnicas de obturação da condensação lateral $(p=0.2695$ e $p=0.2713$ para infiltração bacteriana e de corante respectivamente) e termoplástica System B ( $p=0.5602$ e $p=0.0767$ para infiltração bacteriana e de corante respectivamente). Concluíram que os sistemas possuem capacidade de selamento similar.

Muñoz et al. (2007) estudando a infiltração de Enterococcus faecalis em dentes preparados para retentor intra-radicular (5 $\mathrm{mm}$ apicais) obturados com o sistema RealSeal (RS) ou guta-percha (GP), mostraram que a infiltração no grupo 
RS ocorreu no período médio de 3.5 dias \pm 2.32 dias e no grupo GP ocorreu no período médio de 10 dias \pm 11.53 dias; sendo que este resultado não mostrou diferença estatisticamente significante entre os dois sistemas de obturação $(p=0.09)$.

Baumgartner, Zhender e Paqué (2007) compararam durante um período de 50 dias a percolação de Enterococcus faecalis em canais obturados com gutapercha/AH Plus ou Resilon/Epiphany, utilizando para ambos a técnica de obturação de ondas contínuas de condensação. O tempo para a ocorrência de percolação e turbidez do meio de cultura foi de 35 dias ( $D p=5$ dias) para a associação $A H$ Plus/guta-percha e 33 dias ( $D p=4$ dias) para a combinação Resilon/Epiphany. Concluem os autores que não houve diferença estatisticamente significante entre as obturações analisadas $(p=0.141)$.

Brosco et al. (2008) compararam in vitro a eficiência das técnicas obturadoras de condensação lateral, Microseal, Touch'n Heat/Ultrafil e técnica híbrida de Tagger; quanto a capacidade de selamento marginal (coroa-ápice) em dois níveis de obturação (5 mm e $10 \mathrm{~mm}$ de material obturador remanescente) utilizando como marcador a bactéria Enterococcus faecalis. Os resultados mostraram maior infiltração nos espécimes obturados pela técnica híbrida de Tagger, não havendo diferença estatisticamente significante entre as demais técnicas. Em relação ao nível de obturação, canais com $10 \mathrm{~mm}$ de obturação tiveram um menor número de espécimes com infiltração.

De Deus et al. (2008b) analisaram a infiltração de uma combinação de bactérias em dentes portadores de canal oval obturados com as técnicas de condensação lateral (G1), System B (G2) e Thermafil (G3) sendo $n=10$ pelo período de 15 semanas; seguida da análise da área preenchida pelo material obturador. Em relação à infiltração, ocorreram 30\%, 30\% e 20\% de percolação nos grupos G1, G2 
e G3 respectivamente, e não observaram diferenças estatisticamente significante entre os grupos $(p>0.05)$. A percentagem de área preenchida para cada grupo foi de $68 \%$ (G1), $70 \%$ (G2) e 78\% (G3), não havendo diferença entre os 3 grupos ( $p>0.05$ ).

Os autores concluem não haver correlação entre a qualidade do selamento apical e o preenchimento do conduto $(p=0.128)$.

Fransen et al. (2008) avaliaram a capacidade de selamento de três sistemas de obturação endodôntica (AH Plus/guta-percha, Resilon/Epiphany e ActiV GP/ionômero de vidro) frente a infiltração da bactéria Enterococcus faecalis durante um período de 65 dias. Embora tenham ocorrido infiltrações em 13 espécimes dos grupos obturados com AH Plus e Epiphany, e em 17 espécimes do grupo Activ GP; não houve diferença estatisticamente significante entre todos os cimentos analisados $(p>0.05)$.

\subsection{Estudos de resposta inflamatória in vivo}

Holland et al. (1990) estudaram as respostas periapicais em dentes de cães de obturações realizadas com o cimento Sealapex com ou sem o acréscimo de iodofórmio. Os resultados histopatológicos mostraram selamento biológico com formação de cemento na maioria dos dentes de todos os grupos experimentais. $O$ acréscimo do iodofórmio no cimento não altera as suas propriedades biológicas.

Leonardo et al. (1997) analisaram in vivo a reação histopatológica frente a dentes obturados com os cimentos Sealapex, CRCS, Sealer 26 e Apexit, restaurados com amálgama. Após 180 dias, a análise histológica mostrou que o 
Sealapex foi o cimento que melhor proporcionou a deposição de tecido mineralizado, promovendo o completo selamento em $37,5 \%$ dos casos. Além disso, não se observou a presença de infiltrado inflamatório. Para os demais cimentos, os graus de inflamação foram: médio para o CRCS, severo para o Apexit e leve ou ausente para o Sealer 26.

Barbosa et al. (2003) observaram a influência da infiltração coronária no processo de reparação de dentes obturados com os cimentos Sealer 26 ou Roth e preparados para retentor intra-radicular quando expostos a flora oral pelo período de 90 dias, tendo ou não a proteção da parte coronária realizada com cimento temporário. $\mathrm{Na}$ análise histomorfológica, $70 \%$ e $20 \%$ dos dentes obturados respectivamente com Roth e Sealer 26 tiveram infiltrações coronárias quando não tinham a proteção coronária, enquanto que, com a proteção coronária os índices foram $30 \%$ e 0\% respectivamente. Uma reação inflamatória crônica foi mais comumente observada nos dentes obturados com o cimento Roth $(p<0.01)$

Kopper et al. (2003) avaliaram a capacidade de selamento dos cimentos AHPlus, Sealer 26 e Endofill em dentes de cães expostos a cavidade oral após o preparo para retentor intra-radicular pelo período de 45 dias. Os dentes foram examinados pela penetração do corante tinta da Índia com o auxílio de uma lupa de 20 aumentos. Concluíram que, após 45 dias, nenhum dos cimentos foi capaz de prevenir a infiltração coronária e que o cimento AH Plus (média de $0.13 \mathrm{~mm}$ ) obteve melhores resultados comparados aos cimentos Endofill (média de $2.27 \mathrm{~mm}$ ) e Sealer 26 (média de $3.08 \mathrm{~mm})$, sendo estes resultados significantes $(p<0.001)$

Leonardo et al. (2003) estudaram a reparação apical após tratamento endodôntico em dentes de cães com necrose pulpar e lesão periapical crônica obturados com diversos cimentos obturadores (Sealapex, AH Plus e Sealer Plus). A 
análise histopatológica demonstrou que os dentes obturados com os cimentos Sealapex e AH Plus apresentaram melhor reparação $(p<0.05)$ em relação ao cimento Sealer Plus, que apresentou resultados insatisfatórios.

Shipper et al. (2005) avaliaram in vivo a condição da região periapical de dentes obturados com guta-percha associada ao cimento AH Plus ou com o Resilon associado ao cimento Epiphany denominado Sistema Monobloco Resilon (RMS). Como resultados, inflamação de nível médio foi demonstrada em $82 \%$ dos casos obturados com a associação guta-percha/AH Plus, e em 19\% dos casos obturados com o sistema RMS ( $p$ <0.05). Os autores concluem que a ocorrência deste sistema monobloco Resilon esta associada ao menor índice de patologias periapicais devido a sua grande capacidade de selamento marginal.

Holland et al. (2005) observaram o processo de reparo em dentes de cães após obturações de canais com dois cimentos (Sealer Plus e FillCanal) fazendo ou não a patência apical. Após o período experimental de 60 dias, os autores observaram melhores resultados nos grupos onde não foi realizada a patência apical $(p=0.01)$. Dentre os cimentos avaliados, os melhores resultados foram observados em dentes obturados com o cimento Sealer Plus $(p=0.01)$

Rueda (2006) avaliou a biocompatibilidade e a infiltração no sentido coroa/ápice dos cimentos EndoRez a base de uretano dimetacrilato e Sealapex, com ou sem restauração coronária expostos ao meio bucal por 90 dias. A avaliação histopatológica mostrou que nos grupos obturados com EndoRez (com e sem restauração) e sem Sealapex sem restauração, apresentaram infiltrado inflamatório crônico de grau moderado/severo e severo aumento do espaço periodontal e ausência de selamento biológico. Contrariamente, quando da utilização do cimento 
Sealapex com restauração, apresentaram condições histopatológicas melhores (ausência ou grau leve) e espaço periodontal normal.

Leonardo et al. (2007) avaliaram a resposta periradicular in vivo de dentes de cães obturados pela técnica de condensação lateral e restaurados ou não, sendo os grupos: G1 - Resilon/Epiphany com restauração coronária, G2 - Gutapercha/Sealapex com restauração coronária, G3 - Resilon/Epiphany sem restauração coronária e G4 - Guta-percha/Sealapex sem restauração coronária. Após o período de 90 dias, os animais foram sacrificados e as maxilas e mandíbulas foram submetidas à análise histológica. Os resultados mostraram diferença entre os grupos G1 e G2 ( $p=0.021)$ e entre os grupos G3 e G4 ( $p=0.021)$ nos quais os dentes obturados com Resilon/Epiphany tiveram menores níveis de inflamação periapical. Do mesmo modo não houve diferenças entre G1 e G3 $(p=0,093)$ e entre G2 e G3 $(p=0.269)$. Assim, obturações com o sistema Resilon/Epiphany resultaram em reações teciduais periapicais significantemente mais favoráveis.

Pereira et al. (2007) compararam a capacidade de selamento dos cimentos RoekoSeal, AH Plus e EndoRez; em dentes de cães obturados por condensação lateral, preparados para retentor intra-radicular e expostos ao ambiente oral por 45 dias. Os dentes removidos foram imersos em tinta da Índia por 96 horas e posteriormente a infiltração foi mensurada. O cimento EndoRez mostrou menores índices de infiltração quando comparado ao RoekoSeal $(p<0.05)$. Não houve diferença estatisticamente significante entre o cimento $\mathrm{AH}$ Plus e os outros dois cimentos.

Gomes et al. (2007) analisaram a infiltração apical (IA) e a resposta inflamatória $(\mathrm{RI})$ em dentes de cães após obturação dos canais com 3 cimentos (AH Plus, RoekoSeal e Sealer26) pela técnica da condensação lateral, preparo para 
retentor intra-radicular deixando $4 \mathrm{~mm}$ de obturação e exposição do conduto a cavidade oral pelo período de 90 dias. As médias de escores para IA e RI foram: Sealer 26- 2.44+/-0.98 e 2.50+/-0.70; AH Plus - 2.50+/-0.78 e 2.22+/-0.54; RoekoSeal - 1.84+/-0.95 e 2.63+/-0.83; e grupo controle (sem obturação) - 2.56+/1.23 e 3.11+/-0.60. Embora RoekoSeal tenha obtido o menor índice IA e o AH Plus o menor índice RI, não foram encontradas diferenças estatisticamente significantes entre os 3 cimentos utilizados, e não houve correlação entre infiltração apical e resposta inflamatória.

Leonardo et al. (2008) avaliaram a biocompatibilidade dos cimentos RoekoSeal e AH Plus em tecidos periapicais de cães. Os dentes foram instrumentados, obturados pela técnica da condensação lateral com os cimentos, restaurados e levados a análise histopatológica após 90 dias. A formação total e parcial de barreira de tecido mineralizado foi respectivamente de $43.8 \%$ e $56.2 \%$ para o RoekoSeal e de $12.5 \%$ e $75 \%$ para o cimento AH Plus. Os autores mostraram não haver diferenças entre ambos os cimentos em relação à quantidade e infiltrado inflamatório, espessura do ligamento periodontal e reabsorções $(p>0.05)$.

Pela análise da literatura pode-se observar um grande número de artigos que mostram a grande variedade de metodologias empregadas.

Tal fato remete para a busca de métodos eficazes para a análise dos novos cimentos endodônticos e das suas reações, que seja o mais proximo do modelo clínico de estudo ideal. 


\section{PROPOSIÇÃO}

Face ao exposto, avaliou-se in vivo a reação inflamatória periapical resultante da percolação em dentes de cães obturados pelas técnicas da condensação lateral e termoplástica por condensação vertical aquecida, com os cimentos resinosos $\mathrm{AH}$ Plus $^{\circledR}$, RealSeal $^{\circledR}$ e RealSeal SE ${ }^{\circledR}$. 


\section{MATERIAL E MÉTODOS}

\subsection{Material}

- Ração para cães Kanina (Nestlé Brasil Ltda, Ribeirão Preto, SP)

- Dontral Plus - BayerPet (Bayer S/A, São Paulo , SP)

- Seringas descartáveis de $3 \mathrm{~mL}$ (Injex Indústrias Cirúrgicas Ltda.)

- Seringas descartáveis de $20 \mathrm{~mL}$ (Injex Indústrias Cirúrgicas Ltda.).

- Acepran 0.2\% Injetável (Rhobifarma Ind. Farmacêutica Ltda, Hortolândia, SP)

- Provive $1 \%$ - propofol $10 \mathrm{mg} / \mathrm{mL}$ (Claris Produtos Farmacêuticos do Brasil, São Paulo, SP)

- Isothane - Isoflurano (Baxter Hospitalar Ltda, São Paulo, SP)

- Soro fisiológico (Aster Prod. Médicos Ltda, Sorocaba, SP)

- Aparelho de anestesia Samurai (K.Kataoka Ind. e Com, Ltda, São Paulo, SP)

- Kavo SonicFlex 2000N (Kavo do Brasil Ind. Com. Ltda, Joinville, SC)

- Solução de digluconato de clorexidina a 2\% (FGM- Dentscare Ltda, Joinville,SC)

- Aparelho de radiográfia Spectro 70X Selectronic (Dabi-Atlante SA, Ribeirão Preto, SP)

- Películas radiográficas periapicais Ektaspeed (Eastman Kodak Co.- Rochester, NY- USA).

- Revelador e fixador GBX (Kodak Brasileira Comércio e Indústria Ltda.).

- Sistema de radiografia digital SUNI (New Image do Brasil Ltda,São Paulo,SP)

- Brocas esféricas diamantadas (KG Sorensen SA, São Paulo, SP) 
- Broca tronco-cônica de ponta inativa 3083 (KG Sorensen SA, São Paulo, SP)

- Limas endodônticas tipo K 10/35 (SybronEndo Corp., Orange, CA ,USA)

- Solução de hipoclorito de sódio a 1\% (F\&A Laboratório Farmacêutico Ltda., São Paulo, SP)

- Creme Endo PTC - fórmula acorde Paiva \& Antoniazzi, 1973 (Phytogalen GMA Farmácia de Manipulação Ltda.)

- Limas Pré-Race de números ISO 35/.08 e 40/.10 (FKG Dentaire, La Chaux-desfonds, Suiça)

- Limas K3 seqüência Procedure Pack (SybronEndo- Orange, CA, USA)

- Solução de ácido cítrico a 15\% (Phytogalen GMA Farmácia de Manipulação Ltda.).

- Seringas descartáveis de $10 \mathrm{~mL}$ (Injex Industrias Cirúrgicas Ltda.)

- Pontas Capillary Tips .014" (Ultradent do Brasil Ltda, Indaiatuba, SP)

- Cones de papel absorvente de ISO 35 e 40 (Tanariman Industrial Ltda, Manacapuru, AM).

- Cimento endodôntico AH Plus (Dentsply Ind. e Com. Ltda, Petrópolis, RJ)

- Cimento endodôntico RealSeal (SybroEndo Corp. Orange, CA, USA)

- Cimento endodôntico RealSeal SE (SybroEndo Corp. Orange, CA, USA)

- Cones de guta-percha Autofit FM (SybroEndo Corp. Orange, CA, USA)

- Cones de Resilon tamanhos F e FM (SybroEndo Corp. Orange, CA, USA)

- Cones de guta-percha acessório RS (Tanariman Industrial Ltda, Manacapuru, AM).

- Régua calibradora endodôntica Maillefer (Dentsply Ind. e Com Ltda, Petrópolis, $\mathrm{RJ})$.

- Espaçadores digitais A-D Maillefer (Dentsply Ind. e Com. Ltda.). 
- Espaçador digital BioRace .04 (FKG Dentaire, La Chaux-des-fonds, Suíça)

- Sistema de obturação Elements Obturation Unit (SybronEndo Corp., Orange, CA, USA)

- Pontas LM .08 e M .10 para o System B do Elements Obturation Unit (SybronEndo Corp., Orange, CA , USA)

- Cartuchos de RealSeal para Elements Obturation Unit 23G (SybronEndo Corp., Orange, CA , USA)

- Cartuchos de Guta-percha para Elements Obturation Unit 23G (SybronEndo Corp., Orange, CA , USA)

- Condensadores Endodônticos (Odous Instrumentos Ltda., Contagem, MG).

- Placa de vidro despolida.

- Espátula flexível (Odous Instrumentos Ltda., Contagem, MG)

- Lamparina a álcool

- Fotopolimerizador Demetron LC (SybronEndo Corp., Orange, CA , USA)

- Cimento temporário Villevie (Dentalville do Brasil Ltda, Joinville, SC)

- Zamadol - cloridrato de tramadol 100mg/2mL (Bergamo )

- Ketofen (Merial Saude Animal Ltda, Campinas, SP)

- Thiopentax 1g (Laboratório Cristália Ltda, São Paulo, SP)

- Cloreto de potássio (Isofarma Ind. Farm. Ltda, Eusébio,CE)

- Solução de formaldeído 37\% (LabSynth Prod. para Laboratórios Ltda, Diadema,SP)

- Cabo de bisturi (Swann-Morton Limited, Sheffield, Inglaterra)

- Lamina de bisturi 15C (Swann-Morton Limited, Sheffield, Inglaterra)

- Descolador de periósteo Molt $n^{\circ} 9$ (Trinity Ind. e Com. Ltda, Jaraguá, SP)

- Brocas cirúrgicas Surgical Talon12 (Tri Hawk Corp. Massena,NY, USA) 
- Motor de alta rotação Magnun 604 (Kavo do Brasil SA, Joinville, SC)

- Solução de ácido fórmico 85\% (LabSynth Prod. para Laboratórios Ltda, Diadema,SP)

- Citrato de sódio anidro USP/FCC (Labsynth Prod. para Laboratórios Ltda, Diadema, SP)

- Lâmina para micrótomo Leica 818 High Profile (Leica Microsystems GmbH, Nussloch, Alemanha)

\subsection{Métodos}

Para este estudo foram utilizados cinco cães (Quadro 1) de raça não definida (SRD), de idade entre 5 e 8 anos e de peso entre 15 a 25 quilos, adquiridos no canil do Departamento de Cirurgia (VCI) da Faculdade de Medicina Veterinária e Zootecnia da Universidade de São Paulo (FMVZ-USP).

Os dentes obturados foram os $1^{\text {os }}, 2^{\text {os }}, 3^{\text {os }}$ e $4^{\text {os }}$ pré-molares inferiores, os $1^{\text {os }}$, $2^{\text {os }}$ e $3^{\text {os }}$ pré-molares superiores e os incisivos centrais e laterais superiores. Os pareceres do Comitê de Ética em Pesquisa - Subcomissão de Bioética de Animais da FOUSP e Comissão de Bioética da FMVZ-USP encontram-se aprovados respectivamente sob números 02/07, datado de 07 de Agosto de 2007 (Anexo A) e 1201/2007 datado de 30 de Novembro de 2007 (Anexo B). 


\begin{tabular}{|l|l|l|l|}
\hline \multicolumn{1}{|c|}{ Cão } & Raça/ Sexo & \multicolumn{1}{c|}{ Idade } & \multicolumn{1}{c|}{ Peso } \\
\hline 1 (Mesclado) & SRD / Macho & Aprox. 5-6 anos & $25 \mathrm{~kg}$ \\
\hline 2 (Preto) & SRD / Macho & Aprox. 8 anos & $17 \mathrm{~kg}$ \\
\hline 3 (Implante) & SRD / Macho & Aprox. 8-9 anos & $15 \mathrm{~kg}$ \\
\hline 4 (Branca) & SRD / Fêmea & Aprox. 6 anos & $23 \mathrm{~kg}$ \\
\hline 5 (Dourado) & SRD / Macho & Aprox. 8 anos & $20 \mathrm{~kg}$ \\
\hline
\end{tabular}

Quadro 1 - Cães utilizados no experimento

Previamente, os cães foram vermifugados com dose única de vermífugo Dontra ${ }^{\circledR}$ de acordo com o peso de cada animal e submetidos a exame hematológico (Anexos C, D, E, F e G).

Em todos os procedimentos cirúrgicos os cães foram submetidos à anestesia geral conforme o protocolo recomendado pelo Laboratório de Odontologia Comparada do Departamento de Cirurgia da FMVZ - USP. Este protocolo consistiu de pré-anestesia com Acepromazina (Acepran ${ }^{\circledR} 0.2 \%$ ), indução com Propofol (Provive $^{\circledR} 1 \%$ ) e manutenção da anestesia com Isoflurano (Isothane ${ }^{\circledR}$ ) pelo tempo necessário. $O$ equipo necessário para o procedimento de anestesia foi o Samurai (K.Kataoka Ind e Com. Ltda, São Paulo, SP) acoplado ao Fluovapor 1220 e ao monitor cardíaco Viridia M3 HP M3046A.

Inicialmente foi realizada a radiografia periapical dos dentes a serem submetidos ao tratamento endodôntico, raspagem para remoção da placa bacteriana e do cálculo dentário, e anti-sepsia dos tecidos moles e dentes com solução de clorexidina a $2 \%$. 
A etapa do tratamento endodôntico propriamente dita constituiu-se da cirurgia de acesso coronária realizada com auxílio de brocas diamantadas esféricas número 1014 e tronco-cônicas de ponta inativa número 3083. Para facilitar a cirurgia de acesso, foi removida parte da coroa de cada elemento dental.

A etapa de preparo químico-cirúrgico foi realizada com auxilio da instrumentação rotatória. Utilizaram-se instrumentos rotatórios K3 ISO 25/.12 e PréRace ISO 35/.08 e 40/.10 para o preparo da entrada dos canais conjuntamente com a associação da solução de hipoclorito de sódio a $1 \%$ e creme de EndoPTC , usando $5 \mathrm{~mL}$ da solução a cada troca de instrumento.

Após o preparo cervical, o comprimento de trabalho foi determinado por meio radiográfico a uma distância entre $1 \mathrm{~mm}$ e $1.5 \mathrm{~mm}$ aquém do vértice radiográfico da raiz.

Seguiu-se a instrumentação rotatória com instrumentos K3 seguindo a seqüência Procedure Pack $(25 / .10,25 / .08,40 / .06,35 / .06,30 / .06,25 / .06)$ até a finalização do preparo com um instrumento 40/.06, sempre utilizando o creme de Endo PTC associado a uma irrigação de $5 \mathrm{~mL}$ de hipoclorito de sódio a cada troca de instrumento.

Concluído o preparo químico-cirúrgico, os canais radiculares foram irrigados com $6 \mathrm{~mL}$ da solução de ácido cítrico a $15 \%$, seguido de $6 \mathrm{~mL}$ da solução de clorexidina a $2 \%$ e secos por aspiração com pontas capilares finas e com cones de papel absorvente.

Os dentes assim preparados foram distribuídos aleatoriamente em 8 grupos de acordo com as técnicas de obturação, a saber:

Grupo I (AHCL) - 12 canais obturados com o cimento AHPlus e técnica de condensação lateral. 
Grupo II (AHCW) - 12 canais obturados com o cimento AHPlus e técnica termoplástica por ondas contínuas de condensação (CWC)/injeção.

Grupo III (RSCL) - 12 canais obturados com o cimento RealSeal e técnica de condensação lateral.

Grupo IV (RSCW) - 12 canais obturados com o cimento RealSeal e técnica termoplástica por ondas contínuas de condensação (CWC)/injeção.

Grupo V (SECL) - 12 canais obturados com o cimento RealSeal SE e técnica de condensação lateral.

Grupo VI (SECW) - 12 canais obturados com o cimento RealSeal SE e técnica termoplástica por ondas contínuas de condensação (CWC)/injeção.

Controle positivo - 10 canais sem material obturador.

Controle negativo - 10 canais obturados com cimento AH Plus e técnica de condensação lateral, sendo posteriormente restaurados com resina composta.

Para a técnica termoplástica Elements Obturation Unit que associa as técnicas de ondas contínuas de condensação (CWC) e injeção de material sólido plastificado; anteriormente à etapa de termoplastificação, foi escolhido o condensador LM .08 ou M .10 que apresentava justeza ao canal radicular quando a sua extremidade localizava-se entre 3 e $4 \mathrm{~mm}$ aquém do preparo apical. Com o aparelho System B do Elements Obturation Unit (SybronEndo Corp., Orange, CA, USA) calibrado na temperatura de $200^{\circ} \mathrm{C}$ para a guta-percha e $150^{\circ} \mathrm{C}$ para o Resilon, o condensador foi introduzido no canal radicular previamente preenchido com o cimento e o material sólido até que este alcançasse o limite anteriormente estabelecido. Ao atingir este limite, cessou-se o aquecimento, permanecendo o condensador sob pressão durante 10 segundos. Após este período, acionou-se rapidamente o aquecimento e foi removido o condensador do interior do canal. 
Realizou-se a condensação do material termoplastificado no terço apical com auxílio de condensadores. Completou-se o preenchimento dos terços médio e cervical com sucessivas etapas de injeção de guta-percha ou Resilon termoplastificados pelo sistema Extruder do Elements Obturation Unit (SybronEndo Corp., Orange, CA, USA) e condensação vertical a frio com os condensadores manuais.

À sua vez, para a técnica de condensação lateral foram utilizados cones de guta-percha FM de guta-percha ou Resilon cujas pontas foram calibradas no diâmetro correspondente ao preparo apical com o auxílio de régua calibradora. $\mathrm{O}$ cone principal foi introduzido no conduto conjuntamente ao cimento obturador e a técnica de condensação lateral realizada com auxilio de espaçadores digitais ou com espaçadores de conicidade 0.04 quando possível. Estes espaçadores promoviam espaços na obturação que foram preenchidos com cones de guta-percha RS ou cones de Resilon F até o completo preenchimento do canal radicular.

Os canais obturados pelo sistema RealSeal/Resilon foram fotopolimerizadas por 40 segundos logo após o término da condensação.

Para cada animal, todos os itens do tratamento (dentes, odontometria, técnicas obturadoras, cimento obturador e datas) foram anotados em uma ficha controle (Apêndice A). Ao final dos procedimentos de obturação, cada conduto foi selado com cimento temporário pelo período de sete dias.

Após a sessão de instrumentação e obturação foi administrado cloridrato de tramadol e ketoprofeno visando respectivamente ação analgésica e ação antiinflamatória no pós-operatório imediato.

Após o tempo de presa dos cimentos utilizados (1 semana), os cães foram anestesiados novamente para a remoção do selamento coronário. As cavidades coronárias ficaram então expostas ao meio bucal por um período de 75 dias. 
Passado o período experimental, os cães foram ortotanasiados por superdosagem de anestésico, iniciada com pré-anestesia com Acepromazina, indução com Propofol e superdosagem propriamente dita com Thiopental na dosagem de $50 \mathrm{mg} / \mathrm{kg}$. Na seqüência foi realizada a injeção de $10 \mathrm{~mL}$ de cloreto de potássio para indução da parada cardíaca.

Uma vez constatada a morte, realizava-se a perfusão de formol a $10 \%$ através da carótida e a remoção das partes correspondentes aos pré-molares e incisivos da maxila. Logo após a remoção, as peças foram colocadas em solução de formol a $10 \%$ e fixados por $72 \mathrm{hs}$.

Depois de fixadas as peças foram lavadas e desmineralizadas em solução de ácido fórmico a $20 \%$ + citrato de sódio a $10 \%$ pelo período mínimo de 90 dias. Para acelerar o processo de desmineralização, após as duas primeiras semanas, a peças foram fragmentadas em pequenos blocos contendo uma ou duas raízes, e mensalmente foi verificada a possibilidade do corte de excessos do material (dente e osso).

Constatada a desmineralização por meio de tomadas radiográficas e análise da consistência do material, as peças foram submetidas à rotina histológica, sendo lavadas, desidratadas, diafanizadas em xilol e incluídas em parafina.

Realizou-se a microtomia em cortes seriados com espessura de $6 \mu \mathrm{m}$, sendo dois cortes para cada região apical das raízes. Para a análise histopatológica, os cortes foram corados com hematoxilina e eosina (HE).

Cada corte histológico foi digitalizado e analisado em relação à existência de lesão periapical por três avaliadores (patologistas) independentes. 
Anteriormente à análise, os avaliadores foram balizados em relação a cada escore de reação inflamatória crônica a ser utilizado. A existência de inflamação periapical foi pontuada por meio de escores segundo os seguintes aspectos:

Reação inflamatória aguda (PMN)

Reação inflamatória crônica (Infiltrado mononuclear)

Escore 0 = Ausente $/$ Discreta

Escore 1 = Moderada

Escore 2 = Intensa / Severa

Os dados obtidos foram tabulados e posteriormente submetidos à análise estatística.

Para o teste de Kruskal-Wallis seguido pelo teste comparativo de Dunn quando necessário, a hipótese experimental foi que o cimento ou a técnica de obturação interferem na percolação marginal em dentes de cães. Os testes foram aplicados com um nível de $5 \%$ de significância, isto é, foi rejeitada a hipótese experimental, quando a probabilidade de rejeitá-la (valor de p) fosse maior que $5 \%$. 


\section{RESULTADOS}

\subsection{Da avaliação histopatológica das regiões periapicais}

Para a comprovação da eficiência do balizamento dos avaliadores em relação ao padrão de cada evento inflamatório, foi realizada comparação de todos os dados dos 3 avaliadores com auxílio do teste de Kruskal-Wallis, sendo que o mesmo não mostrou diferença estatisticamente significante $(p=0.9934)$. Os resultados das avaliações encontram-se nos Apêndices B, C, D, E e F.

No quadro 2 encontram-se dispostas as freqüências dos fenômenos histopatológicos avaliados em forma de escores, distribuídas em função de suas ocorrências em cada grupo experimental.

\begin{tabular}{|c|c|c|c|c|c|c|c|c|}
\hline Aspectos Histopatológicos & AHCL & AHCW & RSCL & RSCW & SECL & SECW & CP & CN \\
\hline Ausência de infiltrado inflamatório & 17 & 30 & 18 & 29 & 17 & 11 & 1 & 24 \\
\hline $\begin{array}{c}\text { Infiltrado inflamatório crônico leve } \\
\text { Infiltrado inflamatório crônico } \\
\text { moderado }\end{array}$ & 9 & 2 & 2 & 1 & 4 & 15 & 5 & 6 \\
\hline \begin{tabular}{c} 
Infiltrado inflamatório crônico severo \\
\hline
\end{tabular} & 4 & 0 & 5 & 1 & 9 & 4 & 14 & 0 \\
\hline
\end{tabular}

Quadro 2 - Freqüência dos fenômenos histopatológicos em cada grupo experimental. 


\subsubsection{Análise descritiva do grupo controle positivo (CP)}

Neste grupo, em 14 avaliações, as alterações periapicais mostraram quadros histopatológicos de infiltrados inflamatórios mononucleares intensos por toda a região periapical que se estende até a proximidade do osso alveolar adjacente, inclusive pelos espaços medulares em alguns casos. Na maioria das regiões periapicais se observou um aumento da espessura do ligamento periodontal, edema e dissociação fibrilar (Figuras $1 \mathrm{C}$ a 1H). Notou-se reabsorção óssea e cementária na porção apical e lateral da raiz em alguns espécimes.

O infiltrado inflamatório apresentou-se moderado em 10 avaliações (Figura 1A e 1B), leve em 5 avaliações e ausente somente em uma.

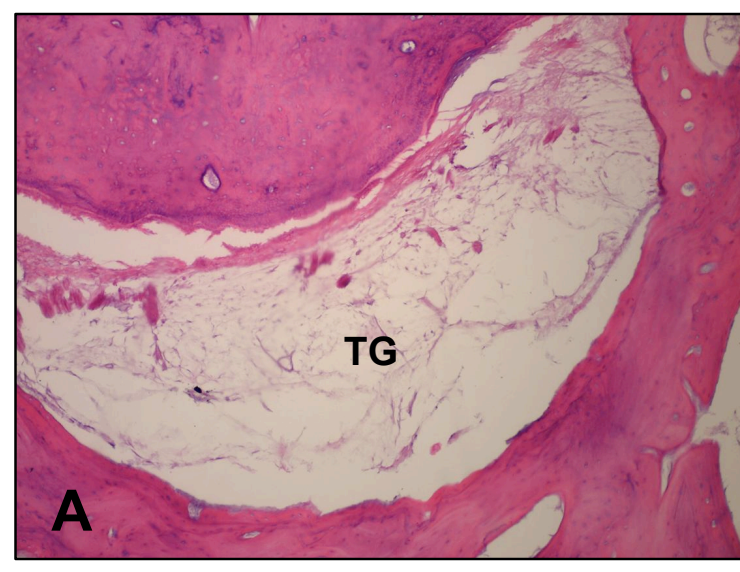

Figura 1A - Região periapical com infiltrado inflamatório de grau moderado, presença de edema. Nota-se a presença de tecido de granulação - TG (100 X).

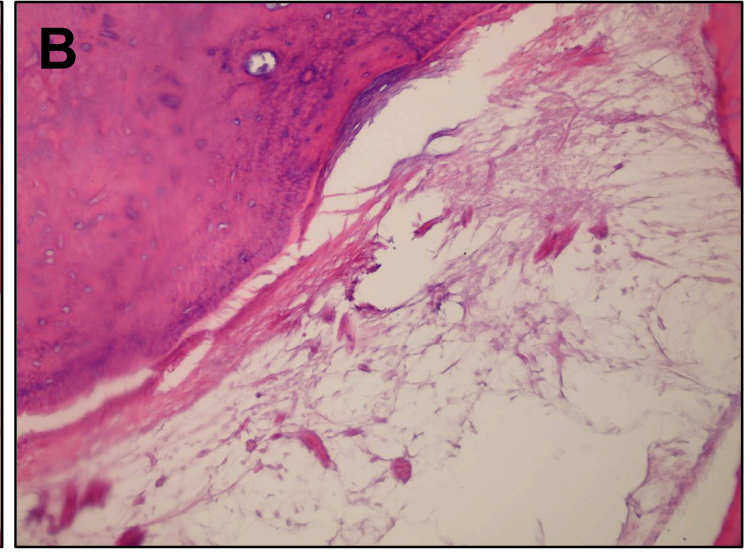

Figura 1B - Maior aumento da figura 1A (200 $\mathrm{X})$. 


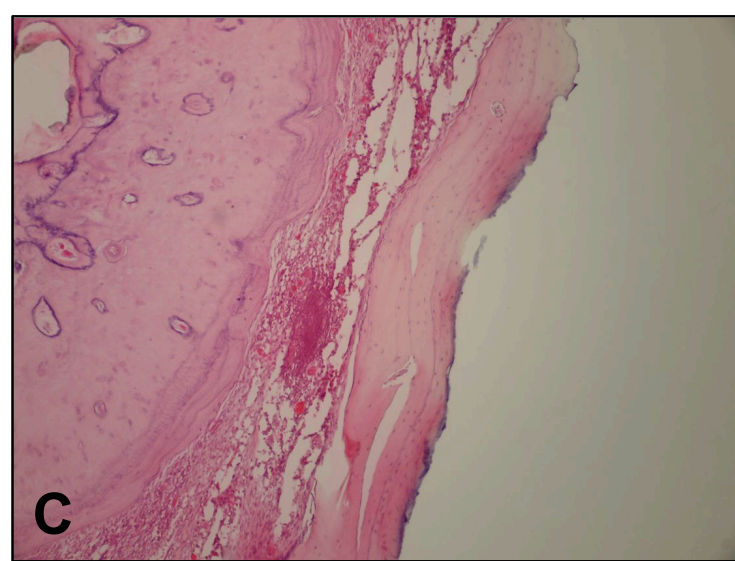

Figura 1C- Infiltrado inflamatório mononuclear intenso, edema moderado e aumento da espessura do ligamento periodontal (100 X).

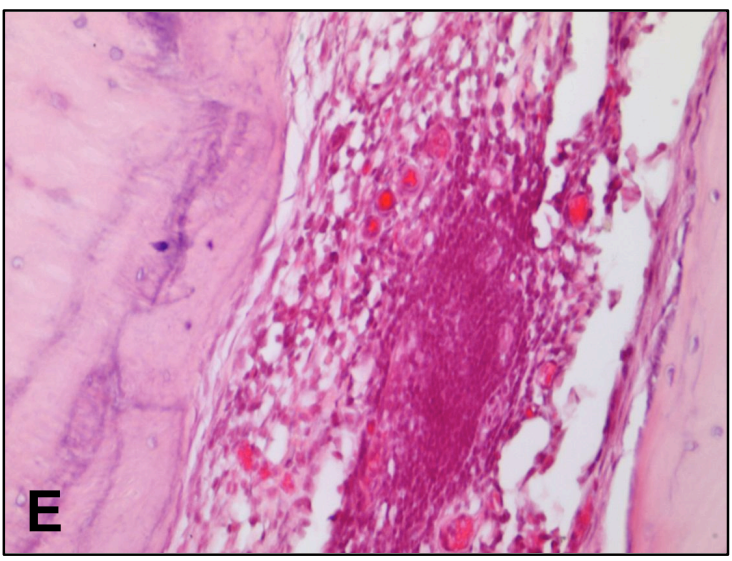

Figura 1E - Maior aumento da figura 1D (400 X).Figura 1F - Infiltrado inflamatório severo com

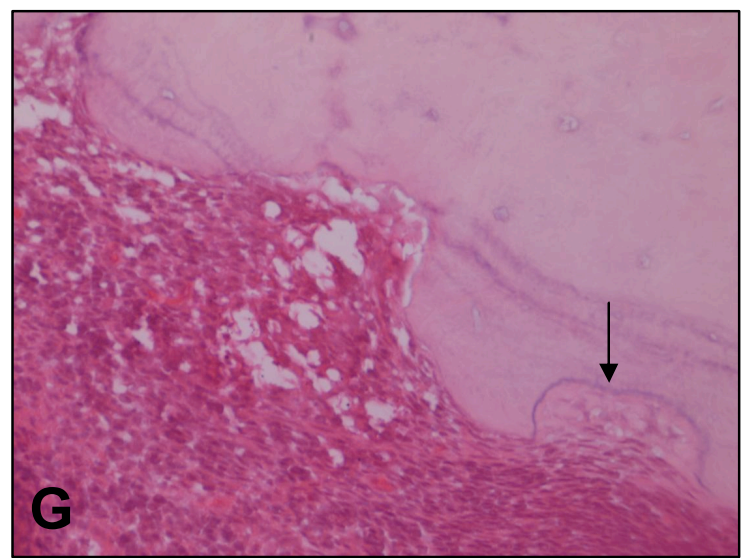

Figura 1G - Infiltrado inflamatório mononuclear intenso com presença de reabsorção cementária - seta $(400 \mathrm{X})$.

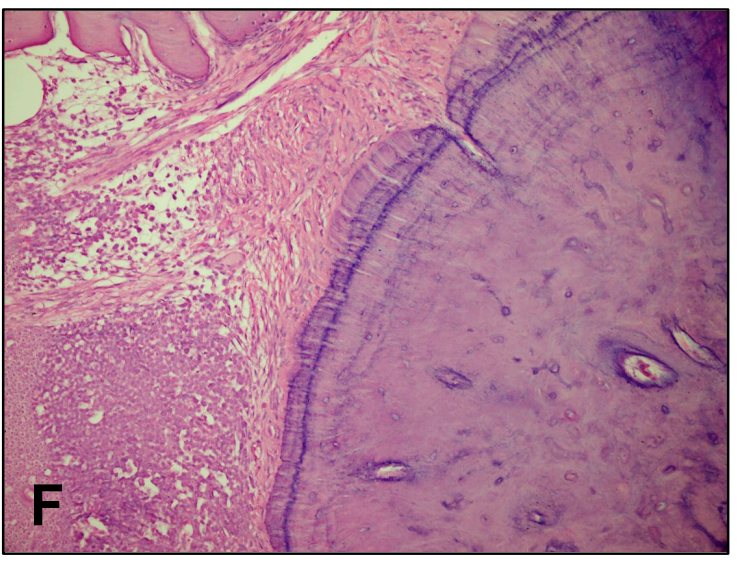
presença de dissociação fibrilar e aumento da espessura do ligamento periodontal $(200 \mathrm{X})$.

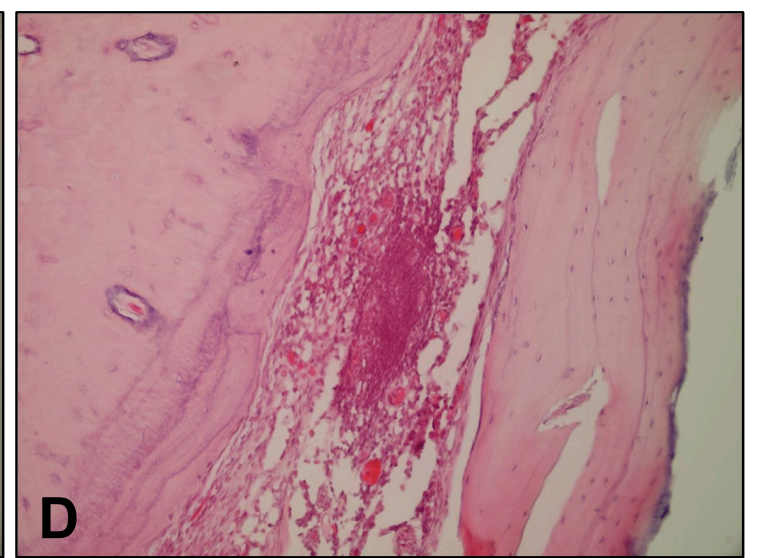

Figura 1D - Maior aumento da figura 1C (200 X).

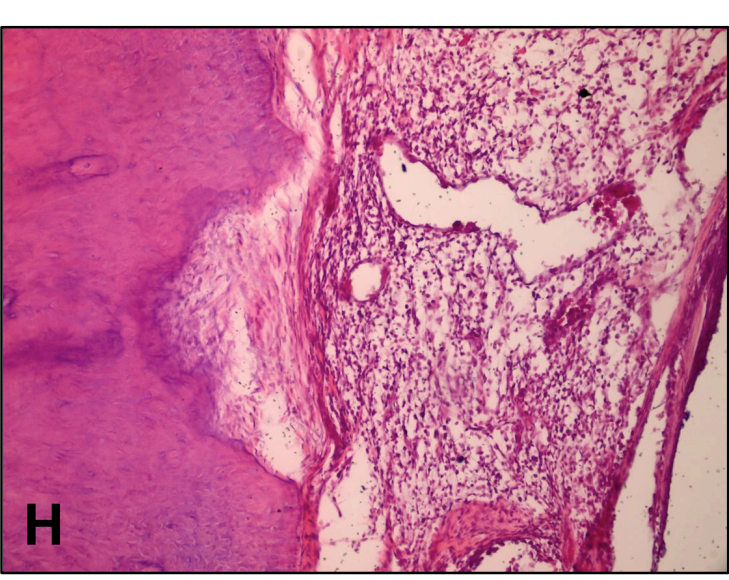

Figura $1 \mathrm{H}$ - Infiltrado inflamatório severo com presença de edema e aumento da espessura do ligamento periodontal $(200 \mathrm{X})$. 


\subsubsection{Análise descritiva do grupo controle negativo (CN)}

Neste grupo as alterações periapicais mostraram ausência de infiltrado inflamatório e ligamento periodontal com características de normalidade em 24 análises (Figuras 2A a 2G). Alguns cortes mostraram canais radiculares com tecido pulpar.

O infiltrado inflamatório leve foi considerado presente em 6 avaliações (Figura 2H). Não foram observados infiltrados inflamatórios moderados ou severos.

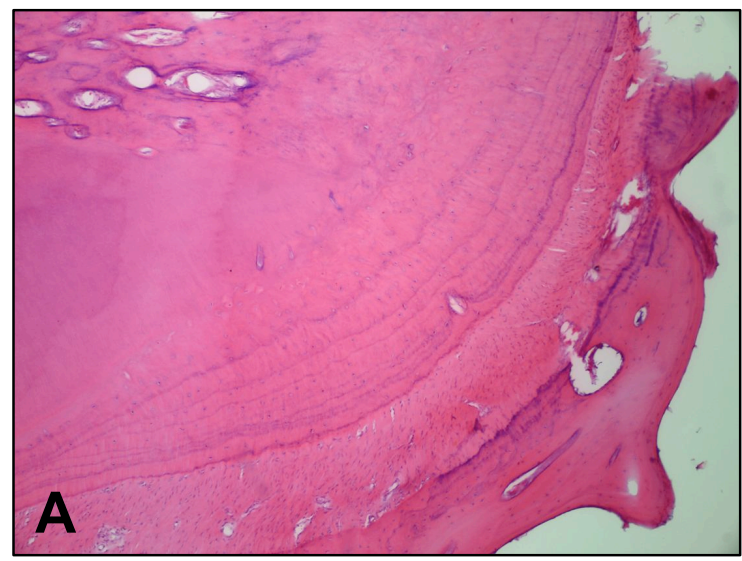

Figura 2A - Região periapical com ausência de infiltrado inflamatório e ligamento periodontal com características de normalidade $(100 \mathrm{X})$.

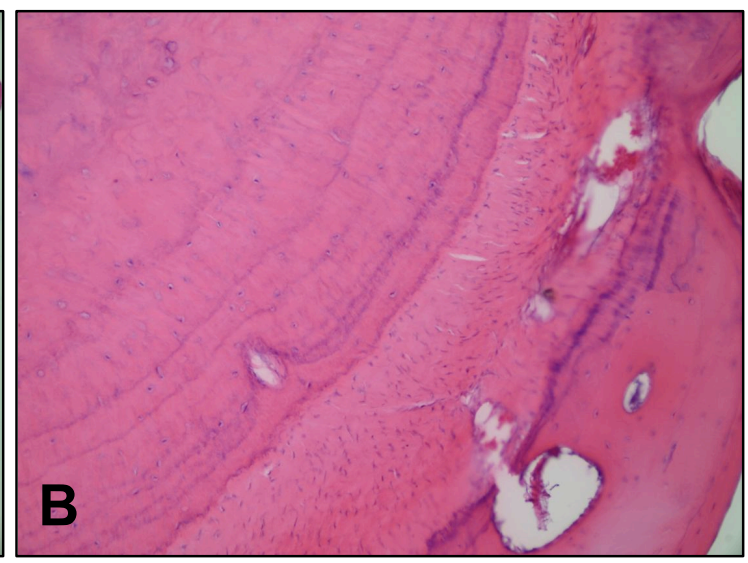

Figura 2B - Maior aumento da figura 2A (200 X). 

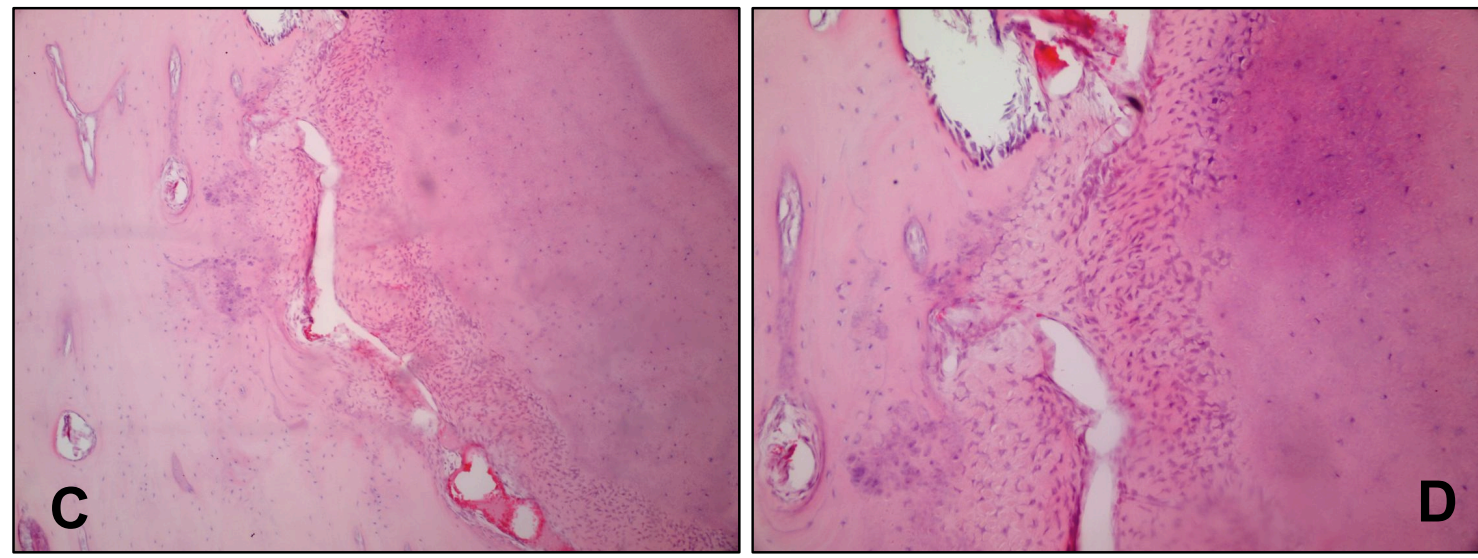

Figura 2C - Região periapical com ausência de Figura 2D - Maior aumento da figura 2C (200 X). infiltrado inflamatório, observa-se discreto aumento da espessura do ligamento periodontal $(100 \mathrm{X})$.
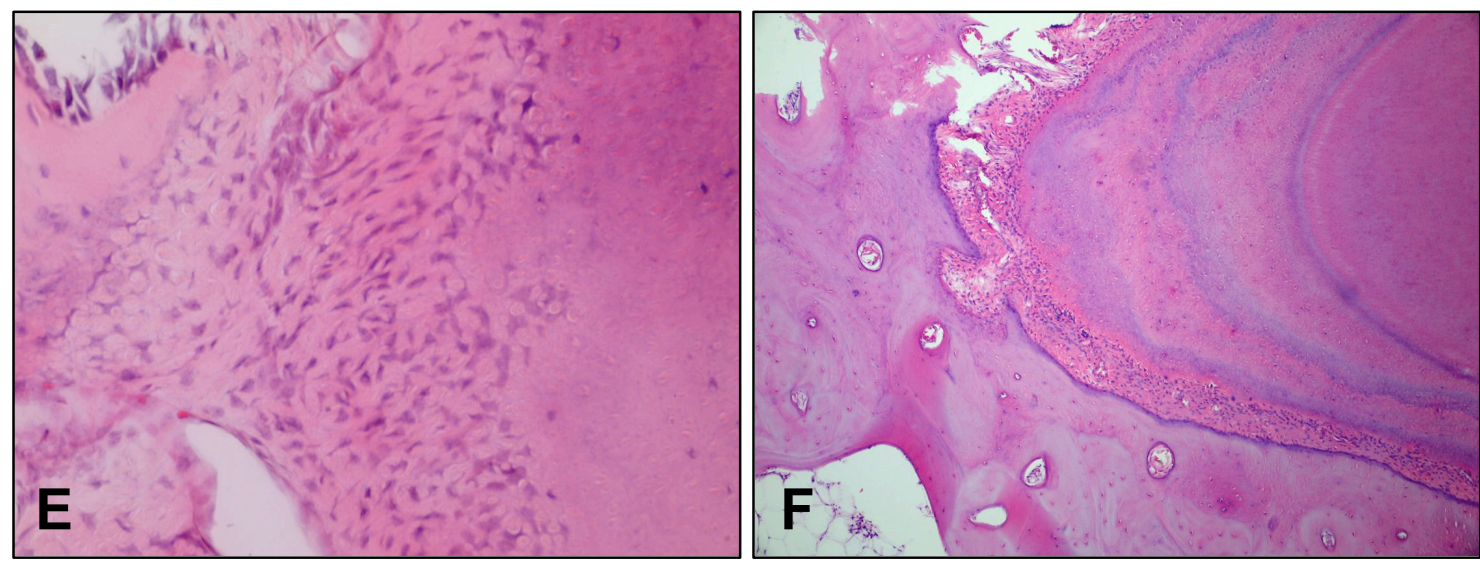

Figura 2E - Maior aumento da figura 2D (400 X) Figura 2F - Ausência de infiltrado inflamatório e ligamento periodontal normal $(100 \mathrm{X})$
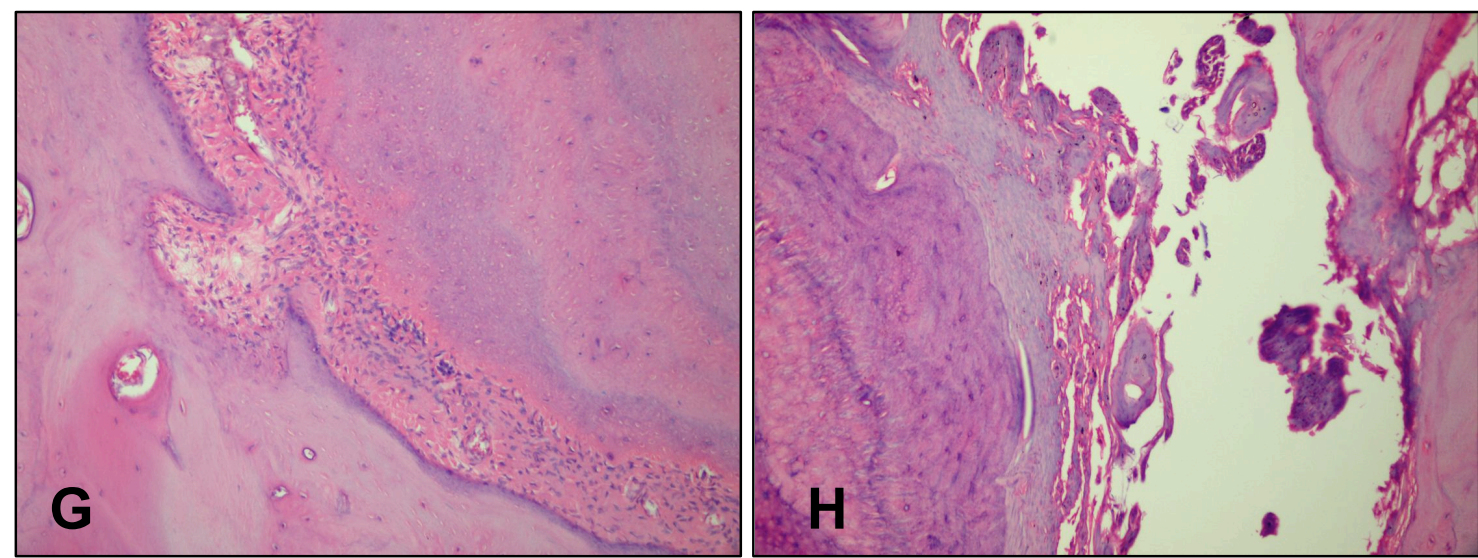

Figura $2 \mathrm{G}$ - Maior aumento da figura $2 \mathrm{~F}(200 \mathrm{X})$ Figura $2 \mathrm{H}$ - Ausência de reação inflamatória periapical com leve aumento da espessura do ligamento periodontal e discreto edema $(200 \mathrm{X})$. 


\subsubsection{Análise descritiva do grupo GI - AH Plus /condensação lateral (AHCL)}

Nas avaliações, 17 apresentaram ausência de infiltrado inflamatório, conduto com remanescentes de material exógeno (material obturador) e ligamento periodontal integro ou com ausência de aumento em sua espessura (Figuras 3C a 3F). Nos análises em que se observou grau severo de inflamação (4 casos), estes mostraram infiltrado mononuclear intenso (Figuras 3A e 3B).

O infiltrado inflamatório leve foi considerado presente em 9 avaliações e moderado em 6 (Figuras 3G e $3 \mathrm{H}$ ).

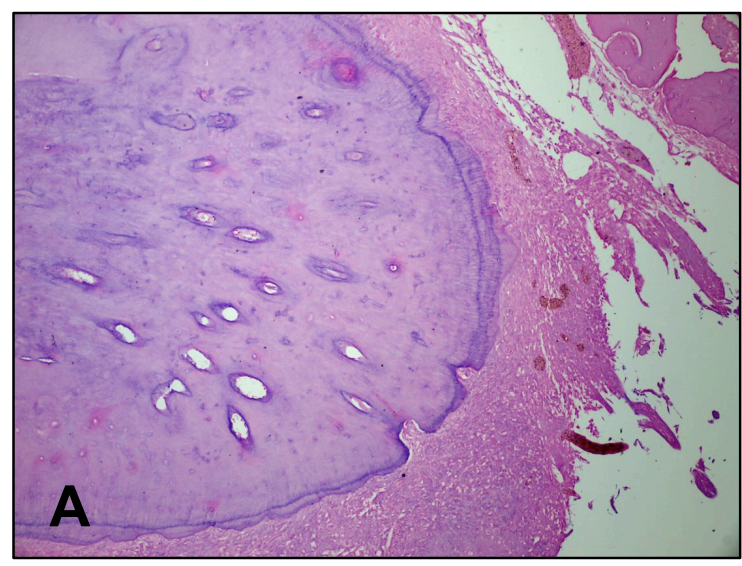

Figura 3A - Região periapical com infiltrado inflamatório mononuclear intenso, com evidente aumento da espessura do ligamento periodontal e edema (100 X).

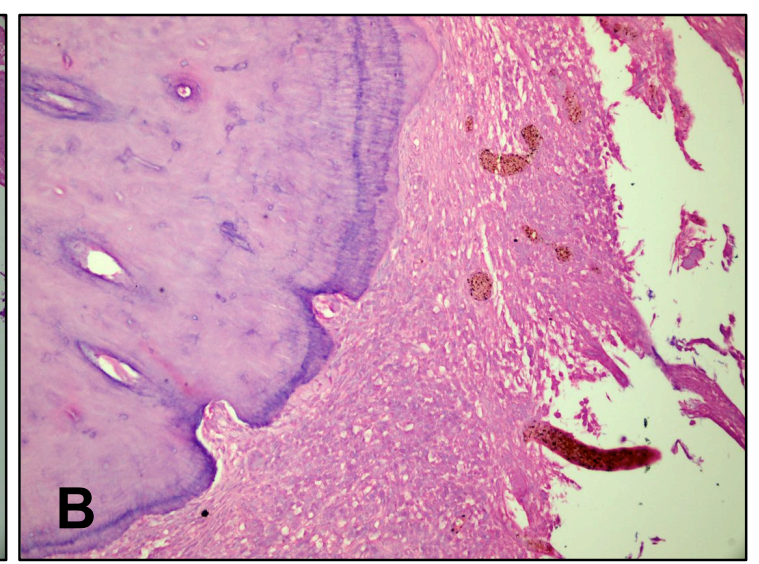

Figura 3B - Maior aumento da figura 3A (200 X). 


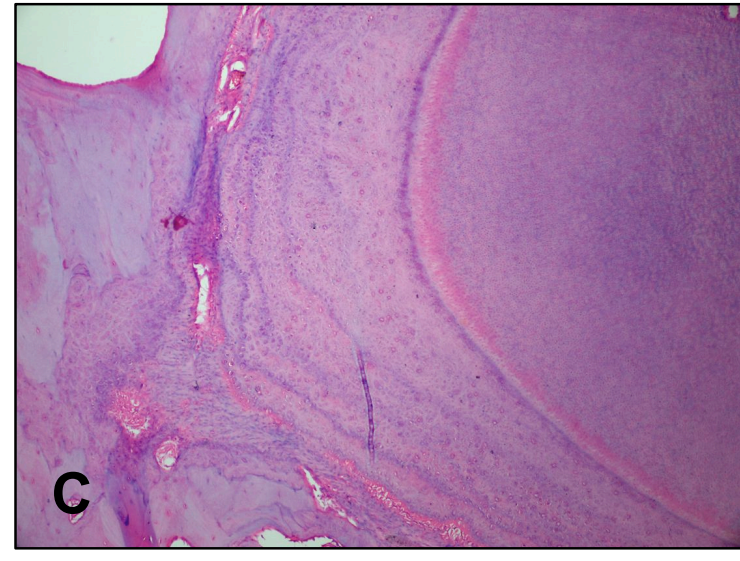

Figura 3C - Ausência de infiltrado inflamatório e ligamento periodontal normal $(100 \mathrm{X})$.

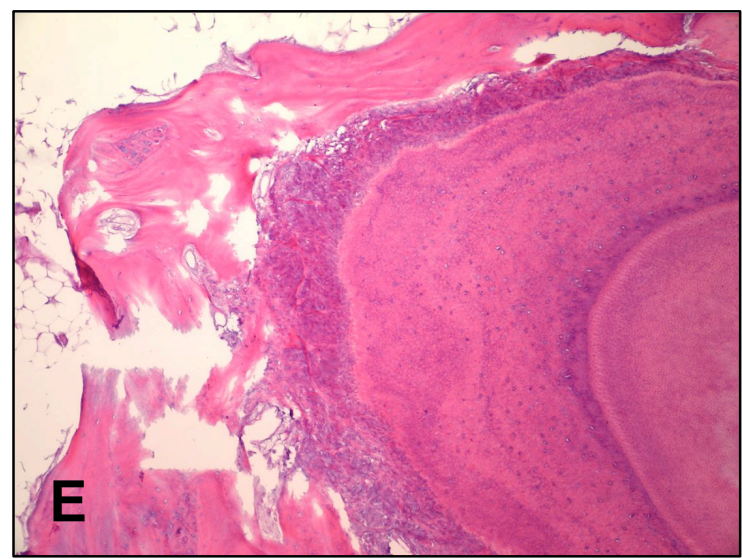

Figura 3E - Ausência de reação inflamatória periapical e presença de discreto aumento da espessura do ligamento periodontal (100 $\mathrm{X}$.

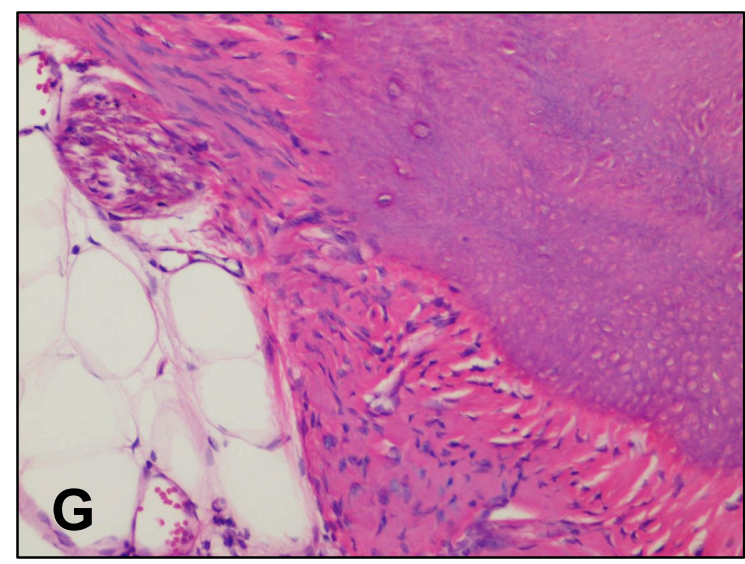

Figura 3G - Presença de reação inflamatória leve associada a edema adjacente ao ligamento periodontal que se mostra com normalidade (200 X).

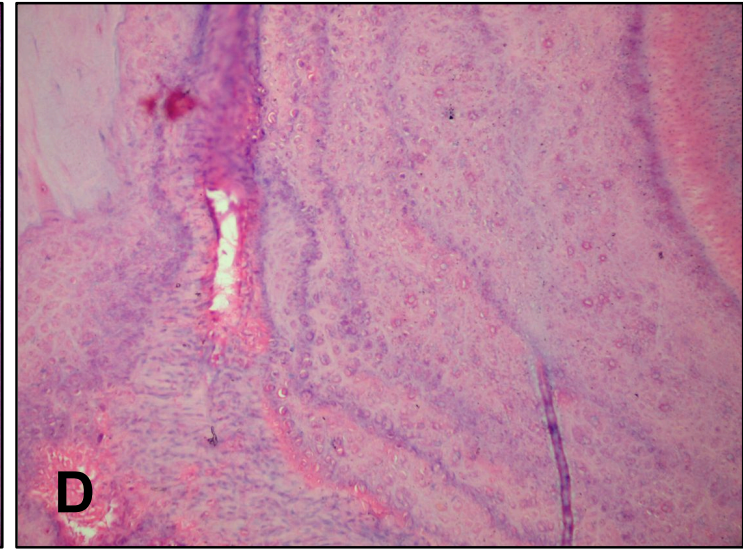

Figura 3D - Maior aumento da figura 3C (200 X).

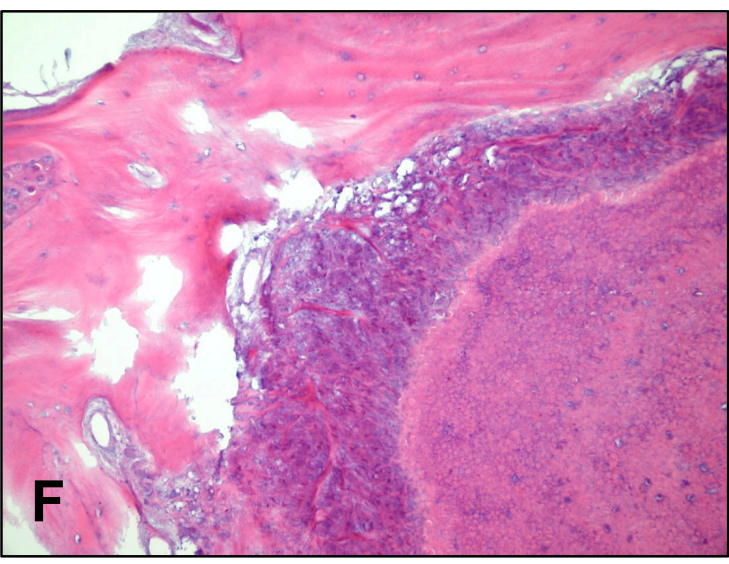

Figura 3F - Maior aumento da figura 3E (200 X).

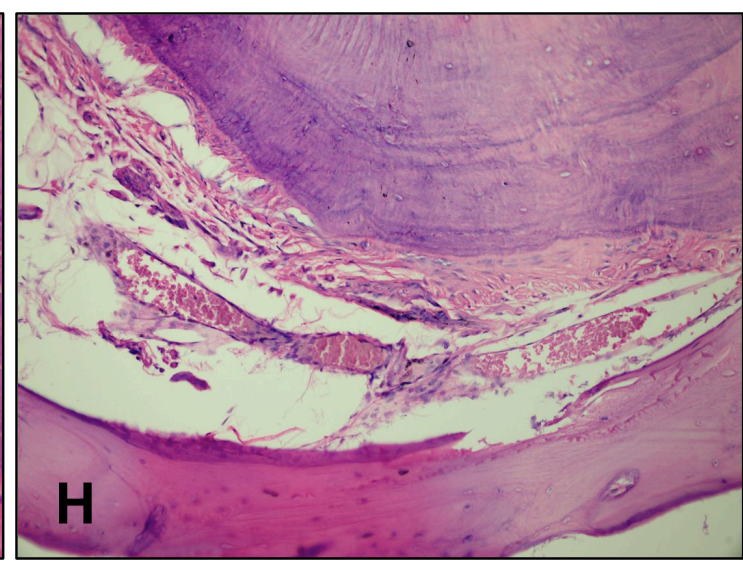

Figura $3 \mathrm{H}$ - Região periapical com infiltrado inflamatório de grau leve, com evidente aumento da espessura do ligamento periodontal e edema $(200 \mathrm{X})$. 


\subsubsection{Análise descritiva do grupo GII - AH Plus / termoplástica (AHCW)}

Este grupo não apresentou avaliações com infiltrado inflamatório severo. Porém, quando observado infiltrado moderado (4 análises) estes se apresentaram próximos a foraminas apicais com características mononucleares; mostrando também um leve aumento da espessura do ligamento periodontal devido a pequenas áreas de edemas (Figuras 4C, 4D e 4E). Em alguns casos nota-se presença da dissociação de fibras colágenas.

O infiltrado inflamatório leve foi considerado em dois casos e a ausência de resposta inflamatória ocorreu em 30 avaliações (Figuras 4A, 4B, 4F, 4G e 4H).

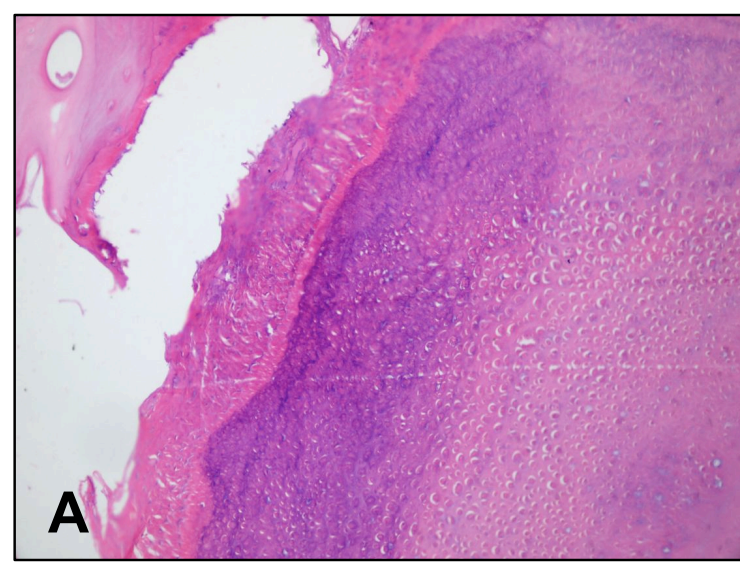

Figura 4A - Ausência de infiltrado inflamatório $(200 \mathrm{X})$.

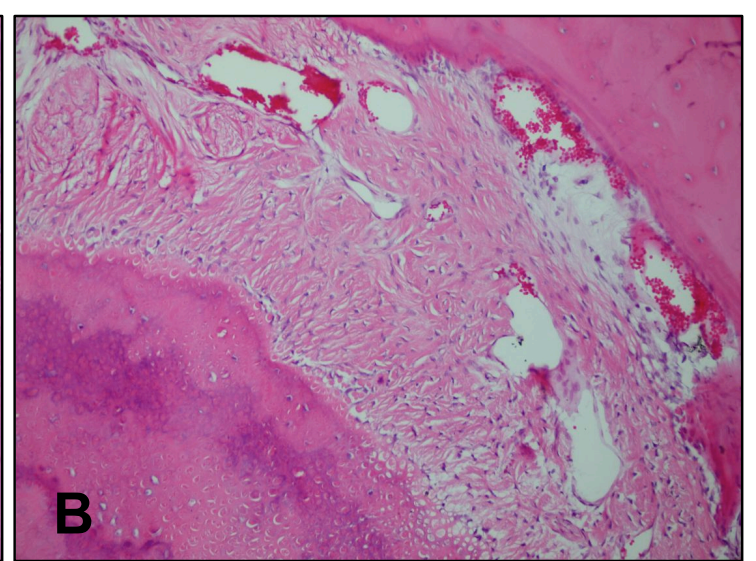

Figura 4B - Ausência de infiltrado inflamatório, discreto edema e dissociação fibrilar, e pequenas áreas hemorrágicas (200 $\mathrm{X})$. 


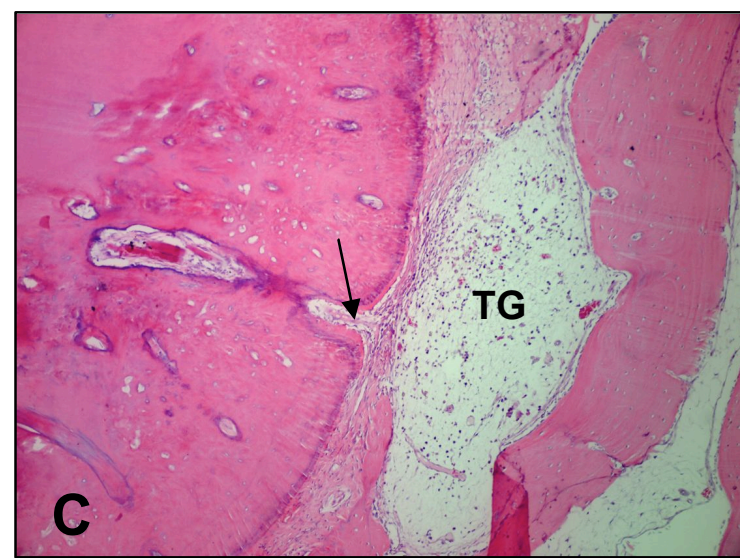

Figura 4C - Região periapical com infiltrado inflamatório mononuclear moderado, aumento da espessura do ligamento periodontal e edema localizado junto a uma foramina apical (seta). Nota-se formação de tecido de granulação -TG (100 X).

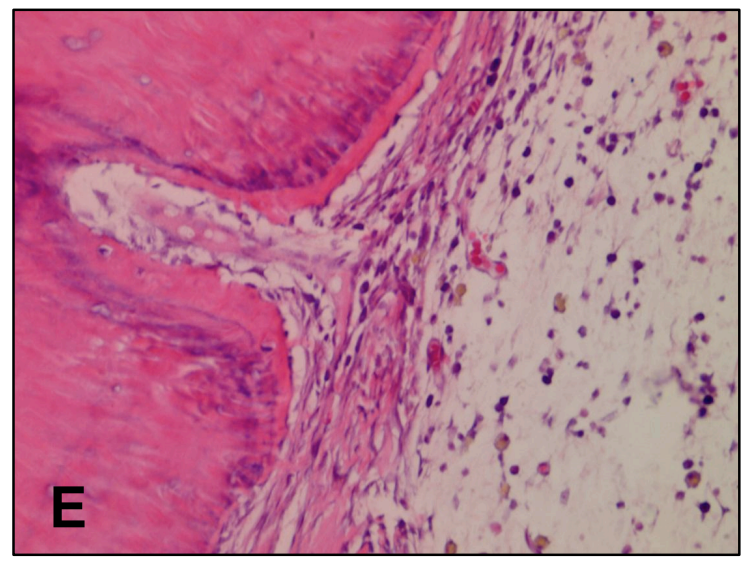

Figura 4E - Maior aumento da figura 4D (400 X) Fig

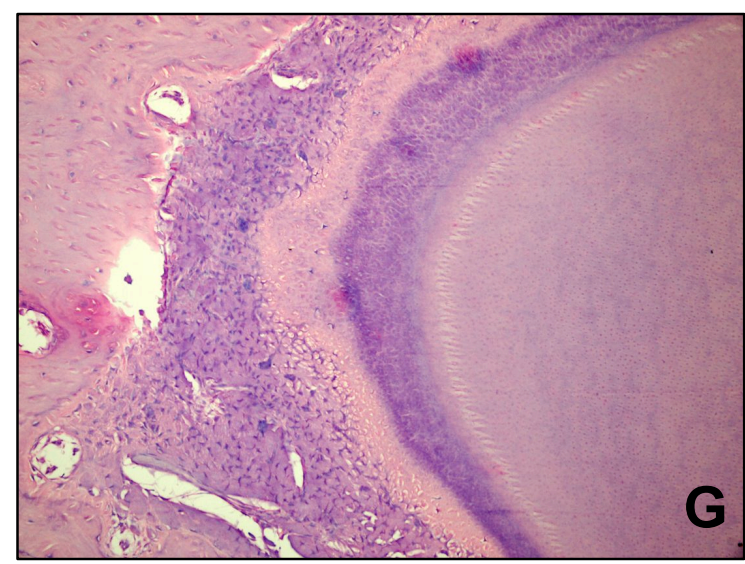

Figura 4G - Maior aumento da figura 4F (200 X). Figura 4H - Maior aumento da figura 4G, mostrando células normais do ligamento periodontal $(400 \mathrm{X})$.

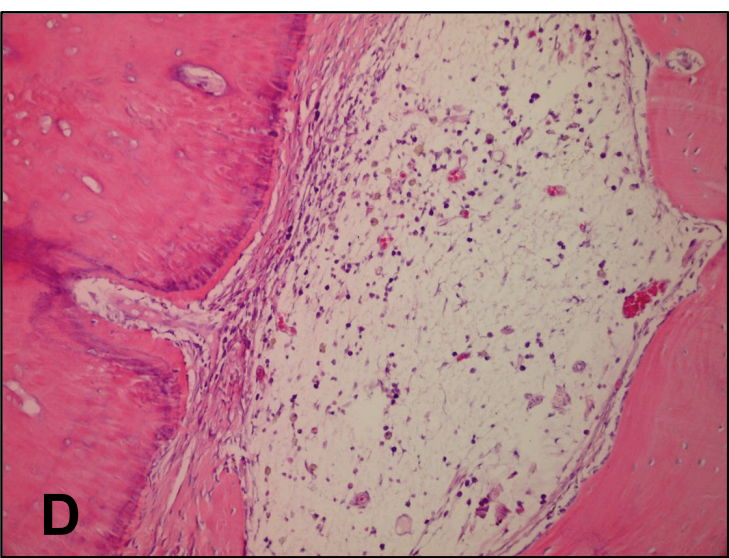

Figura 4D - Maior aumento da figura 4C (200 X).

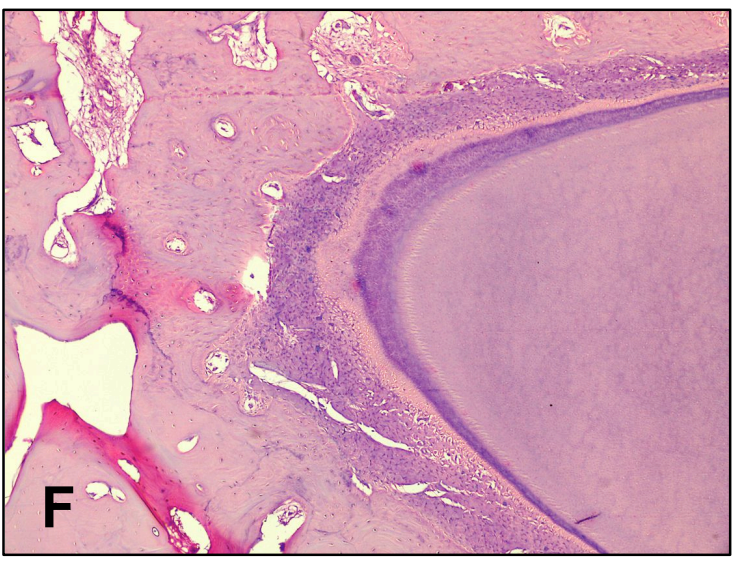

Figura 4F - Ausência de reação inflamatória periapical e ausência de aumento da espessura do ligamento periodontal (100 X).

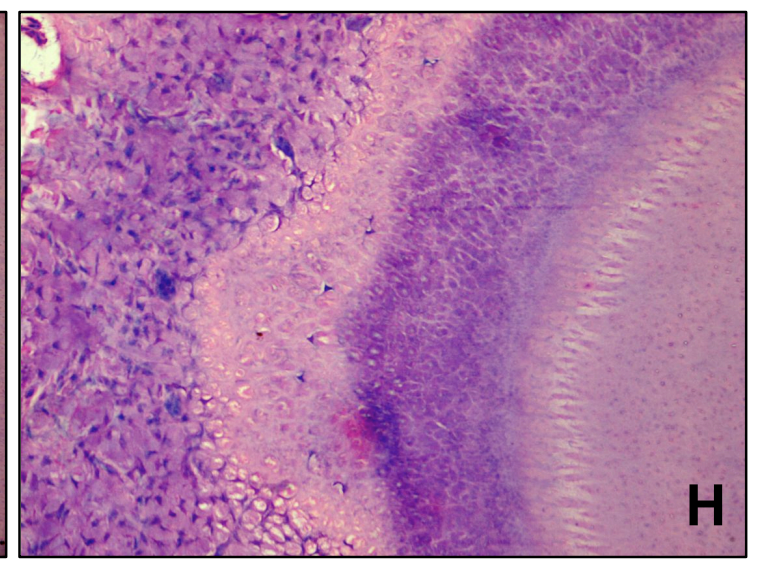

H 


\subsubsection{Análise descritiva do grupo GIII - RealSeal /condensação lateral (RSCL)}

As alterações periapicais mostraram em cinco analises quadros histopatológicos de infiltrado inflamatório mononuclear intenso por toda a região periapical. Quando presente foi acompanhado de edema do tecido conjuntivo e grande aumento da espessura do ligamento periodontal (Figuras 5A a $5 \mathrm{C}$ )

O infiltrado inflamatório se apresentou moderado em 11 avaliações, leve em dois casos (Figura 5F) e a ausência de reação inflamatória ocorreu em 18 analises.

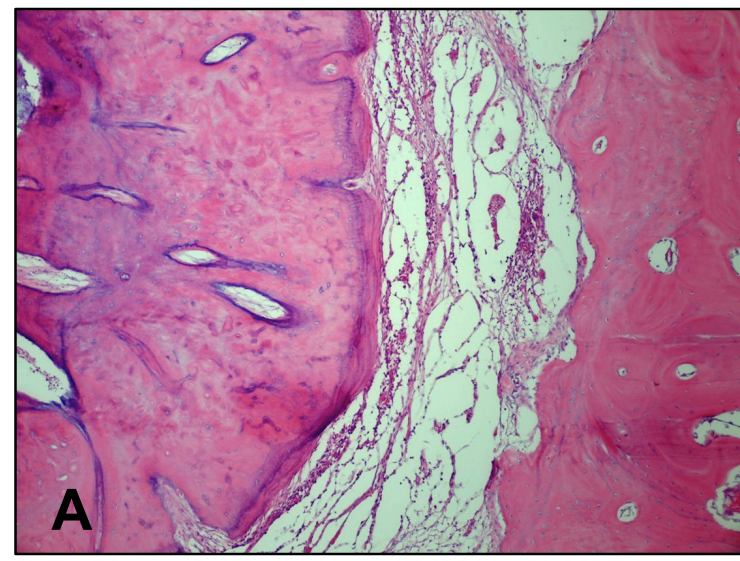

Figura 5A - Região periapical portando infiltrado inflamatório mononuclear severo, com evidente aumento da espessura do ligamento periodontal e edema (100 X).

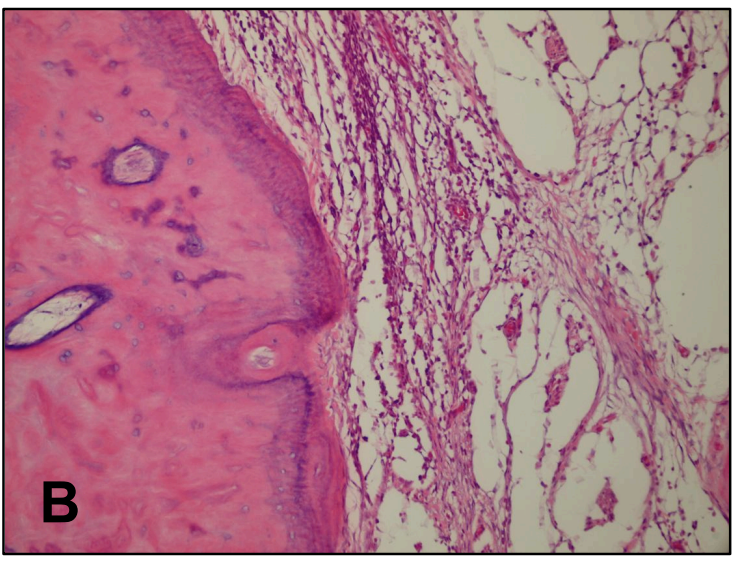

Figura 5B - Maior aumento da figura 5A (200 X). 

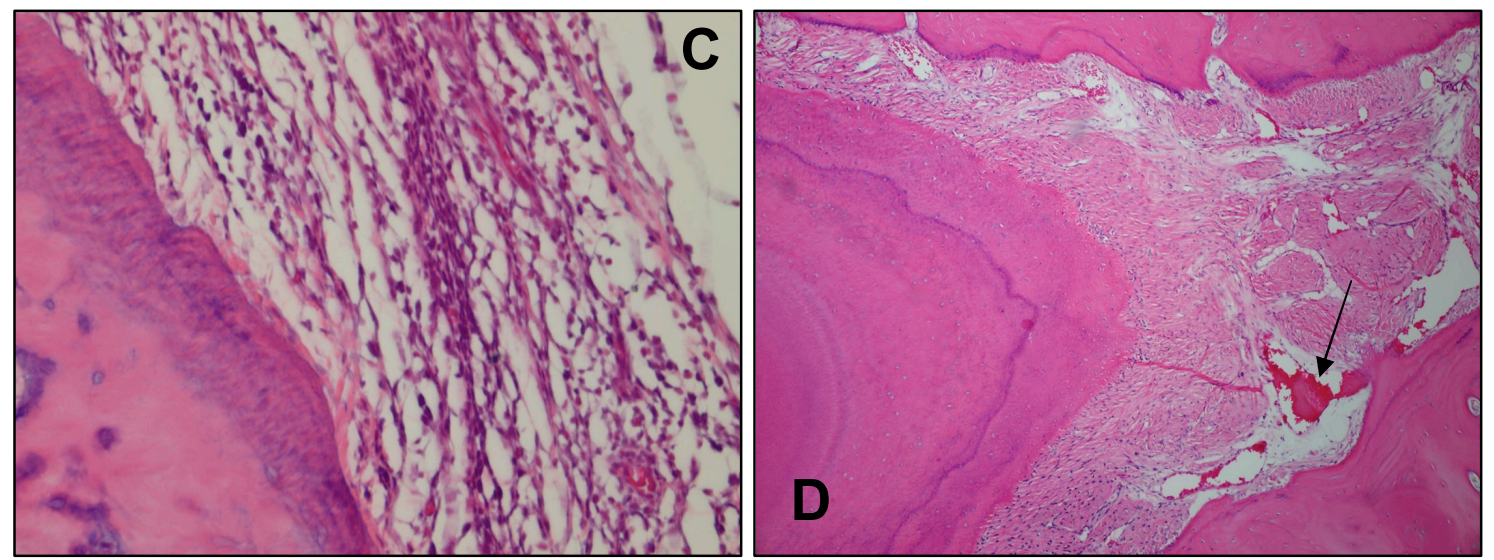

Figura 5C - Maior aumento da figura 5B (400 X). Figura 5D - Ausência de reação inflamatória periapical e leve aumento da espessura do ligamento periodontal. Nota-se discreto edema associado a dissociação de fibras colágenas e pequena área hemorrágica seta $(100 \mathrm{X})$.

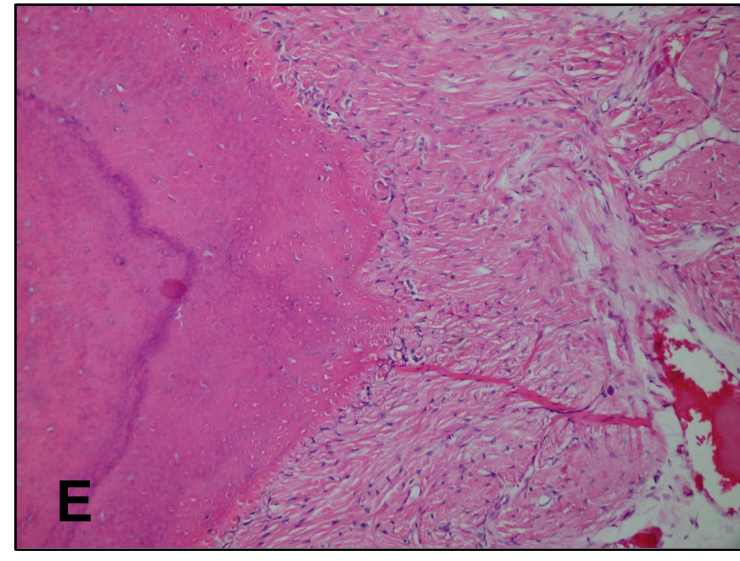

Figura 5E - Maior aumento da figura 5D (200 $X)$, evidenciando a dissociação fibrilar e a hemorragia $(200 \mathrm{X})$.

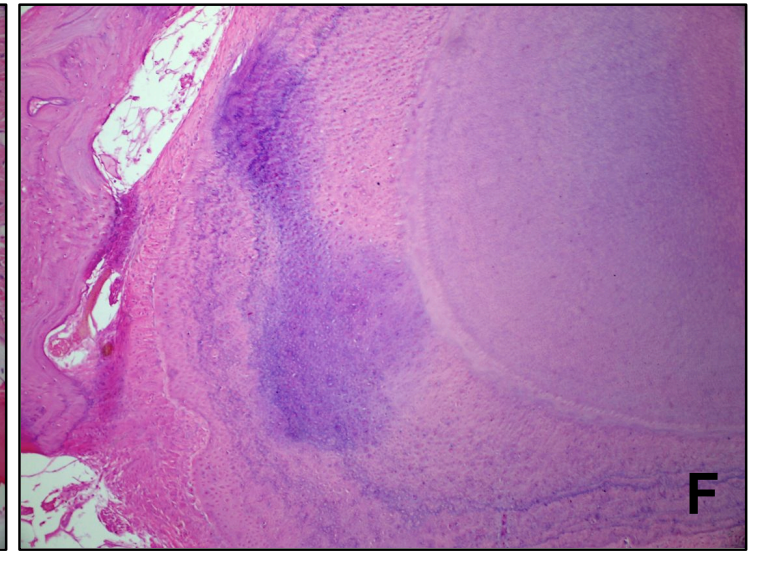

Figura 5F - Discreta reação inflamatória periapical contendo células mononucleares e leve aumento da espessura do ligamento periodontal associado a edema. 


\subsubsection{Análise descritiva do grupo GIV- RealSeal / termoplástica (RSCW)}

Neste grupo houve somente uma avaliação portadora de processo inflamatório crônico severo. Quando da presença de infiltrado inflamatório moderado (5 casos), estes se apresentavam características mononucleares na região periapical e discretos aumentos da espessura do ligamento periodontal devido a pequenos edemas localizados (Figuras 6A e 6B).

Infiltrado inflamatório leve foi observado em apenas uma análise. Ausência de resposta inflamatória ocorreu em 29 avaliações, aonde se notou condutos com material exógeno e região apical sem alterações (Figuras $6 \mathrm{C} \mathrm{a} \mathrm{6H).}$

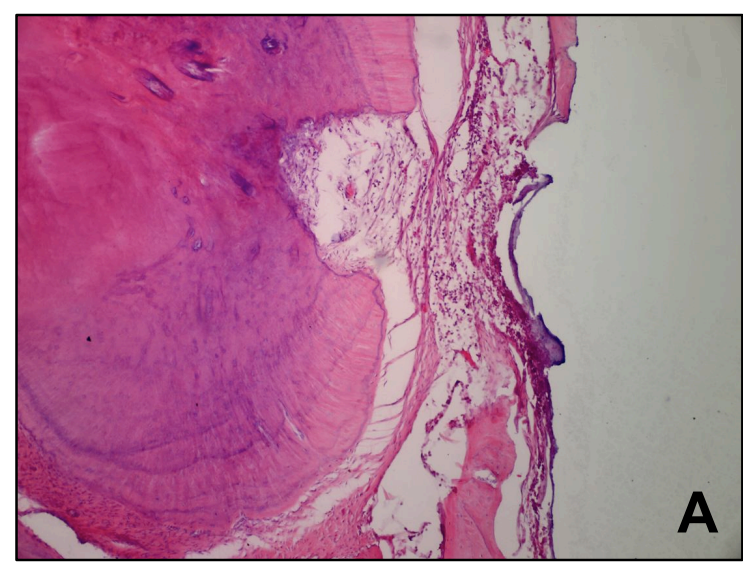

Figura 6A - Presença de reação inflamatória moderada próxima a foramina apical, associada a edema no espaço do ligamento periodontal $(100 \mathrm{X})$.

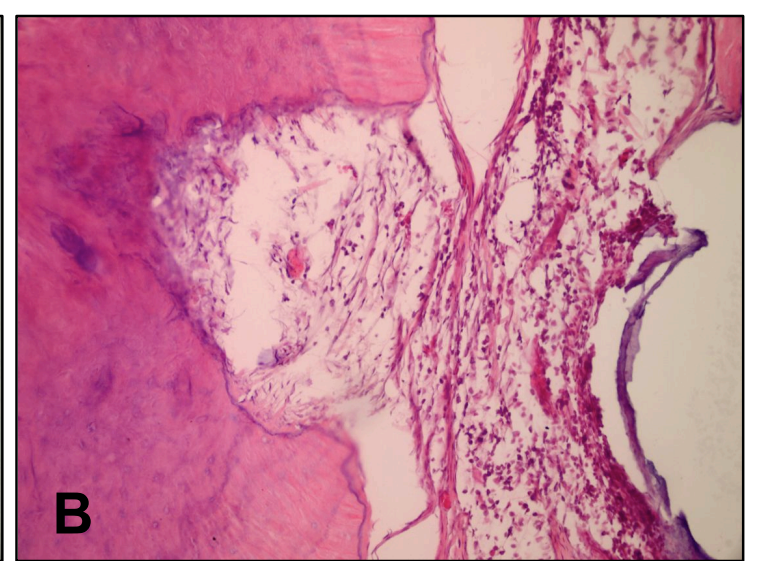

Figura 6B - Maior aumento da figura 6G (200 X). 

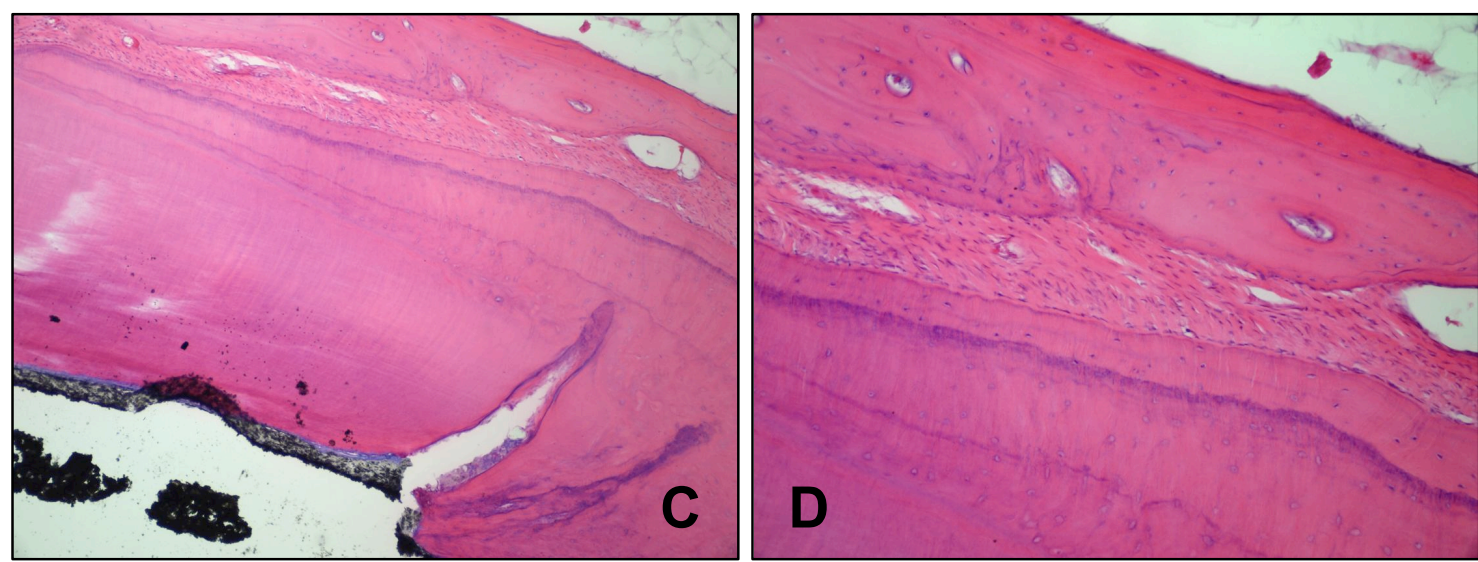

Figura 6C - Ausência de infiltrado inflamatório e espessura normal do ligamento periodontal $(100 \mathrm{X})$.
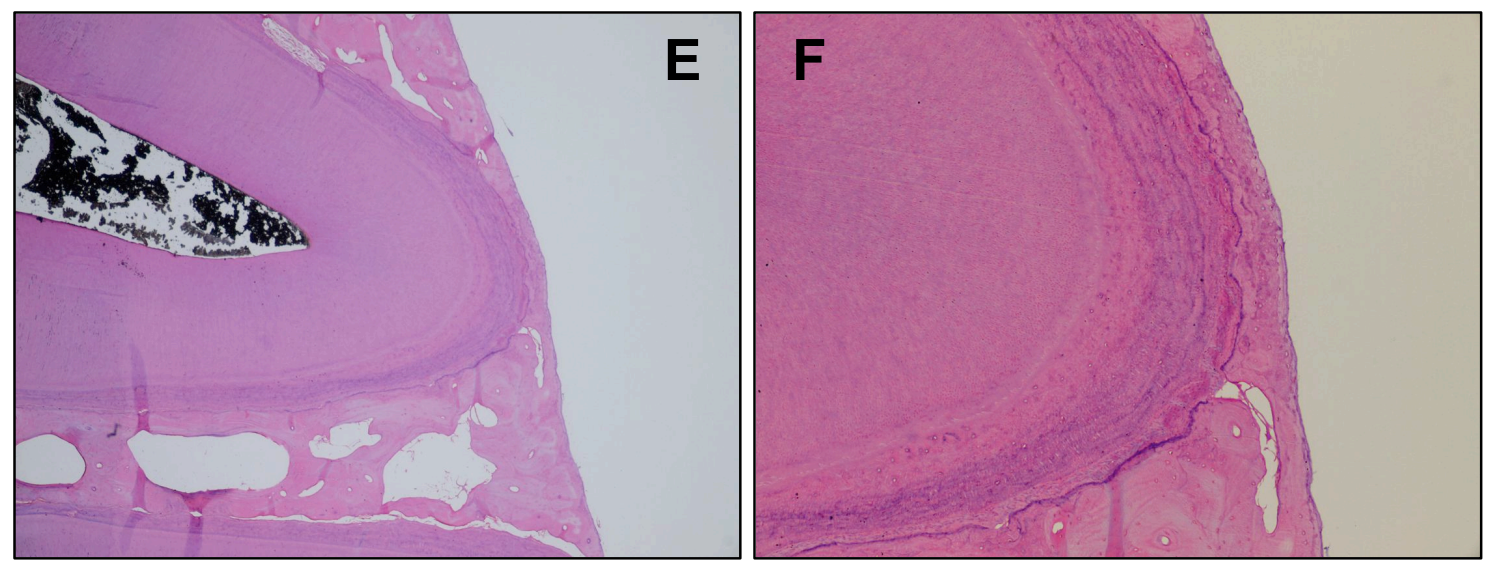

Figura 6E - Ausência de infiltrado inflamatório e espessura normal do ligamento periodontal $(40 \mathrm{X})$.
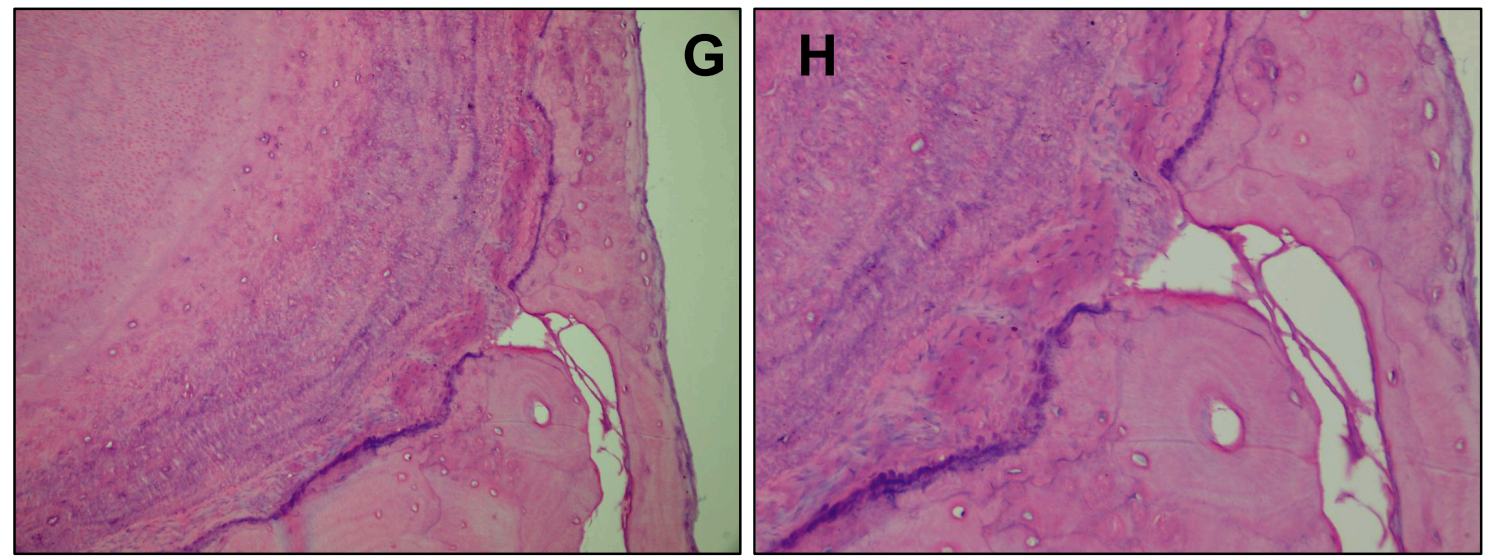

Figura 6G - Maior aumento da figura 6F (200 X). Figura 6H - Maior aumento da figura 6G (400 X) 


\subsubsection{Análise descritiva do grupo GV - RealSeal SE / condensação lateral (SECL)}

Em 17 avaliações, foram observadas ausência de infiltrado inflamatório. Quando analisado quadros histopatológicos de resposta inflamatória crônica moderada e leve (Figuras 7E a 7H), estes ocorreram em 6 e 4 casos respectivamente. Já quadros portadores de infiltrado inflamatório mononuclear intenso, verificados em 9 casos, possuíam uma extensão próxima do osso alveolar adjacente associados a edema e dissociação fibrilar (Figuras 7A a 7D). Estas respostas inflamatórias foram semelhantes às encontradas no grupo controle positivo (CP).

Notou-se também reabsorção óssea e cementária em alguns casos e áreas sugestivas de necrose em um espécime (Figura 7C).

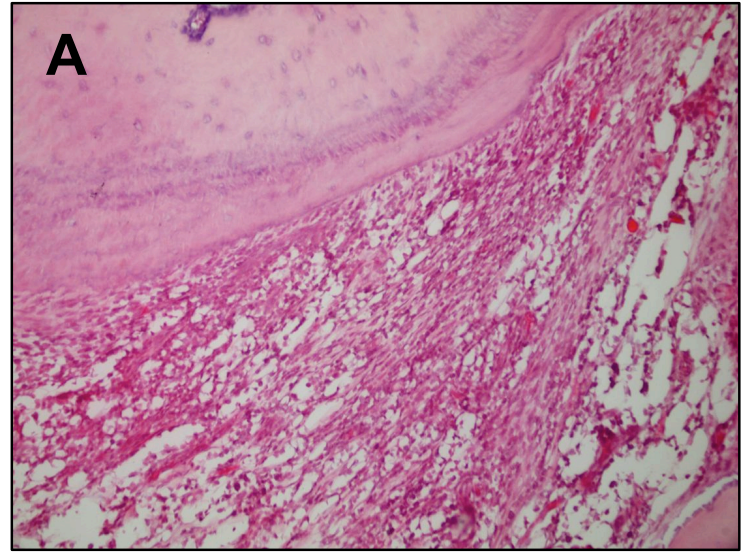

Figura 7A - Intenso infiltrado inflamatório mononuclear, presença de edema e aumento de espessura do ligamento periodontal (200 $\mathrm{X})$.

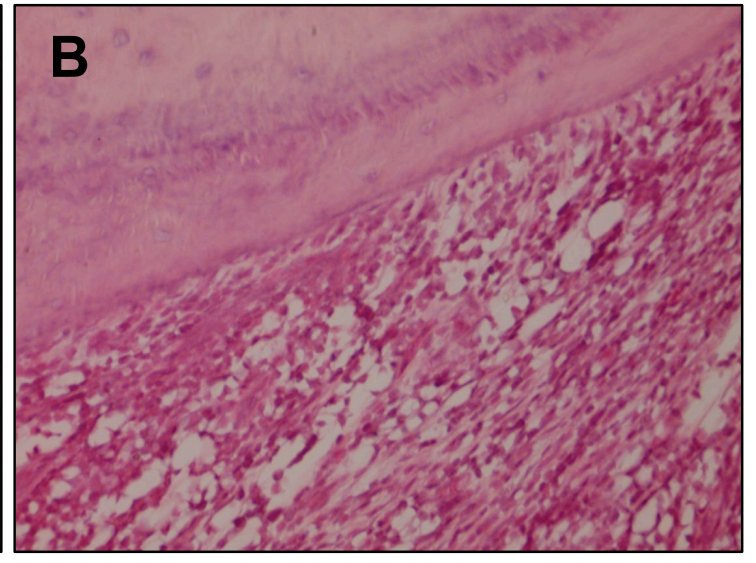

Figura 7B - Maior aumento da figura 7A (400 X). 


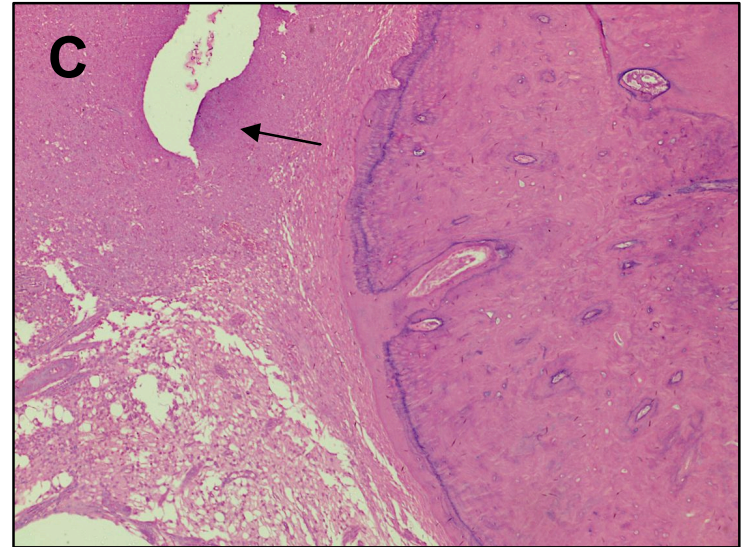

Figura 7C - Infiltrado inflamatório severo contendo grande quantidade de células mononucleares e edema severo com grande aumento da espessura do ligamento periodontal. Área sugestiva de necrose tecidual - seta $(100 \mathrm{X})$.

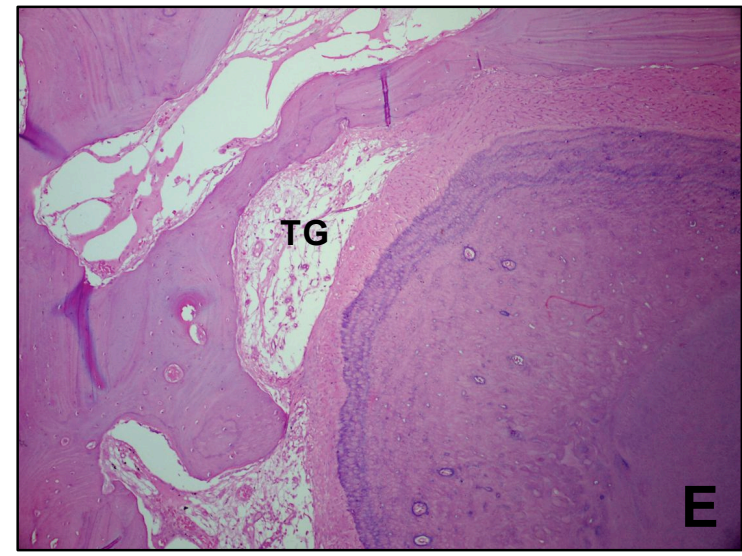

Figura 7E - Infiltrado inflamatório moderado, edema localizado e aumento da espessura do espaço periodontal. Nota-se formação de tecido de granulação - TG $(100 \mathrm{X})$.

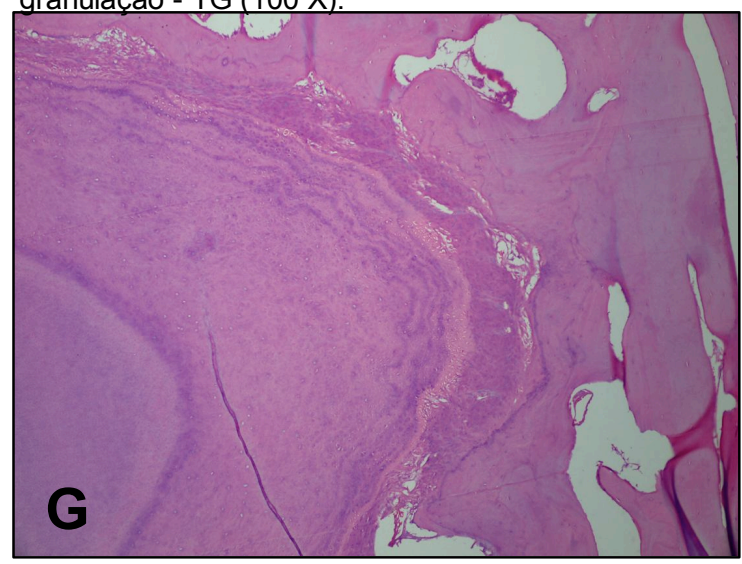

Figura 7G - Ausência de infiltrado inflamatório e espessura normal do ligamento periodontal com pequeno edema localizado na região do ápice radicular $(100 \mathrm{X})$

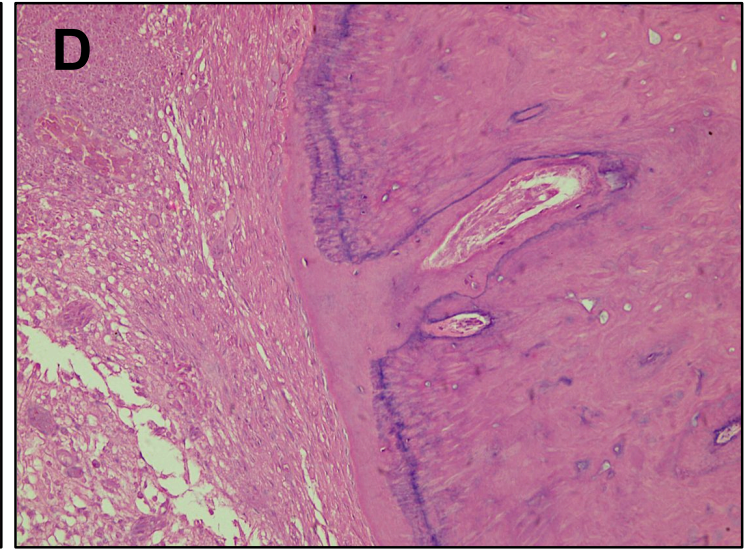

Figura 7D - Maior aumento da figura 7C (200 X).

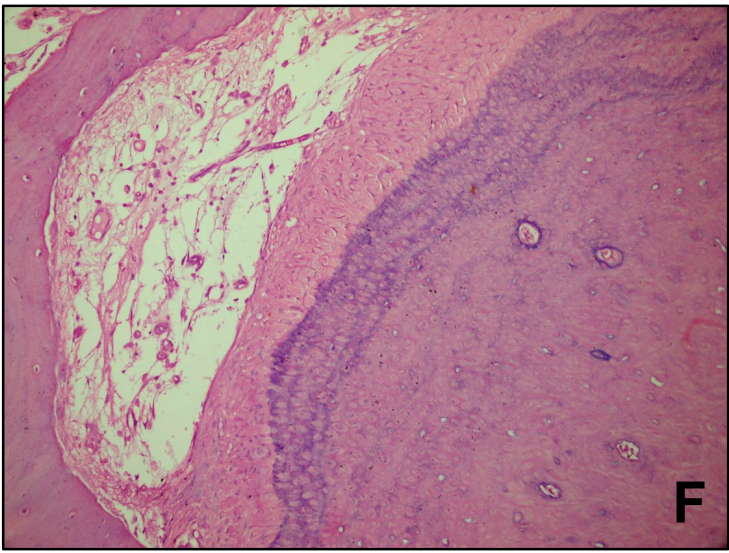

Figura 7F - Maior aumento da figura 7E (200 X).

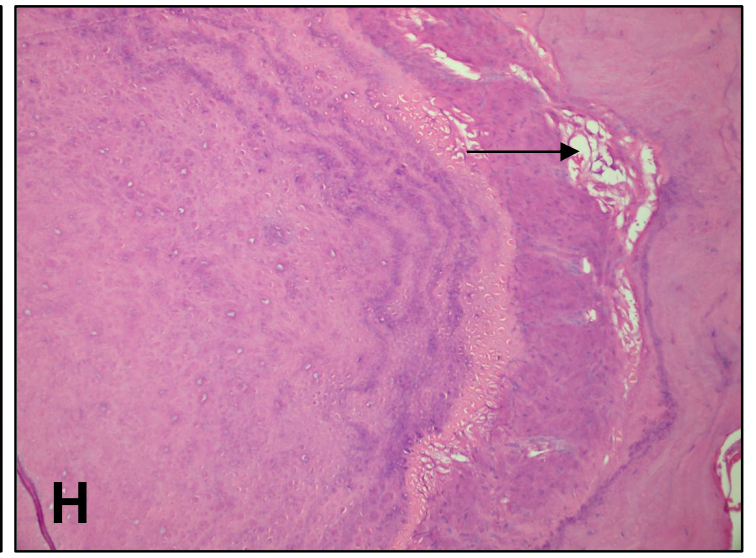

Figura $7 \mathrm{H}$ - Maior aumento da figura 7G, evidenciando o leve edema- seta (200 X). 


\subsubsection{Análise descritiva do grupo GVI - RealSeal SE / termoplástica (SECW)}

Contrariamente aos demais grupos foram observados um menor número de avaliações ausentes de processo inflamatório (11 análises) e grande número de casos contendo leve infiltrado inflamatório (15 casos), que possuíam pequena quantidade de células mononucleares e leve aumento do espaço periodontal em alguns casos.

Igualmente aos quadros histológicos anteriormente descritos, no grau moderado (6 casos) a região periapical continha infiltrado crônico mononuclear, edema e aumento de espessura do ligamento periodontal. Casos severos apresentavam infiltrado inflamatório intenso associado a edema e espessamento do ligamento (ex. Figuras 8A e 8B).

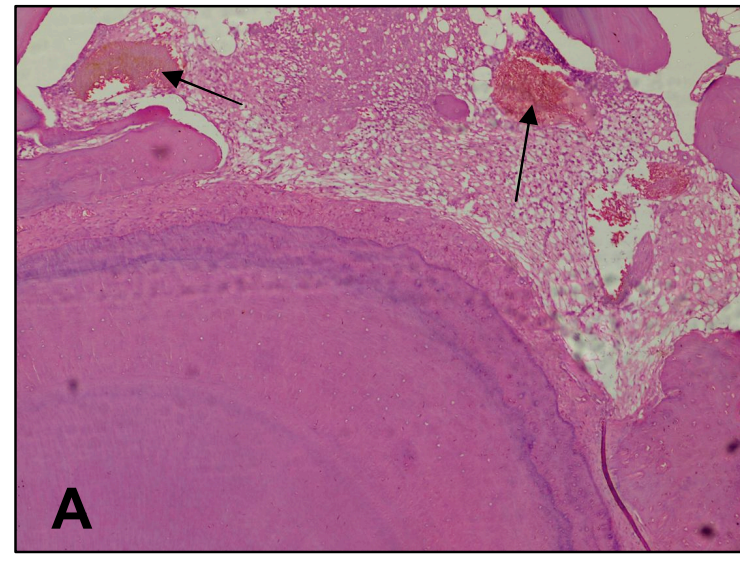

Figura 8A -Região periapical portando infiltrado inflamatório mononuclear severo, com evidente aumento da espessura do ligamento periodontal, edema e pequenas áreas hemorrágicas-setas (100 X).

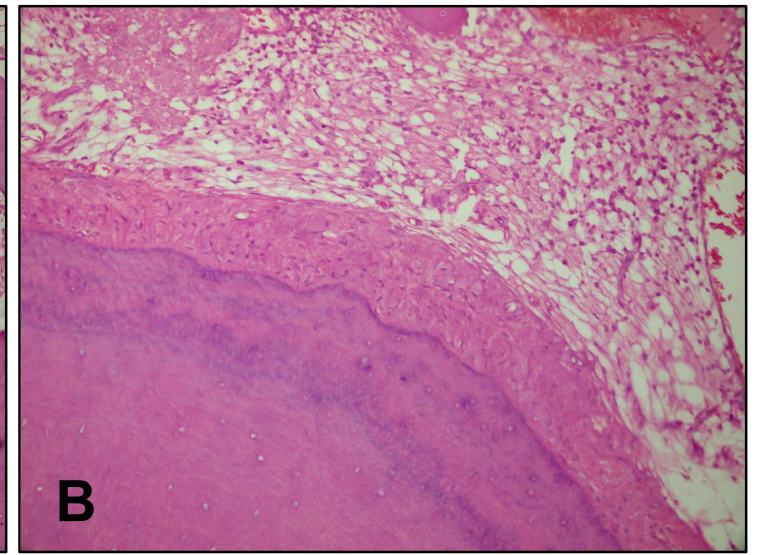

Figura 8B - Maior aumento da figura 8A (200 X). 


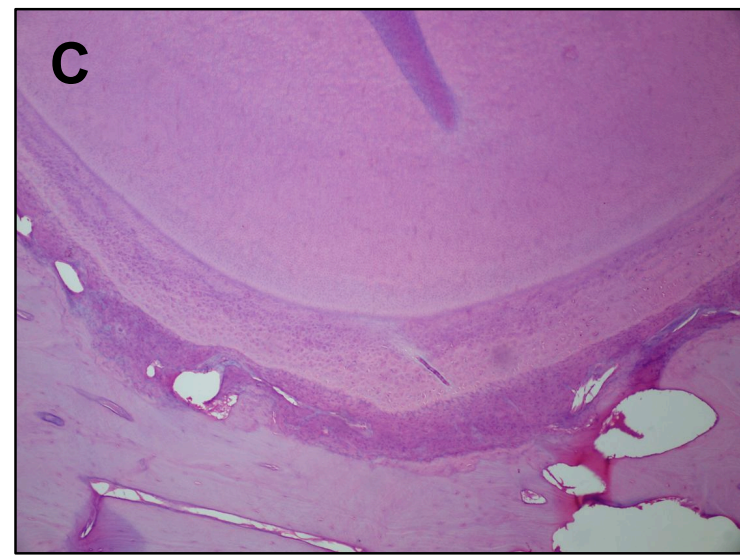

Figura 8C - Ausência de reação inflamatória periapical e de espessamento do ligamento periodontal $(100 \mathrm{X})$.

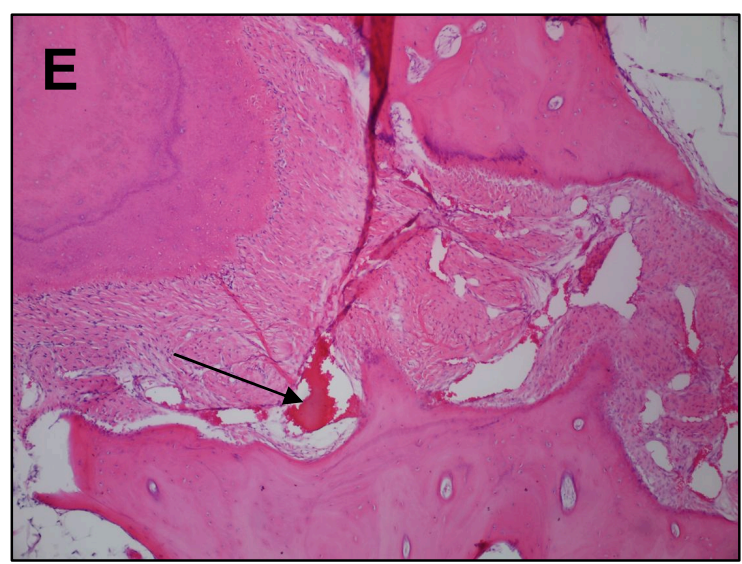

Figura 8E- Ausência de infiltrado inflamatório. Presença de edema, aumento da espessura do espaço periodontal e áreas com hemorragia -seta $(100 \mathrm{X})$.

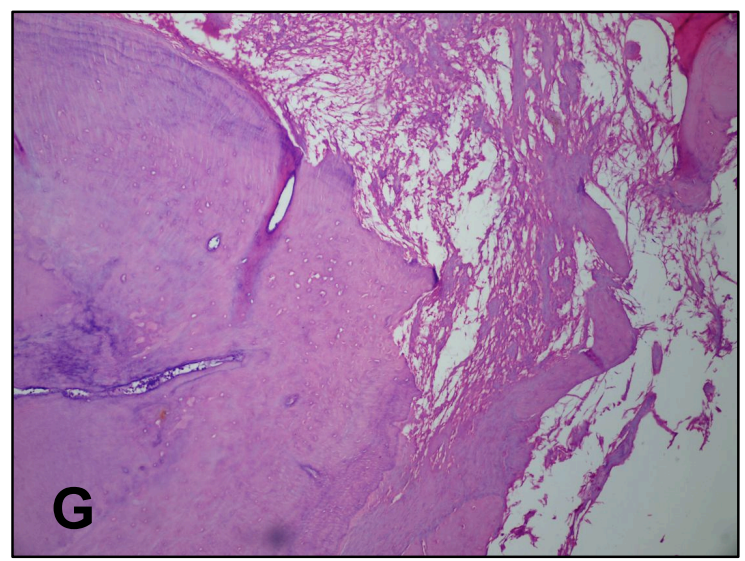

Figura $8 G$ - Infiltrado inflamatório mononuclear intenso com presença de reabsorção cementária e edema (100 X).

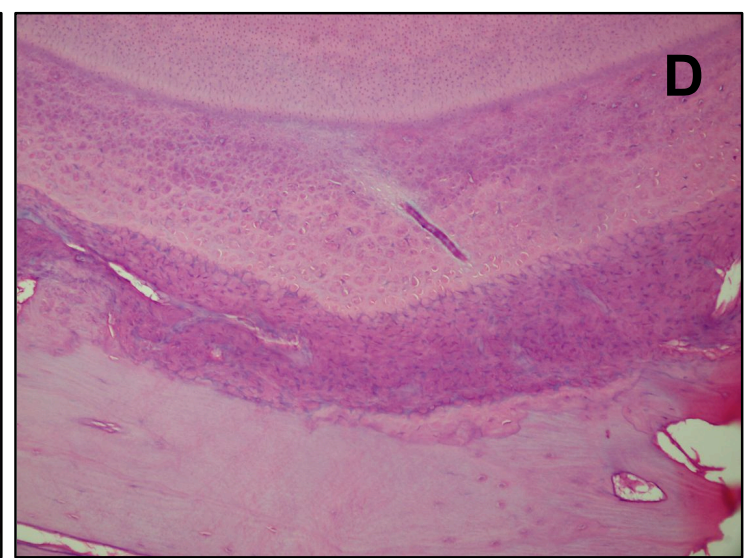

Figura 8D - Maior aumento da figura 8C (200 X).

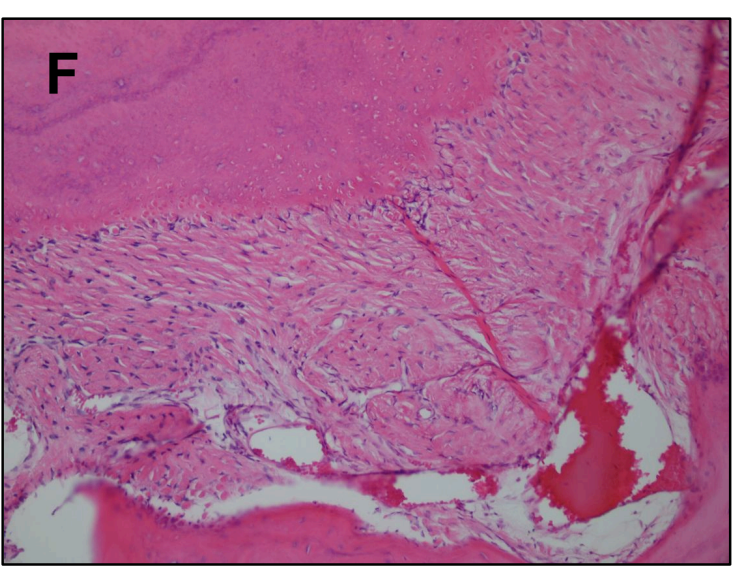

Figura $8 \mathrm{~F}$ - Maior aumento da figura $8 \mathrm{E}$ $(200 \mathrm{X})$. Nota-se a dissociação fibrilar.

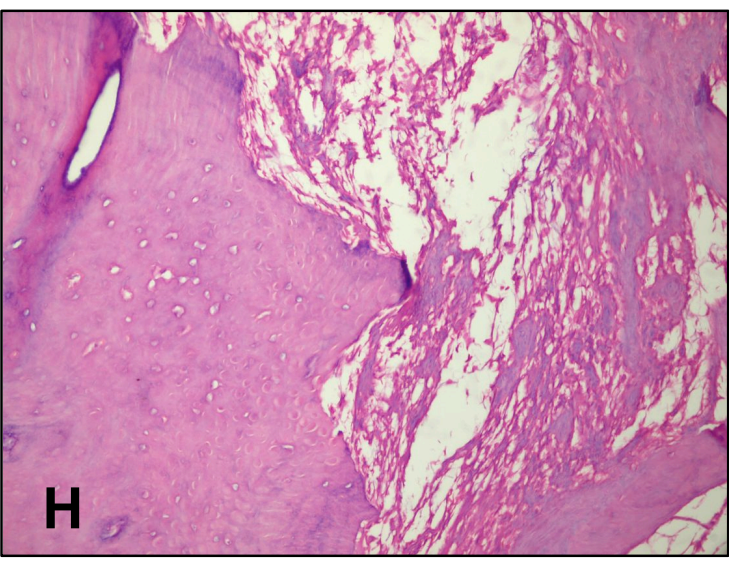

Figura $8 \mathrm{H}$ - Maior aumento da figura 8G (200 X). 


\subsection{Da análise estatística}

\subsubsection{Em relação as técnicas de obturação}

Quando comparadas às técnicas, a técnica termoplástica por ondas contínuas de condensação associada à técnica de injeção $(\mathrm{CW})$ mostrou melhores condições periapicais (Tabela 5.1) quando comparado à técnica de condensação lateral (CL), sendo esta diferença estatisticamente significante $(p=0.0055)$.

\begin{tabular}{c|c|c}
\hline Aspectos Histopatológicos & CL & CW \\
\hline Ausência de infiltrado inflamatório & 52 & 70 \\
\hline $\begin{array}{c}\text { Infiltrado inflamatório crônico leve } \\
\text { moderado }\end{array}$ & 15 & 18 \\
\hline $\begin{array}{c}\text { Infiltrado inflamatório crônico } \\
\text { modiltrado inflamatório crônico severo }\end{array}$ & 23 & 15 \\
\hline
\end{tabular}

Tabela 5.1 - Condições periapicais condensação lateral versus termoplástica (freqüência geral)

Analisando somente a técnica da condensação lateral variando os cimentos, não encontramos diferença estatisticamente significante entre os cimentos AH Plus, RealSeal e RealSeal SE $(p=0.7551)$.

Do mesmo modo, ao se analisar a técnica de ondas contínuas de condensação associada à técnica por injeção, variando somente os cimentos novamente, observamos diferença significante $(p=0.002)$ entre os cimentos, sendo as mesmas mostradas no Quadro 3. 


\begin{tabular}{|c|c|c|c|c|}
\hline Comparações (método de Dunn) & Dif. Postos & z calculado & z crítico & p \\
\hline Postos médios AHPlus X RealSeal & 2.4167 & 0.3274 & 2.394 & ns \\
\hline Postos médios AHPlus X ReaSeal SE & 27.0833 & 3.6686 & 2.394 & $<\mathbf{0 . 0 5}$ \\
\hline Postos médios RealSeal X RealSeal SE & 24.6667 & 3.3413 & 2.394 & $<\mathbf{0 . 0 5}$ \\
\hline
\end{tabular}

Quadro 3 - Análise estatística da técnica CWC, variando-se os cimentos.

\subsubsection{Em relação aos cimentos endodônticos}

Quando comparados os cimentos endodônticos utilizados (AH Plus, RealSeal e RealSeal SE), independente da técnica de obturação utilizada, observamos diferença significante $(p=0.0088)$, sendo as mesmas apresentadas no Quadro 4.

\begin{tabular}{|c|c|c|c|c|}
\hline Comparações (método de Dunn) & Dif. Postos & z calculado & z crítico & p \\
\hline Postos médios AHPlus X RealSeal & 4.7917 & 0.4600 & 2.394 & ns \\
\hline Postos médios AHPlus X ReaSeal SE & 29.6875 & 2.8501 & 2.394 & $<\mathbf{0 . 0 5}$ \\
\hline Postos médios RealSeal X RealSeal SE & 24.8958 & 2.3901 & 2.394 & $\mathbf{n s}$ \\
\hline
\end{tabular}

Quadro 4 - Análise estatística da comparação entre os cimentos no geral.

Analisando somente o cimento $\mathrm{AH}$ Plus $(\mathrm{AH})$ variando as técnicas de obturação (ondas contínuas de condensação - CWC ou condensação lateral - CL), encontramos diferença estatisticamente significante entre as técnicas $(p=0.0082)$, onde a técnica CWC mostrou respostas inflamatórias menos intensas.

Analisando separadamente o cimento RealSeal (RS) variando as técnicas de obturação (ondas continuas de condensação - CWC ou condensação lateral - CL), encontramos diferença estatisticamente significante entre as técnicas $(p=0.0190)$, onde melhores respostas inflamatórias foram encontradas com o uso da técnica CWC. 
Quando analisado o cimento RealSeal SE (SE) variando-se a técnica de obturação, a mesma não apresentou diferença estatisticamente significante entre a técnica convencional - CL - e termoplástica - CWC ( $p=0.9954)$. 


\section{DISCUSSÃO}

\subsection{Da metodologia}

Quando da análise da eficácia do selamento marginal de cimentos resinosos utilizados ou não com técnicas de obturação termoplásticas, vários são os trabalhos que usam metodologias que empregam marcadores não biológicos, dentre eles: corante (AKISUE; GAVINI, 2001; BROSCO, 2002; DAVALOU; GUTMANN; NUNN, 1999; HANSON; RUTLEDGE; JEANSONNE, 2006; KYTRIDOU; GUTMANN; NUNN, 1999; McROBERT; LUMLEY, 1997; ODDONI et al., 2008; SCHAFER; OLTHOFF, 2002; TARANU et al., 2005; VERÍSSIMO; DO VALE; MONTEIRO, 2007), transporte de fluido (BIGGS et al., 2006; BODRUMLU; TUNGA; ALAÇAM, 2007; BOUILLAGUET et al., 2008; COBANKARA et al., 2002; COBANKARA et al., 2006; ECONOMIDES et al., 2004; KARDON et al., 2003; MEDINA et al., 2006; NAGAS et al., 2008; ONAY; UNGOR; ORUCOGLU, 2006; ORUCOGLU; SENGUN; YILMAZ, 2005; PAQUÉ; SIRTES, 2007; POMMEL; CAMPS, 2001; RAINA et al., 2007; SAGSEN et al., 2006; SHEMESH; WU; WESSELINK, 2006; STRATTON; APICELLA; MINES, 2006; TUNGA; BODRUMLU, 2006; WEDDING et al., 2007) e penetração de glicose (KAYA; KECECI; BELLI, 2007; LIN; JHUGROO; LING, 2007; SHEMESH; WU; WESSELINK, 2006; SHEMESH et al., 2007).

Wu e Wesselink (1993) destacaram o grande crescimento no número de trabalhos científicos empregando o método da penetração linear de marcadores corantes. 
A desconfiança da viabilidade dos resultados obtidos por esse método limita as conclusões e comprovadamente, não oferece informações mais próximas à realidade clínica (CAMPS; PASHLEY, 2003; WU; DE GEE; WESSELINK, 1994; WU; WESSELINK, 1993) o que sugere a necessidade da elaboração de metodologias de microinfiltração mais confiáveis, que simulem ao máximo as condições encontradas in vivo, dando preferência às avaliações quantitativas ao invés das semiquantitativas, salientando também a importância da padronização das amostras e a inter-relação entre infiltração, contaminação bacteriana e doença periapical (WU; WESSELINK, 1993).

Assim, o desenvolvimento de metodologias de avaliação da percolação marginal capazes de reproduzir in vitro com maior fidelidade as condições existentes in vivo, é de grande valia. Dentre as metodologias que usam marcadores biológicos in vitro, pode-se citar: bactérias (BAUMGARTNER; ZHENDER; PAQUÉ, 2007; CERUTTI; RE, 2000; De DEUS et al., 2006; De DEUS et al., 2008; FRANSEN et al., 2008; JACOBSON et al., 2002; MILETIC et al., 2002; MUÑOZ et al., 2007; PITOUT et al., 2006; SEVIMAY; KALAYCI, 2005; SHIPPER et al., 2004; SHIPPER; TROPE, 2004; SIQUEIRA et al., 2000; TIMPAWAT; AMORNCHAT; TRISUWAN, 2001; YÜCEL et al., 2005) e a endotoxina (AKISUE, 2003; WILLIAMSON et al., 2005).

Como as verdadeiras respostas periapicais frente ao tratamento endodôntico só podem ser analisadas in vivo, onde se necessita a remoção da parte óssea correspondente ao periápice para exame histopatológico (BROWNE, 1994; PATERSON; WATTS, 1990; WATTS; PATERSON, 1992) e sendo este procedimento descartado por motivos éticos, torna-se necessária a utilização de um modelo experimental animal que permita o exame microscópico das respostas celulares (BROWNE, 1994). 
A escolha de um modelo experimental animal depende de uma série de fatores como: facilidade de obtenção, padrão mastigatório, resistência à infecção e morfologia dental semelhante ao humano. Além disso, a resposta tecidual e o padrão de crescimento devem ser semelhantes ao da espécie humana, porém, rápidos o suficiente para que se obtenham respostas em menores períodos de tempo (CITROME; KAMINSKI; HEUER, 1979; PITT FORD, 1984; ROWE, 1980; SILVA, 2006; TANOMARU, 2002). O cão também permite ser anestesiado por períodos suficientemente longos (SILVA, 2006; TANOMARU, 2002).

Em Endodontia, cães têm sido regularmente empregados em estudos clínicopatológicos (BARBOSA et al. 2003; BERBERT, 1978; BONETTI FILHO, 1990; FUJITA; NAGASAWA; MATSUMOTO, 1981; HOLLAND et al., 1990; HOLLAND et al., 2005; HOLLAND et al., 2000; KATEBZADEH; HUPP; TROPE, 1999; LEONARDO et al., 2007; LEONARDO et al., 2008; LEONARDO et al., 2003; LEONARDO et al., 1997; LEONARDO et al., 1996; PEREIRA et al., 2007; SOARES; HOLLAND; SOARES, 1990; SHIPPER et al., 2005; TANOMARU FILHO, 1996)

Para o presente estudo, foi selecionado o cão como modelo experimental devido à fácil obtenção, manutenção viável economicamente, fácil manuseio, morfologia dental e resposta tecidual semelhante ao humano, e possibilidade de períodos suficientes de trabalho sob anestesia geral.

A relação entre a idade de um cão e o ser humano pode ser realizada utilizando a tabela a seguir (Tabela 6.1) sugerida por Formenti (1987) e Lebeau (1953). 


\begin{tabular}{c|c}
\hline Idade do animal (cão) & Idade humana \\
\hline 1 & 15 \\
\hline 2 & 24 \\
\hline 3 & 28 \\
\hline 4 & 32 \\
\hline A cada ano & Somam-se 4 anos \\
\hline
\end{tabular}

Tabela 6.1 - Relação idade cão/humano

Embora a norma ISO 7405:1997 determine que a idade ideal de cães para utilização experimental seja de 1 a 2 anos (BROON, 2004), a dificuldade da aquisição padronizada de cães devido a lei 107/08 sancionada em 17 de abril de 2008, que dispõe sobre a regulamentação da eliminação da vida de cães em todo território estadual, fez com que neste estudo fossem utilizados cães com idade estimada entre 5 e 9 anos que já estavam no canil do Departamento de Cirurgia (VCI) da FMVZ-USP.

Os dentes utilizados nesse estudo foram os pré-molares inferiores, os prémolares superiores e os incisivos centrais e laterais superiores, por apresentarem semelhança anatômica, mesmo número de raízes e canais retos. Isso permitiu a padronização dos procedimentos endodônticos, principalmente a padronização da modelagem do canal radicular finalizada com 0 instrumento de ponta $n^{\circ} 40$ e conicidade 0.06 .

Devido à presença de um delta apical possuidor de inúmeras foraminas nos dentes de cães (TANOMARU, 2002) em cerca de 60 a 90 (GIOSO, 2007), e considerando ser a proposta deste estudo a avaliação da resposta inflamatória periapical, decidiu-se pela não criação do forame apical devido à melhor resposta inflamatória quando da não realização deste procedimento; como mostrado por Holland et al. (2005) que ao analisar a influência da patência apical no processo 
reparacional em dentes de cães, mostrou que a não realização, resulta em respostas inflamatórias mais amenas com conservação da espessura e organização do ligamento periodontal.

Além disso, o uso de técnicas termoplásticas tende a ocasionar maior extravasamento do material obturador, principalmente quando utilizada em dentes com forame apical amplo (KECECl; UNAL; SEN, 2005; RITCHIE; ANDERSON; SAKAMURA, 1988; TINAZ et al., 2005; VAN ZYL; GULABIVALA; NG, 2005; WU; VAN DER SLUIS; WESSELINK, 2002) e este processo pode influenciar a resposta inflamatória periapical nas áreas a serem avaliadas.

As análises histomorfológicas dos grupos controles positivo e negativo comprovam a não influência da ausência de um forame apical criado cirurgicamente nos resultados, já que os espécimes do grupo controle positivo apresentaram presença de infiltrado inflamatório de grau moderado a severo, e no grupo controle negativo, ausência de reação inflamatória na maioria das regiões periapicais.

A etapa de preparo do conduto radicular foi realizada com ajuda de instrumentos rotatórios de níquel-titânio, por razões de rapidez e padronização da modelagem dos preparos. Sendo a remoção da camada de magma dentinário ("smear layer") importante para um melhor selamento das obturações (CZONSKTOWSKY; WILSON; HOLSTEIN, 1990; SHAHRAVAN et al., 2007; TORABINEJAD et al., 2002), foi preconizada a utilização da solução de ácido cítrico a $15 \%$ por ser o mesmo uma substância desmineralizante (DE DEUS et al., 2008c; GAVINI et al., 1995; MACHADO-SILVEIRO; GONZALEZ-LOPEZ; GONZALEZRODRIGUEZ, 2004; PEREZ-HEREDIA et al.,2008; SOUSA; SILVA, 2005), eficiente na remoção desta indesejada camada (BAUMGARTNER et al., 1984; DI LENARDA; CADENARO; SBAIZERO, 2000; HAZNEDAROGLU, 2003; KHEDMAT; 
SHOKOUHINEJAD, 2008; SCELZA; ANTONIAZZI; SCELZA, 2000; SCELZA et al.,2004; ZEHNDER, 2006) e pouco citotóxica (AMARAL et al., 2007; SCELZA et al., 2001)

Do mesmo modo, a remoção de qualquer resto da solução desmineralizante anteriormente a fase de obturação é desejável e pode ser realizada com o auxílio de outras soluções (ZEHNDER, 2006), que podem ser: o hipoclorito de sódio, a água destilada, o digluconato de clorexidina ou o soro fisiológico.

Trabalhos na área da dentística restauradora mostram a influência da camada inibitória de oxigênio na capacidade de adesão de restaurações que resultam em falhas na polimerização (ENDO et al., 2007a; ENDO et al. 2007b; RUEGGEBERG; MARGESON, 1990); e a menor adesão dos materiais quando da liberação de oxigênio por agentes clareadores utilizados anteriormente ao procedimento restaurador (DISHMAN; COVEY; BAUGHAN, 1994; SANTOS, 2004; TITLEY et al., 1993; TORNECK et al., 1990). Condição semelhante pode ser encontrada após irrigação final com a solução de hipoclorito de sódio devido à liberação de oxigênio; por esta razão, escolhemos para esta irrigação final a solução de digluconato de clorexidina a $2 \%$, pois além de não ter liberação de oxigênio, possui propriedades antimicrobianas frente a possíveis bactérias remanescentes do preparo do canal radicular (BASRANI et al., 2002; KOMOROWSKI et al., 2000; SASSONE et al., 2008b; WANG et al.,2007) e substantividade (KHADEMI; MOHAMMADI; HAVAEE, 2006; KOMOROWSKI et al., 2000; ROSENTHAL; SPANGBERG; SAFAVI, 2004).

Em relação aos cimentos, pelo motivo da associação do polímero termoplástico e cimento a base de metacrilato ter demonstrado uma adequada capacidade de selamento do sistema de canais radiculares in vitro (BAUMGARTNER; ZHENDER; PAQUÉ, 2007; BODRUMLU; TUNGA; ALAÇAM, 
2007; FRANSEN et al., 2008; HANSON; RUTLEDGE; JEANSONNE, 2006; KAYA; KECECI; BELLI, 2007; MUÑOZ et al., 2007; ODDONI et al., 2008; ONAY; UNGOR; ORUCOGLU, 2006; RAINA et al., 2007; SAGSEN et al., 2006; STRATTON; APICELLA; MINES, 2006; TUNGA; BODRUMLU, 2006; VERÍSSIMO; DO VALE; MONTEIRO, 2007) e in vivo (LEONARDO et al., 2007; SHIPPER et al., 2005), e não haver estudos utilizando o novo cimento RealSeal SE, resolveu-se avaliar in vivo as respostas inflamatórias resultante da percolação marginal em obturações realizadas com esses dois cimentos, e compará-las com o cimento AH Plus por ser este um cimento amplamente estudado em relação a capacidade de selamento (BAUMGARTNER;ZHENDER;PAQUÉ, 2007; BOUILLAGUET et al., 2008; DE DEUS et al., 2006; GOMES et al., 2007; KARDON et al., 2003; PAQUÉ; SIRTES, 2007; RAINA et al., 2007; SEVIMAY; KALAYCI, 2005; TIMPAWAT; AMORNCHAT; TRISUWAN, 2001) e por estar sendo amplamente utilizado há quase duas décadas.

Do mesmo modo, em relação às técnicas de obturação, a técnica de condensação vertical aquecida ou ondas contínuas de condensação tem-se mostrado eficiente em relação à capacidade de selamento (AKISUE, 2003; AKISUE; GAVINI, 2001; BAUMGARTNER; ZHENDER; PAQUÉ, 2007; BROSCO, 2002; HANSON; RUTLEDGE; JEANSONNE, 2006; JACOBSON et al., 2002; KAYA; KECECI; BELLI, 2007; KYTRIDOU; GUTMANN; NUNN, 1999; POMMEL; CAMPS, 2001; SHIPPER et al, 2004; SILVA-NETO et al., 2000; SIQUEIRA et al., 2000; WILLIAMSON et al., 2005) quando comparada a técnica de condensação lateral. Porém, da mesma forma, poucos são os trabalhos que avaliam este tipo de obturação termoplástica in vivo (SHIPPER et al., 2005).

A escolha do nível de aquecimento da ponta do System B a $3 \mathrm{~mm}$ do preparo apical, deve-se a estudos anteriores que demonstram um melhor preenchimento do 
canal radicular quanto mais próximo este estiver do comprimento de trabalho (BOWMAN; BAUMGARTNER, 2002). Embora outros trabalhos demonstrem melhores aquecimentos e preenchimentos quando os aquecimentos ocorrem a 2 mm do comprimento de trabalho (JARRET et al., 2004; JUNG et al., 2003; WU; VAN DER SLUIS; WESSELINK, 2002), justificou-se a escolha do nível de aquecimento a $3 \mathrm{~mm}$ por não existirem trabalhos in vivo, em cães, analisando a influência deste aquecimento no estado do ligamento periodontal lateral e região periapical.

Após cada etapa cirúrgica onde foram realizadas as obturações, os animais receberam uma dose de anti-inflamatório e analgésico a fim de evitar exacerbada reação inflamatória e desconforto no pós-operatório imediato. Procedimentos semelhantes foram adotados por Shipper et al. (2005), e os mesmos não ocasionaram interferências nas respostas inflamatórias a longo prazo (14 semanas).

O tempo de exposição dos dentes sem selamento coronário a cavidade oral escolhido foi de $75 \pm 2$ dias baseado em diversos períodos de exposição das obturações ao meio bucal, utilizados em trabalhos anteriores que avaliam a resposta inflamatória frente aos tratamentos endodônticos; os quais variavam entre 60 dias e 98 dias (GOMES et al. 2007; HOLLAND et al., 2005; LEONARDO et al., 2007; LEONARDO et al., 2008; RUEDA, 2006; SHIPPER et al., 2005).

A metodologia empregada para a descalcificação das peças empregando a solução de Ácido Fórmico a 20\% e Citrato de Sódio a 10\% (MORSE, 1945) foi realizada de acordo com estudos prévios, onde a utilização destas substâncias proporcionou a desmineralização do tecido calcificado e a manutenção da morfologia dos tecidos moles (BARBOSA et al.,2003; FERNANDES et al., 2007; HOLLAND et al, 2005; PITT FORD, 1984; RAFTER et al.,2002; SHIBATA et al., 2000; VERDENIUS; ALMA, 1958; YAMAMOTO-FUKUDA et al., 2000). 


\subsection{Dos resultados}

\subsubsection{Em relação as técnicas de obturação}

A técnica de condensação lateral é a técnica mais comumente ensinada e praticada no mundo inteiro (BJORNDAHL; REIT, 2005; HOMMEZ; DE MOOR; BRAEM, 2003; JENKINS; HAYES; DUMMER, 2001; QUALTROUGH; WHITWORTH; DUMMER, 1999; WHITWORTH, 2005). Porém, espaços vazios entre os diversos cones de guta-percha e junto à parede dentinária quando da utilização da técnica da condensação lateral podem ser encontrados em canais pouco preparados, canais curvos e quando do uso inadequado da técnica propriamente dita (PENG et al., 2007). A obturação do conduto nesses casos falha na homogeneidade do preenchimento e confia ao cimento a propriedade de selamento, o que pode levar a um pior prognóstico do tratamento (PENG et al., 2007; PETERS, 1986; WOLLARD et al., 1976).

Os resultados deste estudo mostram que independentemente do cimento utilizado, a técnica da condensação lateral comportou-se igualmente para todos, não demonstrando diferença estatisticamente significante $(p=0.7551)$. Isso mostra a menor eficiência desta técnica em evitar a percolação marginal quando comparado a associação dos sistemas termoplásticos por ondas contínuas de condensação e injeção não está relacionada ao tipo de cimento endodôntico utilizado, e sim, à técnica empregada. 
Valendo-se das vantagens do uso de sistemas termoplásticos em melhorar o selamento marginal in vitro (AKISUE, 2003; AKISUE; GAVINI, 2001; BROSCO, 2002; GILBERT; WITHERSPOON; BERRY, 2001; GOPIKRISHNA; PARAMESWAREN, 2006; JACOBSON et al., 2002; McROBERT; LUMLEY, 1997, POMMEL; CAMPS, 2001; SIQUEIRA et al., 2000), ao comparar os dois sistemas (condensação lateral e termoplastificação) in vivo, os resultados que mostraram respostas inflamatórias menos intensas, resultantes da percolação, foram os dentes obturados com auxílio da técnica termoplástica $(p=0.0055)$, observando-se ausência ou inflamação leve em $81.4 \%$ e severa em apenas $4.6 \%$ dos casos. Contrariamente, para o grupo obturado pela técnica de condensação lateral, observamos ausência/inflamação leve em $62 \%$ e severo em $16.6 \%$ das análises.

Estes resultados são semelhantes aos alcançados por Shipper et al. (2005) que avaliaram in vivo a condição da região periapical de dentes obturados com gutapercha associada ao cimento $\mathrm{AH}$ Plus ou com o Resilon associado ao cimento Epiphany (Sistema Monobloco Resilon - RMS) observando inflamações de nível médio em $82 \%$ dos casos obturados com a associação guta-percha/AH Plus e em $19 \%$ dos casos obturados com o sistema RMS $(p<0.05)$. Os autores concluíram que a ocorrência de menores índices de inflamação periapical deste sistema monobloco Resilon é devido a sua grande capacidade de selamento marginal.

O melhor selamento deve-se à capacidade do sistema termoplástico por ondas contínuas de condensação em promover um melhor preenchimento do canal principal e dos canais laterais com o material obturador (CLINTON; VAN HIMEL, 2001; DE DEUS et al., 2008a; EPLEY et al., 2006; GENCOGLU et al. 2008; GILBERT; WITHERSPOON; BERRY, 2001; GOLDBERG; ARTAZA, DE SILVIO, 2001; JARRET et al., 2004; LEA et al, 2005, MITTAL et al., 2002; NELSON; 
LIEWEHR; WEST, 2000; WU; KAST'AKOVA; WESSELINK, 2001) devido ao chamado "efeito cunha" conseguido por esse tipo de procedimento.

Este efeito pode ser descrito como uma maior força e pressão sobre o material obturador, o que permite sua eficiente adaptação deste junto à parede dentinária e uma maior penetração do material nos túbulos dentinários.

Blum, Esber e Micallef (1997) comparando as forças resultantes de obturações com as técnicas de condensação lateral (LC), compensação vertical aquecida (WVC) e termocompactação (TMC), mostraram maiores forças verticais e laterais resultantes quando do uso da técnica WVC. Do mesmo modo, utilizando um novo aparelho - Endografo - que permite analisar as mesmas forças e também a força de cunha obtida durante procedimentos de obturação com a técnica System B, Blum et al. (2001) mostraram ser esta técnica a melhor em relação à capacidade de resultar em adequadas forças verticais $(16 \pm 2 \mathrm{~N})$, horizontais $(5 \pm 1 \mathrm{~N})$ e efeito de cunha $(9 \pm 1 \mathrm{~N})$ na guta-percha, as quais podem levar a um melhor preenchimento do canal e consequentemente um melhor selamento apical.

Sabe-se também que o limite de aquecimento com o System B possui influência no aquecimento do material obturador e consequentemente na melhora da adaptação da guta-percha junto à parede dentinária do terço apical (JUNG et al., 2003; WU MK; VAN DER SLUIS; WESSELINK, 2002).

Jung et al. (2003) ao analisar a área preenchida pelo sistema System B, variando-se a temperatura e a profundidade da introdução da ponta aquecedora aquém do comprimento de trabalho (CRT), obturou blocos com canais simulados de acordo com os seguintes grupos: G1- $100^{\circ} \mathrm{C}$ à $4 \mathrm{~mm}, \mathrm{G} 2-200^{\circ} \mathrm{C}$ à $4 \mathrm{~mm}, \mathrm{G} 3-350^{\circ} \mathrm{C}$ à $4 \mathrm{~mm}$, GIV- $200^{\circ} \mathrm{C}$ à $2 \mathrm{~mm}$ e GV- $200^{\circ} \mathrm{C}$ à $4 \mathrm{~mm}$ acrescido de condensação a frio à $3 \mathrm{~mm}$. Os resultados não mostraram diferença entre as temperaturas $(p>0.05)$ e que 
a profundidade de introdução da ponta interfere na porcentagem de área preenchida pelo material obturador, encontrando maiores índices a $2 \mathrm{~mm}$ em relação a $4 \mathrm{~mm}$; na temperatura de $200^{\circ} \mathrm{C}$.

O mesmo padrão de resposta foi encontrado quando da analise dos cimentos separadamente, variando-se a técnica de obturação. A técnica termoplástica (CWC) apresentou os melhores resultados em relação à resposta tecidual resultante da percolação tanto para o cimento AH Plus $(p=0.0082)$ quanto para o RealSeal $(p=0.0190)$ quando comparada a técnica de condensação lateral $(C L)$.

Em contrapartida, na mesma análise para o RealSeal SE, não foi encontrada diferença estatisticamente significante entre as duas técnicas obturadoras $(p=0.9954)$, podendo isso ser explicado por possíveis falhas da adesão deste cimento auto-condicionante (self-etched).

\subsubsection{Em relação aos cimentos endodônticos}

Introduzido no mercado em meados do fim dos anos 90, o cimento AH Plus vem sendo amplamente utilizado e mostra-se eficiente em relação à capacidade de selamento nos tratamentos endodônticos em estudos in vitro (BAUMGARTNER;ZHENDER;PAQUÉ, 2007; BOUILLAGUET et al., 2008; DE DEUS et al., 2006; GOMES et al., 2007; KARDON et al., 2003; PAQUÉ; SIRTES, 2007; RAINA et al., 2007; SEVIMAY; KALAYCI, 2005; TIMPAWAT; AMORNCHAT; TRISUWAN, 2001) e in vivo (KOPPER et al., 2003; LEONARDO et al., 2003, 
PEREIRA et al., 2007; LEONARDO et al., 2008). Por estas razões, o cimento AH Plus foi escolhido para ser comparado aos novos cimentos à base de metacrilato.

Embora alguns trabalhos mostrem uma melhor efetividade do sistema Resilon/Epiphany ou Resilon/RealSeal na capacidade de selamento marginal quando comparados com o AH Plus (BODRUMLU; TUNGA; ALAÇAM, 2007; ODDONI et al., 2008; SAGSEN et al., 2006; SOUZA, 2007; STRATTON; APICELLA; MINES, 2006; TUNGA; BODRUMLU, 2006; VERÍSSIMO; DO VALE; MONTEIRO, 2007) outros autores mostram não haver diferença entre os dois (BAUMGARTNER; ZHENDER; PAQUÉ, 2007; BIGGS et al. 2006; FRANSEN et al., 2008; KAYA; KECECI; BELLI, 2007; ONAY; UNGOR; ORUCOGLU, 2006; RAINA et al., 2007).

Vale ressaltar que embora existam trabalhos in vivo analisando os sistemas AH Plus/guta-percha (KOPPER et al., 2003; LEONARDO et al., 2003, ; LEONARDO et al., 2008; PEREIRA et al., 2007) e o Epiphany/Resilon (SHIPPER et al., 2005), não existem trabalhos que comparem diretamente esses dois cimentos endodônticos.

Dois trabalhos recentes avaliaram a resistência a percolação de ambos os cimentos em longo prazo. Paque e Sirtes (2007) mostraram que após 16 meses, obturações com Epiphany/Resilon obturadas pelas técnicas da condensação lateral ou vertical, apresentaram maiores níveis de infiltração pela metodologia de transporte de fluido. Já Bouillaguet et al. (2008) mostraram resultados semelhantes entre os dois sistemas em análises após 1 ano.

Nos últimos anos, diversos trabalhos in vitro têm sido realizados a fim de avaliar as propriedades físicas e químicas destes cimentos à base de metacrilatos. Como este novo sistema de obturação baseia-se nos princípios adesivos oriundos da dentística restauradora, é sábio que a durabilidade de restaurações adesivas 
degradam após um período mínimo de 3 meses (DE MUNCK, 2005), isso permite a mesma premissa ser aplicada aos novos sistemas de obturação que contém polímeros e monômeros em sua composição (SOUZA, 2007).

Uma característica que torna esta degradação possível é a alta susceptibilidade desses materiais, incluindo os cimentos resinosos a base de metacrilatos, é a sorção de água (ITO et al., 2005; MALACARNE et al., 2006; REIS; GIANNINI; PEREIRA, 2007; TAY; PASHLEY, 2003; TAY et al.,2002, TAY et al., 2002a) que resulta na plastificação dos polímeros por hidrólise com conseqüente diminuição das propriedades físico-químicas e longevidade da interface adesiva (KALACHANDRA; TURNER, 1987).

Donnelly et al. (2007) mostrou que o Epiphany possui uma sorção de água cerca de 8 vezes maior que o AH Plus (8,02\% contra 1,07\%), podendo isto ser a justificativa para os seus maiores índices de solubilidade (DONNELLY et al., 2007; VERSIANI et al., 2006) quando comparado ao AH Plus e um inadequado comportamento a longo prazo (PAQUE;SIRTES, 2007).

Outra característica observada é a alta contração de polimerização dos monômeros resinosos (CARVALHO et al., 1996) e, seguindo este princípio, Hammad, Qualtrough e Silikas (2008) mostraram o mesmo acontecendo em cimentos resinosos que possuiam UDMA na sua composição.

Apesar de cimentos duais terem um grau de conversão (polimerização) extremamante dependentes da fotoativação (WATTS et al., 1994), cimentos atuais de cura dual (dual cure) permitem uma lenta polimerização química nas áreas aonde não ocorreu a fotoativação, o que possibilita a sua conversão em polímero estável (BRAGA; CESAR; GONZAGA, 2002), porém Souza (2007) mostrou que o grau de conversão na região apical de dentes obturados com o cimento Epiphany 
corresponde a $30 \%$ da taxa de conversão obtida no terço cervical que recebeu a fotoativação. Esses resultados têm efeito negativo sobre as propriedades mecânicas e estabilidade químicas deste cimento e, conseqüentemente, na capacidade de vedamento (TAY et al., 2003). Achados semelhantes foram mostrados por Beriat et al. (2009) onde, o cimento Epiphany apresentou incompleta polimerização após duas semanas.

Na Endodontia, a capacidade de selamento é influenciada principalmente pela adesividade dos cimentos endodônticos que por sua vez podem ser mensuradas pela resistência de união cimento/dentina (TAGGER et al., 2002, 2003). Teoricamente, a resistência de união à dentina de um sistema adesivo baseia-se à somatória de diversos fatores, porém, dentre os muitos, podemos citar o mais importante: a adesão conseguida pela hibridização e formação de prolongamentos resinosos chamados "tags" (PASHLEY et al., 1995).

O mesmo trabalho de Souza (2007) analisou a formação de camada hibrida e tags pelos cimentos AH Plus e Epiphany; e mostrou que o condicionador primer de acidez forte $(\mathrm{pH}$ 0.3) do cimento a base de metacrilato quando utilizado conjuntamente com um prévio condicionamento é capaz de promover desmineralização dentinária e exposição de fibras colágenas numa profundidade de $7.95 \mu \mathrm{m}$ e consequente formação de camada híbrida numa espessura de $0.82 \pm$ $0.23 \mu \mathrm{m}$. Em relação aos tags, a mesma autora mostrou que a alta fluidez e natureza hidrofílica do cimento Epiphany permite resultar em uma alta densidade de longos tags na fotomicrografias de varredura, diferentemente ao $\mathrm{AH}$ Plus que possui característica hidrofóbica e menor escoamento.

Um dos métodos mais confiáveis para análise da resistência de união é o ensaio de push-out (FISHER; BERZINS; BAHCALL, 2007; JAINAEN; PALAMARA; 
MESSER, 2007). Trabalhos avaliando a adesão dos cimentos que contém metacrilato mostram baixos índices de resistência (GESI et al., 2005; UNGOR; ONAY; ORUCOGLU, 2006; RAHIMI et al., 2009; SLY et al., 2007; UREYEN KAYA et al., 2008). Porém, o fato de avaliarem duas interfaces (dentina/cimento e cimento/cone) gera dúvidas quanta a validade metodológica. Neste rumo, Gesi et al., (2005), Hiraishi et al., (2005) e Tay et al., (2006) citam a não adesão do cone de Resilon ao cimento Epiphany.

Assim, Souza (2007) avaliou a adesão somente do cimento Epiphany à dentina radicular pelo método push out e mostrou também menores valores de adesão que foram $6.3 \pm 5.3 \mathrm{MPa}$ para o Epiphany contra 17.8 \pm 7.5MPa para o AH Plus . A justificativa para este pior resultado provavelmente deve-se ao pequeno grau de conversão alcançado pela polimerização unicamente química.

Estudo semelhante realizado por Akisue, Gavini e Teixeira (2005), ao polimerizarem os corpos de prova previamente ao ensaio de push out, mostraram uma melhor adesão do cimento RealSeal $(4,338 \pm 0,625 \mathrm{MPa})$ em relação ao $\mathrm{AH}$ Plus $(2,688 \pm 0,301 \mathrm{MPa})$, podendo isso contribuir para a assertiva de que a adesão também sofre influência do grau de conversão.

Embora os cimentos a base de metacrilato tenham desvantagens em relação às propriedades físico-químicas (TAY; PASHLEY, 2007), aparentemente mostraram seu adequado comportamento em avaliações in vivo e bons resultados clínicos (CONNER et al., 2007; COTTON et al., 2008).

Trabalhos In vivo de Leonardo et al. (2007) e Shipper et al. (2005) mostraram a melhor eficiência do cimento a base de metacrilato Epiphany ou RealSeal no selamento marginal. Porém, neste estudo, quando comparado ao AH Plus, não houve diferença entre ambos ao analisar somente os cimentos, independentemente 
da técnica obturadora $(p>0.05)$, quando da utilização somente da técnica de condensação lateral variando-se os cimentos $(p=0.7551)$ e quando do uso da termoplastificação com variação do cimento ( $p>0.05)$.

Essas resultados podem sugerir que o tempo experimental decorrido (75 dias) possibilitou uma maior solubilidade e conseqüente percolação, ao contrário dos testes laboratoriais onde, na maioria das vezes, os cimentos são analisados logo após a sua polimerização.

Tentando melhorar as propriedades físico-químicas dos cimentos Epiphany ou RealSeal, uma segunda geração foi introduzida no mercado recentemente com o nome de Epipnahy SE ou RealSeal SE. Nesta, os componentes condicionantes do primer estão incorporados ao cimento, o que elimina uma etapa de condicionamento.

Provavelmente, a incorporação do primer ao cimento justifica-se pelos inconvenientes causados pela alta acidez do condicionador, já que ácidos interferem na reação química peróxido-amina e, consequentemente, diminuem o grau e conversão.

Por ser um produto recente, não se encontra trabalhos em relação à capacidade de selamento deste cimento. Os resultados obtidos neste estudo mostram a ineficiência deste cimento auto-condicionante (self-etched) em evitar a percolação, pois ao analisar a técnica termoplástica variando-se o tipo de cimento endodôntico, os resultados mostram uma diferença $(p=0.002)$ entre o cimento RealSeal SE e os demais cimentos testados. Não houve diferença quando do uso da técnica convencional da condensação lateral $(p=0.07551)$.

Quando analisados somente os cimentos, independentemente da técnica, o ReaSeal SE mostrou diferença significante $(p=0.0088)$ quando comparado ao $A H$ Plus, porém, não mostrou diferença em relação ao RealSeal ( $p>0.05)$. 
Novamente, voltando aos princípios adesivos, uma das possíveis justificativas é a falta de hibridização dentinária, já que estudo realizado por Carvalho et al. (2005) mostrou por microscopia eletrônica de transmissão a existência de áreas de dentina desmineralizada e não infiltrada abaixo da camada híbrida, o que contraria o conceito que os adesivos self-etched desmineralizam e infiltram a dentina na mesma extensão. Temos ainda a possibilidade da ocorrência de um menor grau de conversão característica dos cimentos duais self-etched e de uma menor penetração do material nos túbulos dentinários formando tags.

Embora este estudo tenha demonstrado bons resultados no uso de cimentos à base de metacrilato, principalmente quando associados às técnicas termoplásticas, o mesmo parece não ter alcançando o idealismo do conceito de monobloco. A utilização de cimentos com propriedades adesivas parece ter um futuro promissor, porém, mais estudos laboratoriais e clínicos deverão ser realizados a fim de comprovar sua verdadeira efetividade. Muitas mudanças devem e deverão acontecer na composição destes materiais para que se possa atingir a sonhada absoluta impermeabilização do sistema de canais radiculares. 


\section{CONCLUSÕES}

7.1 Em relação aos cimentos utilizados, não observou-se diferença estatisticamente significante entre os cimentos AH Plus e RealSeal quando da resposta inflamatória provocada pela infiltração marginal, sendo que os quadros inflamatórios mais graves foram observados nos grupos em que se utilizou o cimento RealSeal SE.

7.2 O cimento que possui o agente condicionador incorporado ao cimento (selfetched), mostrou piores resultados quando utilizado com a técnica termoplástica, porém não houve diferença significante quando do uso com a técnica de condensação lateral.

7.3 Dentes obturados pela associação dos sistemas termoplásticos de condensação vertical aquecida e injeção apresentaram graus menores de resposta inflamatória periapical provocado pela infiltração marginal , quando comparados com os grupos em que se utilizou a condensação lateral, independente do cimento obturador. 


\section{REFERÊNCIAS ${ }^{2}$}

Abou-Rass M, Bogen G. Microorganisms in closed periapical lesions. Int Endod J 1998;31(1):39-47.

Akisue E. Análise in vitro da percolação apical em dentes obturados empregando-se o método de infiltração e quantificação do nível de endotoxina [Dissertação de Mestrado]. São Paulo: Faculdade de Odontologia da USP; 2003.

Akisue E, Gavini G. A comparative study of the sealing ability of two root canal obturation techniques. J Dent Res 2001;80:1022.

Akisue E, Gavini G, Teixeira FB. Análise da adesão de cimentos endodônticos resinosos à superfície dentinária radicular [resumo Pc061]. Braz Oral Res 2005;19:210.

Amaral KF, Rogero MM, Fock RA, Borelli P, Gavini G. Cytotoxicity analysis of EDTA and citric acid applied on murine resident macrophages culture. Int Endod J 2007;40(5):338-43.

Aqrabawi JA. Outcome of Endodontic Treatment of Teeth Filled Using Lateral Condensation versus Vertical Compaction (Schilder's Technique). J Contemp Dent Pract 2006;7(1):17-24.

Barbakow FH, Cleaton-Jones P, Friedman D. An evaluation of 566 cases of root canal therapy in general dental practice 2. Postoperative observations. J Endod 1980;6(3):485-9.

Barbosa HG, Holland R, De Souza V, Dezan EJ, Bernabe PF, Otoboni JA, et al. Healing process of dog teeth after post space preparation and exposition of the filling material to the oral environment. Braz Dent J 2003;14(2):103-8.

Barthel CR, Moshonov J, Shuping G, Orstavik D. Bacterial leakage versus dye leakage in obturated root canals. Int Endod J 1999;32(5):370-5.

\footnotetext{
${ }^{2}$ De acordo com Estilo Vancouver. Abreviatura de periódicos segundo base de dados MEDLINE
} 
Basrani B, Santos JM, Tjäderhane L, Grad H, Gorduysus O, Huang J, et al. Substantive antimicrobial activity in chlorhexidine-treated human root dentin. Oral Surg Oral Med Oral Pathol Oral Radiol Endod 2002;94(2):240-5.

Baumgartner G, Zhender M, Paqué F. Enterococcus faecalis type strain leakage through root canal filled with gutta-percha/AH Plus or Resilon/Epiphany. J Endod 2007;33(1):45-7.

Baumgartner JC, Bown CM, Mader CL, Peterson DD, Shulman JD. A Scanning eletron microscope evaluation of root canal debridement using saline, sodium, hypochlorite and citric acid. J Endod 1984;10(11):525-31.

Berbert A. Comportamento dos tecidos apicais e periapicais após biopulpectomia e obturação do canal radicular com AH26, hidróxido de cálcio ou mistura de ambos estudo biológico em dentes de cães [Tese de Livre-Docência]. Bauru: Faculdade de Odontologia da USP; 1978.

Beriat NC, Ertan A, Cehreli ZC, Gulsahi K. Time-dependent conversion of a methacrylate-based sealer polymerized with different light-curing units. J Endod 2009;35(1):110-2.

Biggs SG, Knowles K, Ibarrola JI, Pashley DH. An in vitro assessment of the sealing ability of Resilon/Epiphany using fluid filtration. J Endod 2006;32(8):759-61.

Bjorndahl L, Reit C. The adoption of new endodontic technology amongst Danish general dental practitioners. Int Endod J 2005;38(1):52-58

Blome B, Braun A, Sobarzo V, Jepsen S. Molecular identification and quantification of bacteria from endodontic infections using real-time polymerase chain reaction. Oral Microbiol Immunol 2008;23(5):384-90.

Blum JY, Cathala C, Machtou P, Micallef JP. Analysis of the Endogrammes developed during obturations on extracted teeth using System B. J Endod 2001;27(11):661-5.

Blum JY, Esber S, Micallef JP. Analysis of forces developed during obturations. Comparison of three gutta-percha techniques. J Endod 1997;23(5):340-5. 
Bodrumlu E, Tunga U, Alaçam T. Influence of immediate and delayed post space preparation on sealing ability of resilon. Oral Surg Oral Med Oral Pathol Oral Radiol Endod 2007;103(6):e61-e4.

Bonetti Filho I. Avaliação da biocompatibilidade de quatro técnicas de obturação de canais radiculares. Estudo em dentes de cães [Tese de Doutorado]. Araraquara: Faculdade de Odontologia da UNESP; 1990.

Bouillaguet S, Shaw L, Barthelemy J, Krejci I, Wataha JC. Long-term sealing ability of Pulp Canal sealer, AH Plus, GuttaFlow and Epiphany. Int Endod J 2008;41(3):21926.

Bowman CJ, Baumgartner JC. Gutta-percha obturation of lateral grooves and depressions. J Endod 2002;28(3):220-3.

Braga RR, Cesar PF, Gonzaga CC. Mechanical properties of resin cements with dofferent activation modes. J Oral Rehabil 2002;29:257-62.

Broon NJ. Tratamento de perfurações radiculares em dentes de cães com agregado trióxido mineral (MTA) e cimento de Portland com e sem cloreto de cálcio [Dissertação de Mestrado]. Bauru: Faculdade de Odontologia da USP; 2004.

Brosco VH. Avaliação "in vitro" do selamento apical dos canais radiculares em função de diferentes técnicas de obturação [Dissertação de Mestrado]. Bauru: Faculdade de Odontologia da USP; 2002.

Brosco VH, Bernardineli N, Torres AS, Consolaro A, Bramante CM, de Moraes IG, et al. Bacterial leakage in root canals obturated by different techniques. Part 1: Microbiologic evaluation. Oral Surg Oral Med Oral Pathol Oral Radiol Endod 2008;105(1):e48-e53.

Browne RM. Animal tests for biocompatibility of dental materials - relevance, advantages and limitations. J Dent 1994;22(2):s21-s4.

Buchanan LS. The continuous wave of obturation technique: centered condensation of warm gutta-percha in 12 seconds. Dent Today 1996;15(6):60-2.

Carvalho RM, Pereira JC, Yoshiyama M, Pashley DH. A review of polymerization contraction: The influence of stress development versus stress relief. Oper Dent 1996;21(1):17-24. 
Carvalho RM, Chersoni S, Frankenberger R, Pashley DH, Prati C, Tay FR. A challeng to the conventional wisdow that simultaneous etching and resin infiltration always occurs in self-etch adhesives. Biomaterials 2005;26:1035-42.

Cerutti A, Re D. In vitro bacterial penetration in coronally unsealed teeth after endodontic treatment [abstract PR7]. J Endod 2000;26(9):554.

Chevigny C, Dao TT, Basrani BR, Marquis V, Farzaneh M, Abitbol S, et al. Treatment Outcome in Endodontics: The Toronto Study-Phase 4: Initial Treatment. Int Endod J 2008;34(3):258-63.

Citrome GP, Kaminski EJ, Heuer MA. A comparative study of tooth apexification in dog. J Endod 1979;5(10):290-7.

Clinton K, Van Himel T. Comparison of a warm gutta-percha obturation technique and lateral condensation. J Endod 2001;27(11):692-5.

Cobankara FK, Adanir N, Belli S, Ashley DHA. Quantitative evaluation of apical leakage of four root-canal sealers. Int Endod J 2002;35(12):979-84.

Cobankara FK, Orucoglu H, Sengun A, Belli S. The quantitative evaluation of apical sealing of four endodontic sealers. J Endod 2006;32(1):66-8.

Conner DA, Caplan DJ, Teixeira FB, Trope M. Clinical outcome of teeth treated endodontically with a nonstandartized protocol and root filled with Resilon. J Endod 2007;33(11):1290-2.

Coolidge ED. The status of pulpless teeth as interpreted by tissue tolerance and repair following root canal filling. JADA 1933;20(12):2216-21.

Cotton TP, Schindler WG, Schwartz SA, Watson WR, Hargreaves KM. A retrospective study comparing clinical outcomes after obturation with Resilon/Epiphany or gutta-percha/Kerr sealer. J Endod 2008;34(7):789-97.

Czonstkowsky M, Wilson EG, Holstein FA. The smear layer in endodontics. Dent Clin North Am 1990;34(1):13-25. 
Davalou S, Gutmann JI, Nunn MH. Assessment of apical and coronal root canals seals using contemporary endodontic obturation and restorative materials and techniques. Int Endod J 1999;32(5):388-96.

De Deus G, Coutinho-Filho T, Reis C, Murad C, Paciornik S. Polymicrobial leakage of four root canal sealers at two different thicknesses. J Endod 2006;32(10):9981001.

De Deus G, Murad C, Paciornik S, Reis CM, Coutinho-Filho T. The effect of the canal-filled área on the bacterial leakage of oval-shaped canals. Int Endod J 2008a;41(3):183-90.

De Deus G, Reis C, Beznos D, Abranches AMG, Coutinho-Filho T, Paciornik S. Limited ability of three commonly used thermoplasticized gutta-percha techniques in filling oval-shaped canals. J Endod 2008b;34(11):1401-5.

De Deus G, Reis C, Fidel S, Fidel RAS, Paciornik S. Longitudinal and quantitative evaluation of dentin demineralization when subjected to EDTA, EDTAC, and citric acid: a co-site digital optical microscopy study. Oral Surg Oral Med Oral Pathol Oral Radiol Endod 2008c;105(3):391-7.

De Moor RJ, Hommez GM. The long-term sealing ability of an epoxy resin root canal sealer used with five gutta percha obturation techniques. Int Endod J 2002;35(3):27582.

De Munck J, Van Landuyt K, Peumans M, Poitevin A, Lambreschts P, Braem M, et al. A critical review of the durability of adhesion to tooth tissue: Methods and Results. J Dent Res 2005;84(2):118-32.

Di Lenarda R, Cadenaro M, Sbaizero O. Effectiveness of $1 \mathrm{~mol} \mathrm{~L}^{-1}$ citric acid and 15\% EDTA irrigation on smear layer removal. Int Endod J 2000;33(1):46-52.

Dishman MV, Covey DA, Baughan LW. The effects of peroxide bleaching on composite to enamel bond strength. Dent Mat 1994;10(1):33-6.

Donnelly A, Sword J, Nishitani Y, Yoshiyama M, Agee K, Tay FR, et al. Water sorption and solubility of methacrylate resin-based root canal sealers. J Endod 2007; 33(8):990-4. 
Dow PR, Ingle Jl. Isotope determination of root canal failure. Oral Surg Oral Med Oral Pathol Oral Radiol Endod 1955;8:1100-4.

Economides N, Kokorikos I, Kolokouris I, Panagiotis B, Gogos C. Comparative study of apical sealing ability of a new resin-based root canal sealer. J Endod 2004;30(6):403-5.

Endo T, Finger WJ, Hoffmann M, Kanehira M, Komatsu M. The role of oxygen inhibition of a self-etch adhesive on self-cure resin composite bonding. Am J Dent 2007a;20(3):157-60.

Endo T, Osada T, Finger WJ, Hoffmann M, Kanehira M, Komatsu M. Effect of oxygen inhibition of self-etching adhesives on enamel-dentin polymer bond. J Adhes Dent 2007b;9(1):33-8

Epley SR, Fleischman J, Hartwell G, Cicalese C. Completeness of root canal obturations: Epiphany techniques versus Gutta-Percha techniques. J Endod 2006;32(6):541-4.

Farmakis E, Kontakiotis EG, Tseleni-Kotsovili A, Tsatsas VG. Quantitative microbial leakage of different sealers using a modified dual-chamber model [abstract OR60]. J Endod 2006;32(3):248.

Farzaneh M, Abitbol S, Lawrence HP, Friedman S. Treatment outcome in endodontics: the Toronto study. Phase II: initial treatment. J Endod 2004;30(5):302-9.

Fernandes MI, Gaio EJ, Rosing CK, Oppermann RV, Rado PV. Microscopic qualitative evaluation of fixation time and decalcification media in rat maxillary periodontium. Braz Oral Res 2007;21(2):134-9.

Fisher MA, Berzins DW, Bahcall JK. An in vitro comparison of bond strength of various obturation materials to root canal dentin using a push out test design. $\mathrm{J}$ Endod 2007;33(7):856-8.

Formenti L. Como saber a idade dos bichos. Folha de São Paulo 1987 ago. 30; cad. $\mathrm{B}: 3$.

Fransen JN, He J, Glickman GN, Rios A, Shulman JD, Honeyman A. Comparative assessment of ActiV GP/glass ionômero sealer, Resilon/Epiphany, and guttapercha/AH Plus obturation: a bacterial leakage study. J Endod 2008;34(6):725-7. 
Friedman S, Abitbol S, Lawrence HP. Treatment outcome in endodontics: the Toronto study. Phase 1: initial treatment. J Endod 2003;29(12):787-93.

Frisk F, Hugoson A, Hakeberg M. Technical quality of root fillings and periapical status in root filled teeth in Jönköping, Sweden. Int Endod J 2008;41(11):958-68.

Fujita A, Nagasawa $\mathrm{H}$, Matsumoto K. Reactions of tissue in apical ramification after immediate root canal obturations following pulpectomy in dogs. Int Endod $\mathrm{J}$ 1981;14(3):157-65.

Gavini G, Estrela C, Santos M, Felippe Junior O. In Vitro analysis of the demineralizing effect of some root canal irrigating solutions in different periods of time. Rev Odontol UNICID 1995;7(3):83-9.

Gencoglu N, Yildirim T, Garip Y, Karagenc B, Yilmaz H. Effectiveness of different gutta-percha techniques when filling experimental internal resorptive cavities. Int Endod J 2008;41(10):836-42.

Gesi A, Raffaelli O, Pashley DH, Tay FR, Ferarri M. Interfacial strength of Resilon and gutta-percha to intraradicular dentin. J Endod 2005;31(11):809-13.

Gilbert SD, Witherspoon DE, Berry CW. Coronal leakage following three obturation techniques. Int Endod J 2001;34(6):293-9.

Gilhooly RM, Hayes SJ, Bryant ST, Dummer PM. Comparison of cold lateral condensation and a warm multiphase gutta-percha technique for obturating curved root canals. Int Endod J 2000;33(5):415-20.

Gioso MA. Odontologia veterinária para o clínico de pequenos animais, $2^{\mathrm{a}}$ ed. rev. Barueri: Manole; 2007.

Goldberg F, Artaza L, De Silvio A. Effectiveness of different obturation techniques in the filling of simulated lateral canals. J Endod 2001;27(5):362-4.

Gomes BPFA, Lilley JD, Drucker DB. Associations of endodontic symptoms and signs with particular combinations of specific bacteria. Int Endod J 1996;29(2):69-75. 
Gomes BPFA, Pinheiro ET, Gadê-Neto CR, Sousa EL, Ferraz CC, Zaia AA, et al. Microbiological examination of infected dental root canals. Oral Microbiol Imunn 2004;19(2):71-6.

Gomes BPFA, Pinheiro ET, Jacinto RC, Zaia AA, Ferraz CCR, Souza-Filho FJ. Microbial analysis of canals of root-filled teeth with periapical lesions using Polymerase Chain Reaction. J Endod 2008;34(5):537-40.

Gomes MS, Barletta FB, Della Bona A, Vanni JR, Pereira Cda C, Figueiredo JA. Microbial leakage and apical inflammatory response in dog's teeth after root canal filling with different sealers, post space preparation and exposure to the oral environment. J Appl Oral Sci 2007;15(5):429-36.

Gopikrishna V, Parameswaren A. Coronal sealing ability of three sectional obturation techniques - SimpliFill, Thermafil and warm vertical compaction - compared with cold lateral condensation and post space preparation. Aust Endod J 2006;32(3):95100.

Greene HA, Wong M, Ingram TA. Comparison of the sealing ability of four obturation techniques. J Endod 1990;16(9):423-8.

Grossman LI. Endodontic practice. 10 ${ }^{\text {th }}$ ed. Philadelphia: Lea \& Febiger; 1981.

Hammad M, Qualtrough A, Silikas N. Extended setting shrinkage behavior of endodontic sealers. J Endod 2008;34(1):90-3.

Hanson SR, Rutledge RE, Jeansonne BG. Apical leakage comparison of guttapercha and Resilon using warm vertical condensation and single cone obturation techniques [abstract OR30]. J Endod 2006;32(3):241.

Haznedaroglu F. Efficacy of various concentrations of citric acid at different $\mathrm{pH}$ values for smear layer removal. Oral Surg Oral Med Oral Pathol Oral Radiol Endod 2003;96(3):340-4.

Hiraishi N, Papacchini F, Loushine RJ, Weller RN, Ferrari M, Pashley DH, et al. Shear bond strength of Resilon to a methacrylate-based root canal sealer. Int Endod J 2005;38(10):753-63.

Holland R, Mello W, de Souza V, Nery MJ, Bernabé PFE, Otoboni-Filho JA. Comportamento dos tecidos periapicais de dentes de cães após a obturação de 
canal com Sealapex acrescido ou não de iodofórmio. Rev Odontol UNESP 1990;19(1/2):97-104.

Holland R, Sant'Anna Junior A, Souza V, Dezan-Jr E, Otoboni-Filho JA, Bernabé PFE, et al. Influence of apical patency and filling material on healing process of dog's teeth with vital pulp after root canal therapy. Braz Dent J 2005;16(1):9-16.

Holland R, de Souza V, Otoboni-Filho JA, Bernabé PFE, Dezan-Jr E, Garlippe O. Comportamento dos tecidos apicais e periapicais de dentes de cães a obturação de canal com o cimento experimental Sealer Plus. Rev Bras Odontol 2000;57(2):114-6.

Hommez GMD, De Moor RJG, Braem M. Endodontic treatment performed by Flemish dentists. Part 2. Canal filling and decision making for referrals and treatment of aoical periodontites. Int Endod J 2003;36(5):344-51.

Imura N, Pinheiro ET, Gomes BPFA, Zaia AA, Ferraz CCR, Souza-Filho FJ. The outcome of endodontic treatment: a retrospective study of 2000 cases performed by a specialist. J Endod 2007;33(11):1278-82.

Ingle JI. Exitos e fracasos em endodoncia. Rev Asoc Odontol Argent 1962;50(2):6772 .

Ingle JI. Root canal obturation. JADA 1956;53(1):47-55.

Ito S, Hashimoto M, Wadgonkar B, Svizero N, Carvalho RM, Yiu C, et al. Effect of resin hidrophilicity on water sorption and changes in modulus of elasticity. Biomaterials 2005;26:6449-59.

Jacinto RC, Gomes BPFA, Desai M, Rajendram D, Shah HN. Bacterial examination of endodontic infections by clonal analysis in concert with denaturing highperformance liquid chromatography. Oral Microbiol Immunol 2007;22(6):403-10.

Jacobson HI, Xia T, Baumgartner JC, Marshall JG, Beeler WJ. Microbial leakage evaluation of the continuous wave of condensation. J Endod 2002;28(4):269-71.

Jainaen A, Palamara JEA, Messer HH. Pus-out bond strengths of the dentine-sealer interface with and without a main core. Int Endod J 2007;40:882-90. 
Jarret IS, Marx D, Covey D, Karmazin I, Lavin M, Gound T. Percentage of canals filled in apical cross sections - an in vitro study of seven obturation techniques. Int Endod J 2004;37(6):392-8.

Jenkins SM, Hayes SJ, Dummer PMH. A study of endodontic treatment carried out in dental practice within the UK. Int Endod J 2001;34(1):16-22.

Johnson B. A new gutta-percha tecnique. J Endod 1978;4(6):184-8.

Jung IY, Lee SB, Kim ES, Lee CY, Lee SJ. Effect of different temperatures and penetration depths of a System B plugger in the filling of artificially created oval canals. Oral Surg Oral Med Oral Pathol Oral Radiol Endod 2003;96(4):453-7.

Khademi AA, Mohammadi Z, Havaee A. Evaluation of the antibacterial substantivity of several intra-canal agents. Aust Endod J 2006;32(3):112-5.

Kakehashi S, Stanley HR, Fitzgerald RJ. The effects of surgical exposures of dental pulps in germ-free and conventional laboratory rats. Oral Surg Oral Med Oral Pathol Oral Radiol Endod 1965;20(3):340-9.

Kalachandra S, Turner DT. Water sorption of polymethacrylate networks: bisGMA/TEGDMA copolymers. J Biomed Mater Res 1987;21:329-38.

Kardon BP, Kuttler S, Hardigan P, Dorn SO. An in vitro evaluation of the sealing ability of a new root canal obturation system. J Endod 2003;29(10):122.

Kataia MA, El-Sayed JM. Comparative sealability study on root canal obturation using multiphase gutta percha and lateral condensation technique. Egypt Dent $\mathrm{J}$ 1994;40(3):847-53.

Katebzadeh N, Hupp J, Trope M. Histological periapical repair after obturation of infected root canals in dogs. J Endod 1999;25(5):364-8.

Kaya BU, Kececi AD, Belli S. Evaluation of the sealing ability of gutta-percha and thermoplastic synthetic polymer-based systems along the root canals through the glucose penetration model. Oral Surg Oral Med Oral Pathol Oral Radiol Endod 2007;104(6):e66-e73. 
Kececi AD, Unal GÇ, Sen BH. Comparison of cold lateral compaction and continuous wave of obturation techniques following manual or rotary instrumentation. Int Endod $\mathrm{J}$ 2005;38(6):381-8.

Khedmat S, Shokouhinejad N. Comparison of the efficacy of three chelating agents in smear layer removal. J Endod 2008;34(5):599-602.

Komorowski, Grad H, Wu XY, Friedman S. Antimicrobial substantivity of chlorhexidine-treated bovine root dentin. J Endod 2000;26(6):315-7.

Kopper PM, Figueiredo JA, Della Bona A, Vanni JR, Bier CA, Bopp S. Comparative in vivo analysis of the sealing ability of three endodontic sealers in post-prepared root canals. Int Endod J 2003;36(12):857-63.

Korzen $\mathrm{BH}$. Endodontic obturation using the Microseal technique. Oral Health 1997;87(Oct):67-70.

Kytridou V, Gutmann JI, Nunn MH. Adaptation and seability of two comtemporary obturation techniques in the absence of the dentinal smear layer. Int Endod $\mathrm{J}$ 1999;32(6):464-74.

Lea CS, Apicella MJ, Mines P, Yancich PP, Parker MH. Comparison of the obturation density of cold lateral compaction versus warm vertical compaction using the continuous wave of condensation technique. J Endod 2005;31(1):37-9.

Lebeau A. L'age du chien et celuli de i'homme. Essai de statistique sur la mortalité canine. Bull Acad Vet 1953;26:229-32.

Leonardo MR, Barnett F, Debelian GJ, de Pontes Lima RK, Bezerra da Silva LA. Root canal adhesive filling in dog's teeth with or without coronal restoration: A histopathological evaluation. J Endod 2007;33(11):1299-303.

Leonardo MR, Flores DSH, Paula e Silva FWG, Leonardo RT, Silva LAB. A comparison study of periapical repair in dogs' teeth using RoekoSeal and AH Plus root canal sealers: a histopathological evaluation. J Endod 2008;34(7):822-5.

Leonardo MR, Salgado AAM, Silva LAB, Tanomaru Filho M. Apical and periapical repair of dogs' teeth with periapical lesions after endodontic treatment with different root canal sealers. Pesqui Odontol Bras 2003;17(1):69-74. 
Leonardo MR, Silva LAB, Utrilla LS, Assed S, Ether SS. Calcium hydroxide root canal sealers - histopathologic evaluation of apical and periapical repair after endodontic treatment. J Endod 1997;23(7):428-32.

Leonardo MR, Utrilla LS, Assed S, Silva LAB. Avaliação histopatológica dos tecidos apicais e periapicais de dentes de cães após biopulpectomia e utilização de diferentes curativos de demora. Rev Bras Odontol 1996;32(1):14-9.

Lin ZM, Jhugroo A, Ling JQ. An evaluation of the sealing ability of a polycaprolactone-based root canal filling material (Resilon) after retreatment. Oral Surg Oral Med Oral Pathol Oral Radiol Endod 2007;104(6):846-51.

Lumley PJ, Lucarotti PSK, Burke FJT. Ten-year outcome of root fillings in the general dental services in England and Wales. Int Endod J 2008;41(7):577-85.

Machado-Silveiro LF, Gonzalez-Lopez S, Gonzalez-Rodriguez MP. Decalcification of root canal dentine by citric acid, EDTA and sodium citrate. Int Endod J 2004;37(6):365-69.

Malacarne J, Carvalho RM, de Goes MF, Svizerd V, Tay FR, Pashley DH. Water sorption/solubility of dentinal adhesives resins. Dent Mater 2006;22:973-80.

Marlin J, Krakow AA, Desilets RP, Gron P. Clinical use of injection molded thermoplasticized gutta-percha for obturation of the root canal system: a preliminary study. J Endod 1981;7(6):277-81.

Marquis VL, Dao T, Farzaneh M, Abitbol S, Friedman S. Treatment outcome in endodontics: the Toronto study. Phase III: initial treatment. J Endod 2006;32(4):299306.

McRobert AS, Lumley PJ. An in vitro investigation of coronal leakage with three gutta-percha backfilling techniques. Int Endod J 1997;30(5):413-7.

McSpadden J. Self study course for the thermatic condensation of gutta-percha. Toledo, OH, USA: Ransom \& Randolph; 1980.

McSpadden J. The endo quantic series Handbook. Advanced Endodontic Concepts. Chattanooga, OH, USA: 1991. 
Medina N, Valle G, Kuttler S, Namerow K. Comparison of the sealing ability of a new cold flowable Gutta-percha system and conventional obturation techniques [abstract OR12]. J Endod 2006;32(6):236.

Michanowicz AE, Czonstkowsky M. Sealing properties of an injectionthermoplasticized low-temperature $\left(70^{\circ}\right)$ gutta-percha: a preliminary study. J Endod 1984;10(12):563-6.

Miletic I, Prpic-Mehicic G, Marsan T, Tambic-Andrasevic A, Plesko S, Karlovic Z, et al. Bacterial an fungal microleakage of $\mathrm{AH} 26$ and $\mathrm{AH}$ Plus root canal sealers. Int Endod J 2002;35(5):428-32.

Miletic I, Ribarick SP, Karlovic Z, Jukic S, Bosnjack A, Anic I. Apical leakage of five root canal sealers after storage. J Endod 2002;28(6):431-2.

Mittal N, Dewan N, Gupta P, Sharma GMK. In-vivo radiographicevaluation of sealing ability of root canals with various obturation techniques. Endodontology 2002;14(2):46-51.

Möller AJR, Fabricius L, Dahlén G, Öhman AE, Heyden G. Influence on periapical tissues of indigenous oral bacteria and necrotic pulp tissue in monkeys. Scand $\mathrm{J}$ Dent Res 1981;89(6):475-84.

Morse A. Formic acid-sodium citrate decalcification and butyl alcohol dehydration of teeth and bone for sectioning in paraffin. J Dent Res 1945;24(3-4):143-53.

Muñoz HR, Saraiva-Lemus GA, Florián WE, Lainfiesta JF. Microbial leakage of Enterococcus faecalis after post space preparation in teeth filled in vivo with RealSeal versus Gutta-percha. J Endod 2007;33(6):673-5.

Nagas E, Uyanik MO, Sabin C, Durmaz V, Cebreli ZC. Effects of different light-curing units and obturation techniques on the seal of Resilon/Epiphany system. J Endod 2008;34(10):1230-2.

Naidorf IJ. Clinical microbiology in endodontics. Dent Clin North Am 1974;18:329-44.

Nair PNR. On the causes of persistent apical periodontitis: a review. Int Endod J 2006;39(4):249-81. 
Nair PNR, Sjogren U, Kahnberg KE, Sunquist G. Intraradicular bacteria and fungi in root files, assyntomatic human teeth with therapy-resistant periapical lesions: a long term light and electron microscopic follow-up study. J Endod 1990;16(12):580-8.

Nelson EA, Liewehr FR, West LA. Increased density of gutta-percha using a controlled heat instrument with lateral condensation. J Endod 2000;26(12):748-50.

$\mathrm{Ng} \mathrm{YL,} \mathrm{Mann} \mathrm{V,} \mathrm{Rahbaran} \mathrm{S,} \mathrm{Lewsey} \mathrm{J,} \mathrm{Gulabivala} \mathrm{K.} \mathrm{Outcome} \mathrm{of} \mathrm{primary} \mathrm{root} \mathrm{canal}$ treatment systematic review of the literature - Part 1. Effect of study characteristics on probability of success. Int Endod J 2007;40(12):921-39.

Ng YL, Rahbaran S, Lewsey J, Gilthrope M, Gulabivala K. Primary root canal treatment outcome - systematic review and meta-analyses [abstract R12]. Int Endod J 2003;36(12):926.

Oddoni PG, Mello I, Coil JM, Antoniazzi JH. Coronal and apical leakage analysis of two different root canal obturation systems. Braz Oral Res 2008;22(3):211-5.

Oliver CM, Abbott PV. Relationship between apical leakage and clinical success of root fillings [abstract OR18]. J Endod 1997;23(4):253.

Oliver CM, Abbott PV. An in vitro study of apical and coronal microleakage of laterally condensed gutta percha with Ketac-Endo and AH26. Aust Dent J 1998;43(4):262-8.

Onay EO, Ungor M, Orucoglu $\mathrm{H}$. An in vitro evaluation of the apical sealing ability of a new resin-based root canal obturation system. J Endod 2006;32(10):976-8.

Orucoglu $\mathrm{H}$, Sengun A, Yilmaz N. Apical leakage of resin root canal sealers with a new computerized fluid filtration meter. J Endod 2005;31(12):886-90.

Pagavino G, Giachetti L, Nieri M, Giuliani V, Russo DS. The percentage of guttapercha filled area in simulated curved canals when filled using Endo Twinn, a new heat device source. Int Endod J 2006;39(8):610-5.

Paiva JG, Antoniazzi JH. Endodontia: base para a prática clínica. $2^{a}$ ed. São Paulo: Artes Medicas; 1988. 886 p.

Paqué $F$, Sirtes G. Apical sealing ability of Resilon/Epiphany versus gutta-percha/AH Plus: immediate and 16-months leakage. Int Endod J 2007;40(9):722-9. 
Pashley DH, Ciucchi B, Sano H, Carvalho RM, Russel CM. Bond strength versus dentine structure: a modelling approach. Arch Oral Biol 1995;40(12):1109-18.

Paterson RC, Watts A. Pulpal involvement and endodontic treatment. In: Elderton BJ, editor. The dentition and dental care. Oxford: Heinemann Medical Books; 1990. chap. 15.

Peng L, Ye L, Tan H, Zhou X. Outcome of root canal obturation by warm guttapercha versus cold lateral condensation: A meta-analysis. J Endod 2007;33(2):106-9.

Pereira CC, Oliveira EPM, Gomes MS, Della-Bona A, Vanni JR, Kopper PMP, et al. Comparative in vivo analysis of the sealing ability of three endodontic sealers in dog teeth after post-space preparation. Aust Endod J 2007;33(3):101-6.

Perez-Heredia M, Ferrer-Luque CM, Gonzalez-Rodrıguez MP, Martın-Peinado FJ, Gonzalez-Lopez S. Decalcifying effect of 15\% EDTA, 15\% citric acid, 5\% phosphoric acid and $2.5 \%$ sodium hypochlorite on root canal dentine. Int Endod J 2008;41(5):418-23.

Peters DD. Two-year in vitro solubility evaluation of four gutta-percha sealer obturation techniques. J Endod 1986;12(4):139-45.

Peters LB, Wesselink PR, van Winkelhoff AJ. Combinations of bacterial species in endodontic infections. Int Endod J 2002;35(8):698-702.

Petersson K, Petersson A, Olsson B, Hakansson J, Wennberg A. Technical quality of root fillings in an adult Swedish population . Endod Dent Traumatol 1986;2(3):99-102.

Pitout E, Oberholzer TG, Blignaut E, Molepo J. Coronal leakage of teeth root-filled with gutta-percha or Resilon root canal filling material. J Endod 2006;32(9):879-81.

Pitt Ford TR. The radiographic detection of periapical lesion in dogs. Oral Surg Oral Med Oral Pathol Oral Radiol Endod 1984;57(6):662-7.

Pommel L, Camps J. In vitro apical leakage of System B compared with other filling techniques. J Endod 2001;27(7):449-51.

Qualtrough AJ, Whitworth JM, Dummer PM. Preclinical endodontology: an international comparison. Int Endod J 1999;32(5):406-14. 
Rafter M, Baker M, Alves M, Daniel J, Remeikis N. Evaluation of healing with use of an internal matrix to repair furcation perforations. Int Endod J 2002;35(9):775-83.

Rahimi M, Jainaen A, Parashos $\mathrm{P}$, Messer $\mathrm{HH}$. Bonding of resin-based sealers to root dentin. J Endod 2009;35(1):121-4.

Raina R, Loushine RJ, Weller RN, Tay FR, Pashley DH. Evaluation of the quality of the apical seal in Resilon/Epiphany and Gutta-percha/AH Plus - filled root canals by using a fluid filtration approach. J Endod 2007;33(8):944-7.

Reis AF, Giannini M, Pereira PNR. Influence of water-storage time on the sorption and solubility behavior of current adhesives and primer/adhesive mixtures. Oper Dent 2007;32(1):53-9.

Ritchie GM, Anderson DM, Sakamura JS. Apical extrusion of thermoplasticized guttapercha used as a root canal filling. J Endod 1988;14(3):128-32.

Rosenthal S, Spangberg L, Safavi K. Chlorhexidine substantivity in root canal dentin. Oral Surg Oral Med Oral Pathol Oral Radiol Endod 2004;98(4):488-92.

Rowe AHR. Problems of intracanal testing of endodontic materials. Int Endod J 1980;13(2):96-103.

Rueda JCA. Material obturador de canal radicular à base de uretano metacrilato: estudo histológico e da infiltração coronária em dentes de cães [Dissertaçao de Mestrado]. Araraquara: Faculdade de Odontologia da UNESP; 2006.

Rueggeberg FA, Margeson DH. The effect of oxygen inhibition on an unfilled/filled composite system. J Dent Res 1990;69(10):1652-8

Sagsen B, Er O, Kabraman Y, Orucoglu H. Evaluation of microleakage of roots filled with different techniques with a computerized fluid filtration technique. J Endod 2006;32(12):1168-70.

Salehrabi R, Rotstein I. Endodontic treatment outcomes in a large patient population in the USA: an epidemiological study. J Endod 2004;30(12):846-50.

Santos MG. Avaliação da força de adesão de resina composta sobre esmalte bovino previamente clareado com gel de peróxido de carbamida, em diferentes 
concentrações, por meio de teste de microcisalhamento [Tese de Doutorado]. São Paulo: Faculdade de Odontologia da USP; 2004.

Sassone LM, Fidel RAS, Faveri M, Fidel SR, Figueiredo L, Feres M. Microbiological evaluation of primary endodontic infections in teeth with and wiyhout sinus tract. Int Endod J 2008;41(6):508-15.

Sassone LM, Fidel RAS, Murad CF, Fidel SR, Hirata Jr R. Antimicrobial activity of sodium hypochlorite and chlorhexidine by two different tests. Aust Endod J 2008;34(1):19-24.

Saunders WP, Saunders EM. Coronal leakage as a cause of failure in root canal therapy: a review. End Dent Traum 1994;10(3):105-8.

Scelza MFZ, Antoniazzi JH, Scelza P. Efficacy of final irrigation - A scanning electron microscopic evaluation. J Endod 2000;26(6):355-8.

Scelza MFZ, Daniel RLDP, Santos EM, Jaeger MMM. Cytotoxic effects of $10 \%$ citric acid and EDTA-T used as root canal irrigants: An in vitro analysis. J Endod $2001 ; 27(12): 741-3$.

Scelza MFZ, Pierro V, Scelza P, Pereira M. Effect of three different time periods of irrigation with EDTA-T, EDTA, and citric acid on smear layer removal. Oral Surg Oral Med Oral Pathol Oral Radiol Endod 2004;98(4):499-503.

Schafer E, Olthoff G. Effect of three different sealers on the sealing ability of both thermafil obturators and cold laterally compacted Gutta-Percha. J Endod 2002;28(9):638-42.

Schilder HC. Filling root canals in three dimensions. Dent Clin North Am 1967;11:723-44.

Sevimay S, Kalayci A. Evaluation of apical sealing ability and adaptation to dentine of two resin-based sealers. J Oral Rehabil 2005;32(2):105-10.

Shahravan A, Haghdoost AA, Adl A, Rahimi H, Shadifar F. Effect of smear layer on sealing ability of canal obturation: A systematic review and meta-analysis. J Endod 2007;33(2):96-105. 
Shemesh $\mathrm{H}$, van den Bos M, Wu Mk, Wesselink Pr. Glucose penetration an fluid transport through coronal root structure and filled root canals. Int Endod J 2007;40(11):866-72.

Shemesh H, Wu MK, Wesselink PR. Leakage along apical root fillings with and without smear layer using two different leakage models: a two-month longitudinal ex vivo study. Int Endod J 2006;39(12):968-76.

Shibata Y, Fujita S, Takahashi H, Yamaguchi A, Koji T. Assessment of decalcifying protocols for detection of specific RNA by non-radioctive in situ hybridization in calcified tissues. Histochem Cell Biol 2000;113(3):153-9.

Shipper G, Orstavik D, Teixeira FB, Trope M. An evaluation of microbial leakage in roots filled with a thermoplastic synthetic polymer-based root canal filling material (Resilon). J Endod 2004;30(5):342-7.

Shipper G, Teixeira FB, Arnold RR, Trope M. Periapical inflammation after coronal microbial inoculation of dog roots filled with gutta-percha or Resilon. J Endod 2005;31(2):91-6.

Shipper G, Trope M. In vitro microbial leakage of endodontically treated using new and standard obturation techniques. J Endod 2004;30(3):154-8.

Silva FWGP. Resposta pulpar e periapical de dentes de cães após pulpotomia e utilização da proteína óssea morfogenética (rHuBMP-7) estudo histopatológico e radiográfico [Dissertação de Mestrado]. Ribeirão Preto: Faculdade de Odontologia da USP; 2006.

Silva-Neto UX, Brochado VHD, Gonçalves-Jr JF, Westphalen VPD, Moraes IG. Selamento apical com as técnicas de Tagger e System B [resumo I124]. Pesqui Odontol Bras 2000;14:27.

Siqueira JF Jr. Reaction of periradicular tissues to root canal treatment: benefits and drawbacks. Endod Topics 2005;10:123-147

Siqueira JF Jr, Roças IN. Clinical implications and microbiology of bacterial persistence after treatment procedures. J Endod 2008;34(11):1291-301.

Siqueira JF Jr, Roças IN, Favieri A, Abad EC, Castro AJ, Gahyva SM. Bacterial leakage in coronally unsealed root canals obturated with 3 different techniques. Oral Surg Oral Med Oral Pathol Oral Radiol Endod 2000;90(5):647-50. 
Siqueira JF Jr, Roças IN, Lopes HP, De Uzeda M. Coronal leakage of two root canal sealers containing calcium hydroxide after exposure to human saliva. J Endod 1999;25(1):14-6.

Siqueira JF Jr, Roças IN, Souto R, Uzeda M, Colombo AP. Actinomyces species, Streptococci and Enterococcus faecalis in primary root canal infections. J Endod 2002;28(3):168-71.

Sjorgren U, Hagglund B, Sundquist G, Wing K. Factors affecting the long term results of endodontic treatment. J Endod 1990;16(10):498-504.

Sly MM, Moore BK, Platt JA, Brown CE. Push-out bond strength of a new endodontic obturation system (Resilon/Epiphany). J Endod 2007;33(2):160-2.

Smith CS, Setchell DJ, Harty FJ. Factors influencing the success of conventional root canal therapy - a five year retrospective study. Int Endod J 1993;26(6):321-33.

Soares IJ, Holland R, Soares IML. Comportamento dos tecidos periapicais após o tratamento endodôntico em uma ou duas sessões - influência do cimento obturador. Rev Bras Odontol 1990;47(2):34-41.

Sousa SM, Silva TL. Demineralization effect of EDTA, EGTA, CDTA and citric acid on root dentin: a comparative study. Braz Oral Res 2005;19(3):188-92.

Souza SFC. Cimentos resinosos endodônticos: selamento apical, aspectos micromorfológicos, características físicas e resistência de união à dentina [Tese de Doutorado]. São Paulo: Faculdade de Odontologia da USP; 2007.

Stratton RK, Apicella MJ, Mines P. A fluid filtration comparison of Gutta-percha versus Resilon, a new soft resin endodontic obturation system. J Endod 2006;33(7):642-5.

Sundqvist G. Ecology of the root canal flora. J Endod 1992;18(9):427-30.

Sundqvist G. Taxonomy, ecology, and pathogenicity of the root canal flora. Oral Surg Oral Med Oral Pathol Oral Radiol Endod 1994;78(4):522-30. 
Sundqvist G, Fidgor D, Persson S, Sjorgen U. Microbiologic analysis of teeth with failed endodontic treatment and the outcome of conservative re-treatment. Oral Surg Oral Med Oral Pathol Oral Radiol Endod 1998;85(1):86-93.

Tagger M, Tagger E, Tjan AHL, Bakland LK. Measurement of adhesion of endodontic sealers to dentin. J Endod 2002;28(5):351-4.

Tagger M, Tagger E, Tjan AHL, Bakland LK. Shearing bond strength of endodontic sealers to gutta-percha. J Endod 2003;29(3):191-3.

Tanomaru JMG. Efeito de soluções irrigadoras e do hidróxido de calico como curativo de demora sobre o LPS-Endotoxina. Estudo histopatológico em dentes de cães [Dissertação de Mestrado]. Araraquara: Faculdade de Odontologia da UNESP; 2002.

Tanomaru Filho M. Comportamento dos tecidos apicais e periapicais de dentes de cães portadores de reação periapical crônica en função da técnica de neutralização do conteúdo séptico-tóxico e do cimento obturador empregado no tratamento endodôntico. Avaliação radiográfica e histopatológica [Tese de Doutorado]. Araraquara: Faculdade de Odontologia da UNESP; 1996.

Taranu R, Wegerer U, Roggendorf MJ, Ebert J, Pestchelt A, Frankenberger R. Leakage analysis of three modern root filling material after 90 days of storage [abstract R31]. Int Endod J 2005;38(12):928.

Tay FR, King NM, Chan K, Pashley DH. How can nanoleakake occur in self-etching adhesive systems that demineralize and infiltrate simultaneously?. J Adhes Dent 2002;4(4):255-68.

Tay FR, Hiraishi N, Pashley DH, Loushine RJ, Weller RN, Gillespie WT, et al. Bondability of Resilon to a methacrylate-based root canal sealer. J Endod 2006;32(2):133-7.

Tay FR, Pashley DH. Monoblocks in root canals: a hypothetical or a tangible goal. J Endod 2007;33(4):391-98.

Tay FR, Pashley DH. Water treeing-a potential for degradation of dentin adhesives. Am J Dent 2003;16:6-12. 
Tay FR, Pashley DH, Suh BI, Carvalho RM, Itthagarun A. Single-step adhesives are permeable membranes. J Dent 2002;30(7-8):371-82.

Tay FR, Pashley DH, Yiu CKY, Sanares AME, Wei SHY. Factors contribuiting to the incompatibility between simplified-step adhesive and chemically-cured or dual-cured composites. Part I. Single-step self etching adhesive. J Adhes Dent 2003;5(1):27-39.

Timpawat S, Amornchat C, Trisuwan WR. Bacterial coronal leakage after obturation with three root canal sealers. J Endod 2001;27(1):36-9.

Tinaz AC, Alacam T, Uzun O, Maden M, Kayaoglu G. The effect of disruption of apical constriction on periapical extrusion. J Endod 2005;31(7):533-5.

Titley KC, Torneck CD, Ruse ND, Krmec D. Adhesion of a resin composite to bleached and unbleached human enamel. J Endod 1993;19(3)112-5.

Torabinejad M, Handysides R, Khademi AA, Bakland LK. Clinical implications of the smear layer in endodontics: A review. Oral Surg Oral Med Oral Pathol Oral Radiol Endod 2002;94(6):658-66.

Torabinejad M, Skobe Z, Tromblay PI, Krakow AA, Gron P, Marlin J. Scanning electron microscope study of root canal obturation using thermoplasticized guttapercha. J Endod 1978;4(8):245-50.

Torneck CD, Titley KC, Smith DC, Adibfar A. The influence of time of hydrogen peroxide exposure on the adhesion of composite resin to bleached bovine enamel. $\mathrm{J}$ Endod 1990;16(3):123-8.

Touré B, Kane AW, Sarr M, Ngom CTH, Boucher Y. Prevalence and technical quality of root dillings in Dakar, Senegal. Int Endod J 2008;41(1):41-9.

Tunga $U$, Bodrumlu $E$. Assessment of the sealing ability of a new root canal obturation material. J Endod 2006;32(9):876-8.

Ungor M, Onay EO, Orucoglu H. Push-out bond strength: the Resilon-Epiphany endodontic system compared with different pairings of Epiphany, AH Plus and guttapercha. Int Endod J 2006;39:643-7.

Üreyen Kaya B, Keçeci AD, Orhan H, Belli S. Micropush-out bond strengths of guttapercha versus thermoplastic synthetic polymer-based systems - an ex vivo study. Int Endod J 2008;41(3):211-8. 
Van Zyl SP, Gulabivala K, Ng YL. Effect of customization of master gutta-percha cone on apical control of root filling using different techniques: an ex vivo study. Int Endod J 2005;38(9):658-66.

Verdenius HMW, Alma L. A quantitative study of decalcification methods in histology. J Clin Pathol 1958;11(3):229-36.

Veríssimo DM, do Vale MS, Monteiro AJ. Comparison $\mathrm{n}$ of apical leakage between canals filled with Gutta-percha/AH Plus and the Resilon/Epiphany system, when submitted to two filling techniques. J Endod 2007;33(3):291-4.

Versiani MA, Carvalho-Júnior JR, Padilha MIAF, Lacey S, Pascon EA, Sousa-Neto MD. A comparative study of physicochemical properties of AH Plus and Epiphany root canal sealants. Int Endod J 2006;39:464-71.

Vianna ME, Horz HP, Gomes BPFA, Conrads G. Microarrays complement culture methods for identification of bacteria in endodontic infections. Oral Microbiol Immunol 2005;20(4):253-8.

Wang CS, Arnold RR, Trope M, Teixeira FB. Clinical efficiency of $2 \%$ chlorhexidine gel in reducing intracanal bacteria. J Endod 2007;33(11):1283-9.

Watts A, Paterson RC. Pulp response to, and carcinogenicity of a further strain of Streptococcus mutans. Int Endod J 1992;25(3):142-9.

Watts DC, Cash AJ, Chauhan J, Rathore S. Variables influencing hardness development in dual-cure composite luting materials [Abstract 115]. J Dent Res 1994;73:801.

Wedding JR, Brown CE, Legan JJ, Moore BK, Vail MM. An in vitro comparison microleakage between Resilon and Gutta-percha with a fluid filtration model. J Endod 2007;33(12):1447-9.

Whitworth J. Methods of filling root canals: principles and practice. Endod Topics 2005;11:2-24. 
Williamson AE, Dawson DV, Drake DR, Walton RE, Rivera EM. Effect of root canal filling/sealer systems on apical endotoxin penetration: a coronal leakage evaluation. J Endod 2005;31(8):599-604.

Wolcott J, Himel VT, Powell W, Penney J. Effect of two obturation techniques on the filling of lateral canals and the main canal. J Endod 1997;23(10):632-5.

Wollard RR, Brough SO, Maggio J, Seltzer S. Scanning electron microscopic examination of root canal filling materials. J Endod 1976;2(4):98-110.

Wu MK, De Gee AJ, Wesselink PR. Fluid transport and dye penetration along root canal fillings. Int Endod J 1994;27(5):233-38.

Wu MK, Kast'akova A, Wesselink PR. Quality of cold and warm gutta-percha fillings in oval canals in mandibular premolars. Int Endod J 2001:34(4):485-91.

Wu MK, van der Sluis LW, Wesselink PR. A preliminary study of the percentage of gutta-percha filled area in the apical canal filled with vertically compacted warm guttapercha. Int Endod J 2002;35(6):527-35.

Wu MK, van der Sluis LW, Wesselink PR. Fluid transport along gutta-percha backfills with and without sealer. Oral Surg Oral Med Oral Pathol Oral Radiol Endod 2004;97(2):257-62.

Wu MK, Wesselink PR. Endodontic leakage studies reconsidered.Part I. Metodology, application and relevance. Int Endod J 1993;26(1):37-43.

Yamamoto-Fukuda T, Shibata Y, Hishikawa Y, Shin M, Yamaguchi A, Kobayashi T, et al. Effects of various decalcification protocols on detection of DNA strand breaks by terminal dUTP nick end labeling. Histochem J 2000;32(11):697-702.

Yee FS, Marlin J, Krakow AA, Gron P. Three dimensional obturation of the root canal using injection-molded thermoplasticized dental gutta-percha. J Endod 1977;3(5):168-74.

Yoshida M, Fukushima H, Yamamoto K, Ogawa K, Toda T, Sagawa H. Correlation between clinical symptoms and microorganisms isolated from root canals of teeth with periapical pathosis. J Endod 1987;13(1):24-8. 
Yücel AÇ, Güler E, Güler AU, Ertas E. Bacterial penetration after obturation with four different root canal selaers. J Endod 2005;32(9):890-3.

Zehnder M. Root canal irrigants. J Endod 2006;32(5):389-98. 


\title{
ANEXO A - Parecer do Comitê de Ética em Pesquisa da FOUSP.
}

\section{UNIVERSIDADE DE SÃO PAULO FACULDADE DE ODONTOLOGIA}

\author{
$2^{\mathrm{a}}$ via
}

\author{
PARECER DE APROVAÇÃO \\ Protocolo 60/06
}

O Grupo de Trabalho indicado pelo Comitê de Ética em Pesquisa, APROVOU o protocolo de pesquisa "Análise da infiltração marginal em dentes obturados variando-se o tipo de cimento e a técnica", de responsabilidade do Pesquisador Eduardo Akisue, sob orientação do Professor Doutor Giulio Gavini.

Tendo em vista a legislação vigente, devem ser encaminhados a este Comitê relatórios anuais referentes ao andamento da pesquisa e ao término cópia do trabalho em "cd". Qualquer emenda do projeto original deve ser apresentada a este CEP para apreciação, de forma clara e sucinta, identificando a parte do protocolo a ser modificada e suas justificativas.

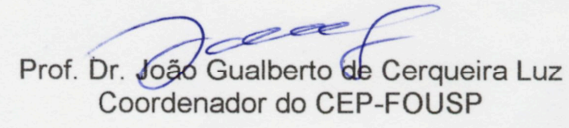

Av. Prof. Lineu Prestes, 2227 - Cidade Universitária "Armando de Salles Oliveira" CEP 05508-900 São Paulo - SP - Diretoria Telefax: (011) 3091- 0062/3091-7817/3091-7860 - Compras (011) 3091-7895 Impresso no S.D.O. 


\title{
ANEXO B - Parecer do Comitê de Ética em Pesquisa da FMVZ-USP
}

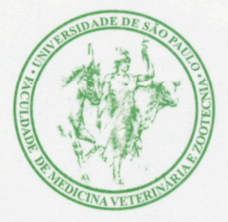

\author{
UNIVERSIDADE DE SÃO PAULO \\ Faculdade de Medicina Veterinária e Zootecnia
}

Comissão de Bioética

\section{PARECER}

Interessado: Aduardo Akisue (Faculdade de Odontologia-USP)

Assunto: Protocolo de Experimentação adotado em experimento animal.

A Presidência da Comissão de Bioética da Faculdade de Medicina Veterinária e Zootecnia da Universidade de São Paulo, e após analisar o projeto protocolado sob o número 1201/2007, intitulado: “Análise in vivo da infiltração bacteriana em dentes tratados endodonticamente", no qual foram utilizados 05 (cinco) dogs, sob responsabilidade dos Professores Dr. Giulio Gavini (Orientador-FOUSP) e Dr. Marco Antonio Gioso (Co-Orientador), constatou que o mesmo foi realizado de acordo com os princípios de bioética, adotados por esta Comissão.

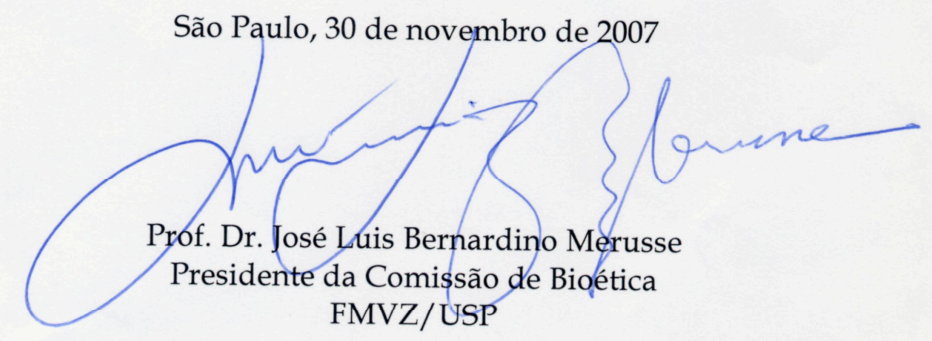

Av. Prof. Dr. Orlando Marques de Paiva, n 87 - 05508-270 - Cidade Universitária "Armando de Salles Oliveira". Fax: (11) 3032-2224 - fones: (11) 3091-7676/7671 - email: fmvz@edu.usp.br 


\section{ANEXO C - Hemograma do cão 1}

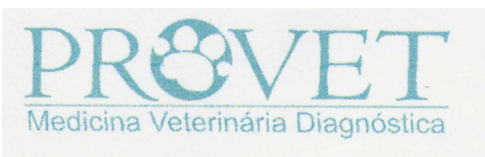
Rua Francisco Zicardi, 16 - Jd. Anália Franco - São Paulo - CEP 03335-090
Tel. (11) 3467-3006 Internet: www. provet.com.br analiafranco@provet.com.br

\begin{tabular}{|c|c|}
\hline $\begin{array}{l}\text { Animal: Cão } 1 \\
\text { Espécie: Canina } \\
\text { Proprietário: FO-USP / FMVZ-USP Raça: Sem Raça Definida } \\
\text { Requisitante: Experimental FO-USP / FMVZ-USP } \\
\text { Clínica: Experimental FO-USP / FMVZ-USP } \\
\text { EndereçO: Prof. Orlando Marques de Paiva, } 87 \text { - Cidade Universitária }\end{array}$ & $\begin{array}{c}\text { Data: } 17 / 09 / 07 \\
\text { Sexo:M } \\
\text { Cor: Mesclado }\end{array}$ \\
\hline
\end{tabular}

Hemograma

Material: SANGUE COM E.D.T.A.

Equipamento: PENTRA 120 DX

Valores de Referencia

Eritrograma

Eritrócitos........... 7 milhões $/ \mathrm{mm}^{3}$

Hemoglobina............. 14,21 g/dl

Hematocrito............ $43 \%$

V.c.m............. $61,43 \mathrm{u}^{3}$

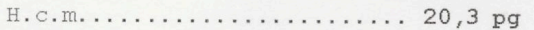

c.h.c.m............ 33,05 g/dl

Proteína total.......... 7,00

Eritroblastos............ 0,00

Reticulócitos........... 0,00

5,5 A $8,5 \mathrm{milhores} / \mathrm{mm}^{3}$

12,0 A $18,0 \mathrm{~g} / \mathrm{dl}$

37 A. 55 \&

60 A $77 \mathrm{u}^{3}$

19,5 A 24,5 pg

30 A $36 \mathrm{~g} / \mathrm{dl}$

5,5 A $8,0 \mathrm{~g} / \mathrm{dl}$

08

O A 12 \&

Observaçoes série vermelha... MORFOLOGIA CELULAR NORMAL.

Leucograma Leucócitos....... 10,50 mil/ $/ \mathrm{mm}^{3}$

Mielócitos.............. $00 \%$

$0 / \mathrm{mm}^{3}$

6,0 A $17,0 \mathrm{mil} / \mathrm{mm}^{3}$

Metamielócitos........... $00 \%$

$0 / \mathrm{mm}^{3}$

0 8

$0 / \mathrm{mm}^{3}$

0 8

Bastonetes.............. $00 \%$

$8400 / \mathrm{mm}^{3}$

O A 3 \%

segmentados............. 80 \%

$315 / \mathrm{mm}^{3}$

60 A 778

Eosinófilos............. 03 \%

$0 / \mathrm{mm}^{3}$

2 A $10 \%$

Basófilos.............. 00 웅

$1575 / \mathrm{mm}^{3}$

$0 / \mathrm{mm}^{3}$

O A 1 \&

infócitos típicos......... $15 \%$

$210 / \mathrm{mm}^{3}$

12 A 308

$0 \div$

Monócitos............... 02 \%

$0 / \mathrm{rmm}^{3}$

Observações série branca..... MORFOLOGIA CELUL.AR NORMAL.

Contagem plaquetária...... $210 \mathrm{mil} / \mathrm{mm}^{3}$

200 a $500 \mathrm{mil} / \mathrm{mm}^{3}$

Avaliação plaquetária....... NORMAIS EM QUANTIDADE E MORFOLOGIA.

Pesquisa de hematozoários.... NÃO FORAM OBSERVADOS

Assinado eletronicamente por: CASSIANO DE CASTRO D. E. GOMES - CRMV: 14056

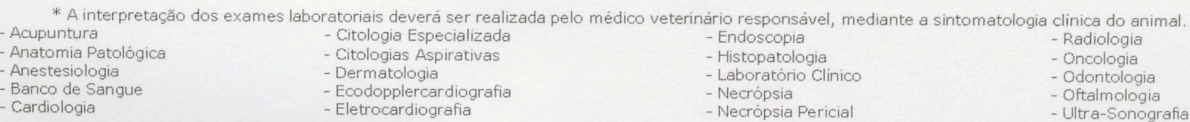


ANEXO D - Hemograma do cão 2

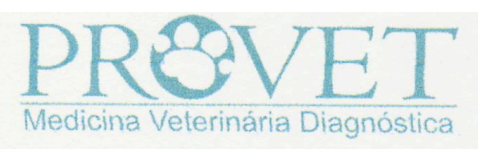

Rua Francisco Zicardi, 16 - Jd. Anália Franco - São Paulo - CEP 03335-090 Tel. (11) 3467-3006 Fax: (11) 3926-0683

Internet: www. provet.com.br analiafranco@provet.com.br

Animal: Cão 2

Espécie: Canina

Proprietário: FO-USP / FMVZ-USP

Requisitante: Experimental FO-USP / FMVZ-USP

Clínica: Experimental FO-USP / FMVZ-USP

Endereço: Prof. Orlando Marques de Paiva, 87 - Cidade Universitária

Data: $22 / 10 / 07$

Sexo: Macho

Raça: Sem Raça Definida

Cor: Preto

Hemograma

Material: SANGUE COM E.D.T.A.

Equipamento: PENTRA 120 DX

Valores de Referência

Eritrograma

Eritrócitos........... 6, $13 \mathrm{milhoes} / \mathrm{mm}^{3}$

Hemoglobina........... 14, $3 \mathrm{~g} / \mathrm{dl}$

Hematócrito........... 44,8 뭉

v.c.m............. $73 \mathrm{u}^{3}$

H.c.m............. 23,4 pg

C.h.c.m............ $32 \mathrm{~g} / \mathrm{dl}$

Proteína total........... 8,00

Eritroblastos........... 0,00

Reticulocitos............ 0,00

5,5 A 8,5 milhões $/ \mathrm{mm}^{3}$

12,0 A $18,0 \mathrm{~g} / \mathrm{dl}$

37 A 55 \&

60 A $77 \mathrm{u}^{3}$

19,5 A $24,5 \mathrm{pg}$

30 A $36 \mathrm{~g} / \mathrm{dl}$

$5,5 \mathrm{~A} 8,0 \mathrm{~g} / \mathrm{dl}$

$0 \%$

O A 12 은

Observações série vermelha... MORFOLOGIA CELULAR NORMAL. PLASMA LIGEIRAMENTE HEMOLISADO.

Leucograma Leucócitos....... 11, $10 \mathrm{mil} / \mathrm{mm}^{3}$

Mielócitos................ 00 8 $0 / \mathrm{mm}^{3}$

6,0 A $17,0 \mathrm{mil} / \mathrm{mm}^{3}$

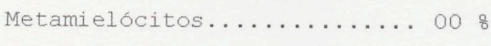

$0 / \mathrm{rmm}^{3}$

0 z

0 웅

Bastonetes.............. 008

$0 / \mathrm{mm}^{3}$

O A. 3 :

segmentados............. 58 g

$6438 / \mathrm{mm}^{3}$

60 A 778

Eosinófilos............. 04 웅

$444 / \mathrm{mm}^{3}$

2 A 10 \%

Basófilos............... 00 웅

$0 / \mathrm{mm}^{3}$

O A 1 \&

Linfócitos típicos........ 318

$3441 / \mathrm{mm}^{3}$

12 A 308

0 $/ \mathrm{mm}^{3}$

0 웅

Monócitos............... 078

$777 / \mathrm{mm}^{3}$

3 A 108

Outros (*) . . . . . . . . . 00 \%

$0 / \mathrm{mm}^{3}$

Observações serie branca..... MORFOLOGIA CELULAR NORMAL.

Contagem plaquetária....... $351 \mathrm{mil} / \mathrm{mm}^{3}$

Avaliação plaquetária....... NORMAIS EM QUANTIDADE E MORFOLOGIA.

Pesquisa de hematozoários.... NÃO FORAM OBSERVADOS

Assinado eletronicamente por: CELINA KAZUE MORINISHI - CRMV: 19573 


\section{ANEXO E - Hemograma do cão 3}

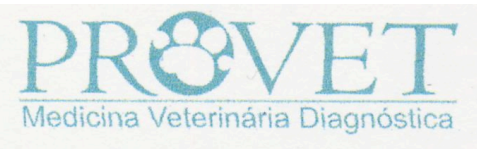

Rua Francisco Zicardi, 16 - Jd. Anália Franco - São Paulo - CEP 03335-090

$\begin{array}{ll}\text { Tel. (11) 3467-3006 } & \text { Fax: (11) 3926-0683 } \\ \text { Internet: www.provet.com.br } & \text { analiafranco@provet.com.br }\end{array}$

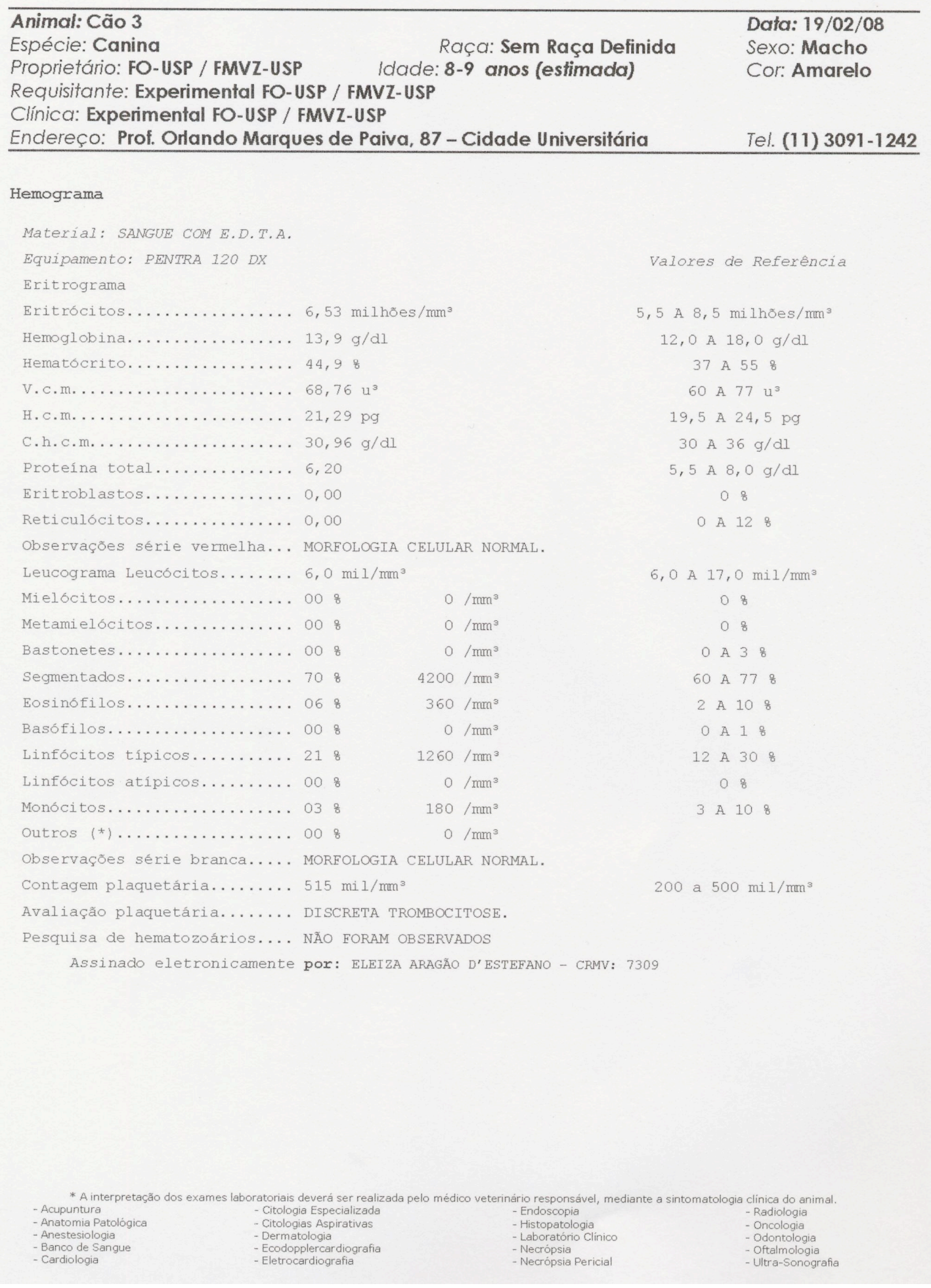




\section{ANEXO F - Hemograma do cão 4}

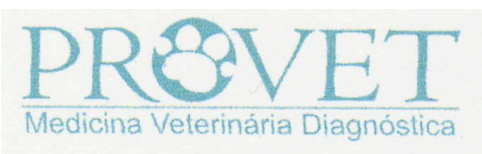
Rua Francisco Zicardi, 16 - Jd. Anália Franco - São Paulo - CEP 03335-090 $\begin{array}{ll}\text { Tel. (11) 3467-3006 } & \text { Fax: (11) 3926-0683 } \\ \text { Internet: www. provet.com,br } & \text { analiafranco @provet.com. br }\end{array}$

\section{Animal: Cão 4}

Espécie: Canina

Proprietário: FO-USP / FMVZ-USP

Requisitante: Experimental FO-USP / FMVZ-USP

Clínica: Experimental FO-USP / FMVZ-USP

Endereço: Prof. Orlando Marques de Paiva, 87 - Cidade Universiłária

(11) $3091-1242$

Data: 12/05/08

Data: $12 / 05 / 08$

Sexo: Fêmea

Cor: Branca

Hemograma

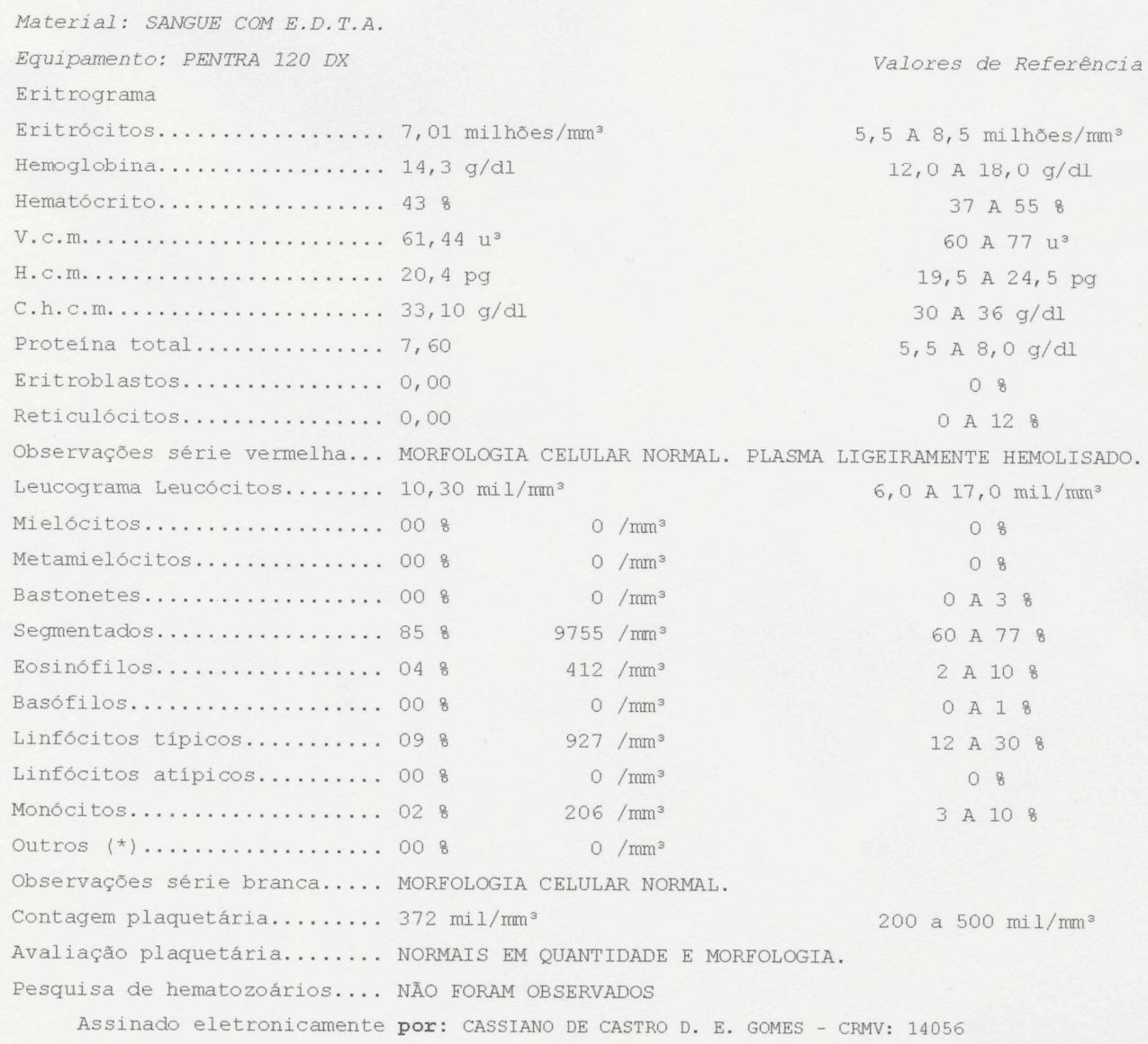

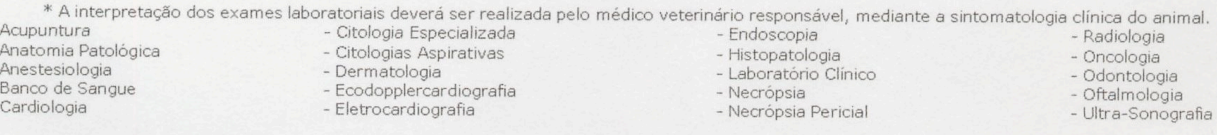




\section{ANEXO G - Hemograma do cão 5}

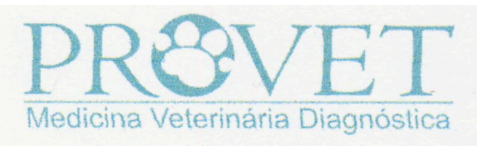

Rua Francisco Zicardi, 16 - Jd. Anália Franco - São Paulo - CEP 03335-090 Tel. (11) 3467-3006 Fax: (11) 3926-0683 Internet: www.provet.com.br analiafranco@provet.com.br

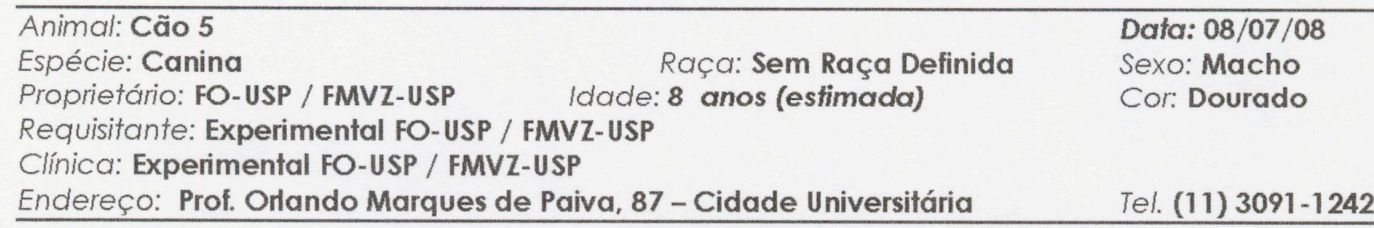

Hemograma

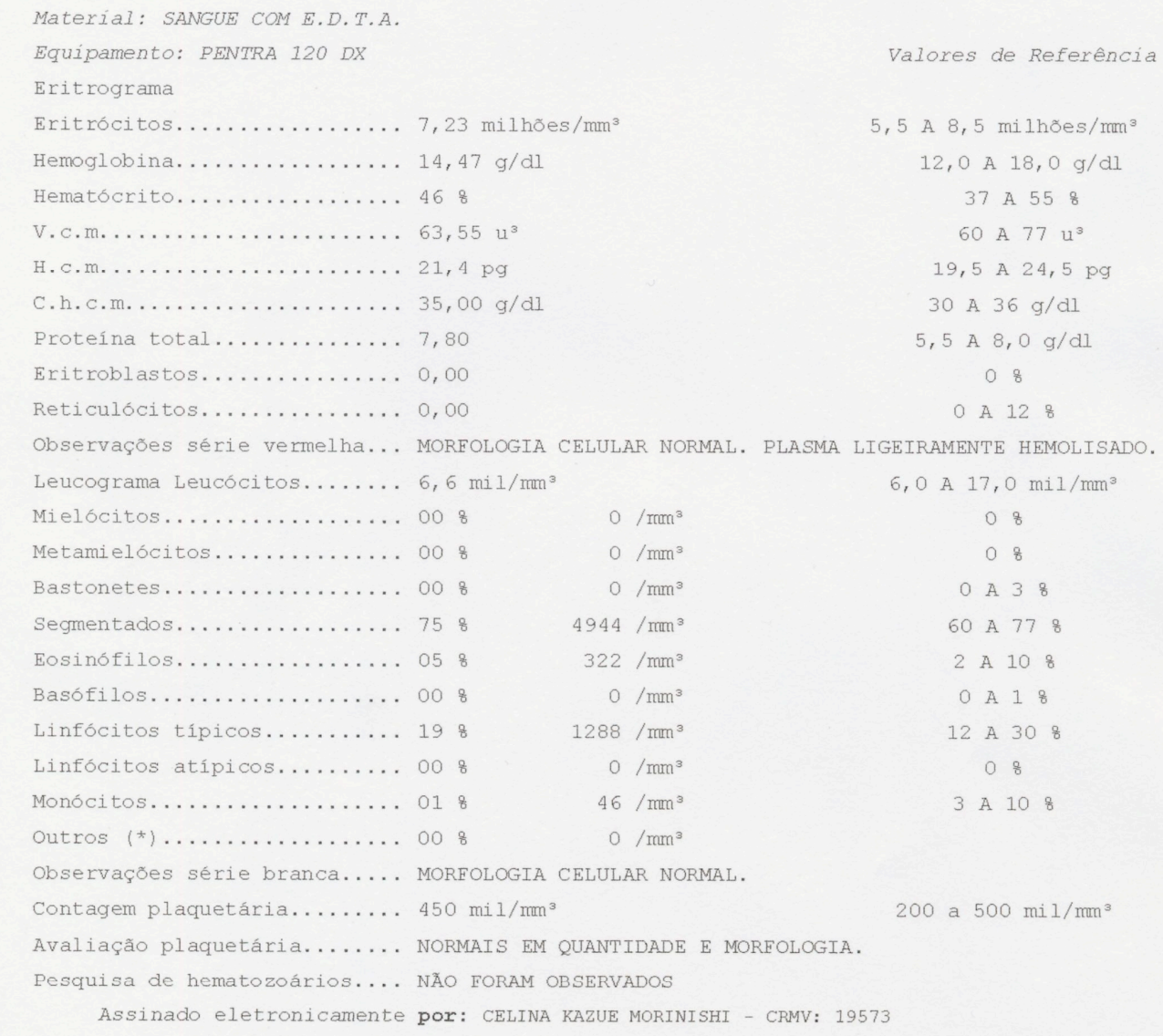

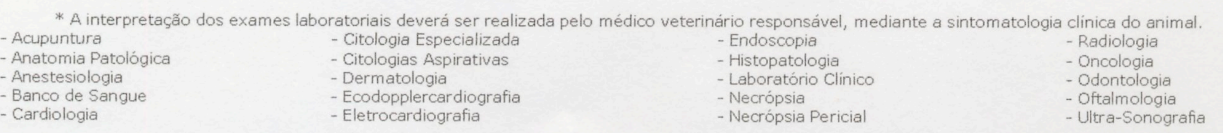


APÊNDICE A - Ficha de Tratamento

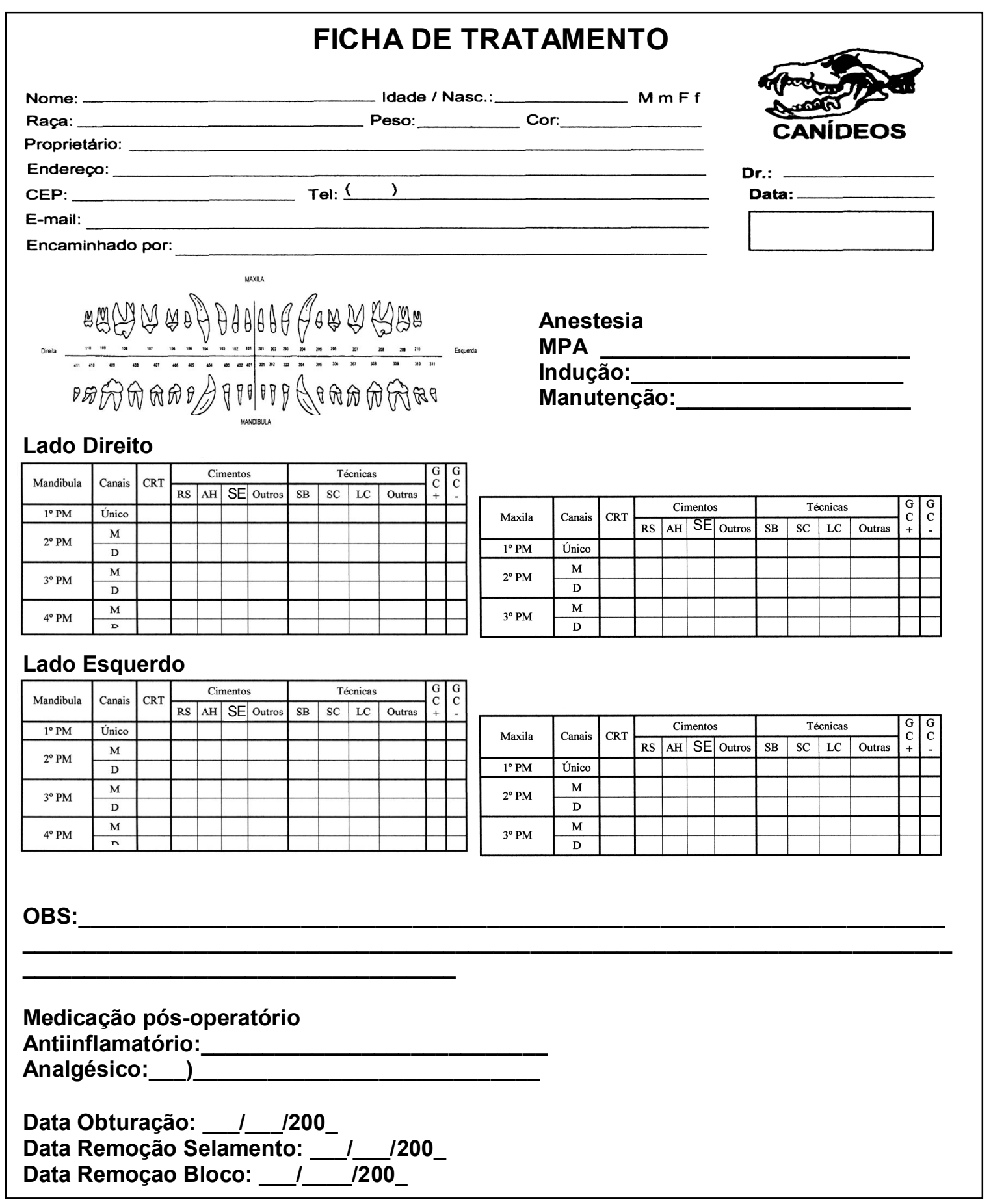


APÊNDICE B - Planilha das avaliações (Cão 1)

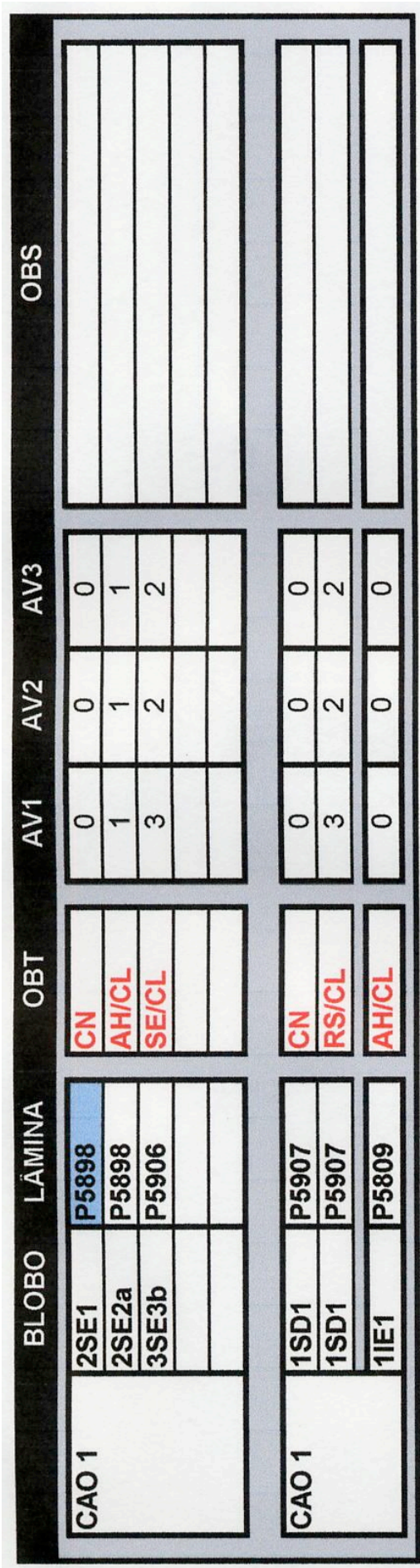


APÊNDICE C - Planilha das avaliações (Cão 2)

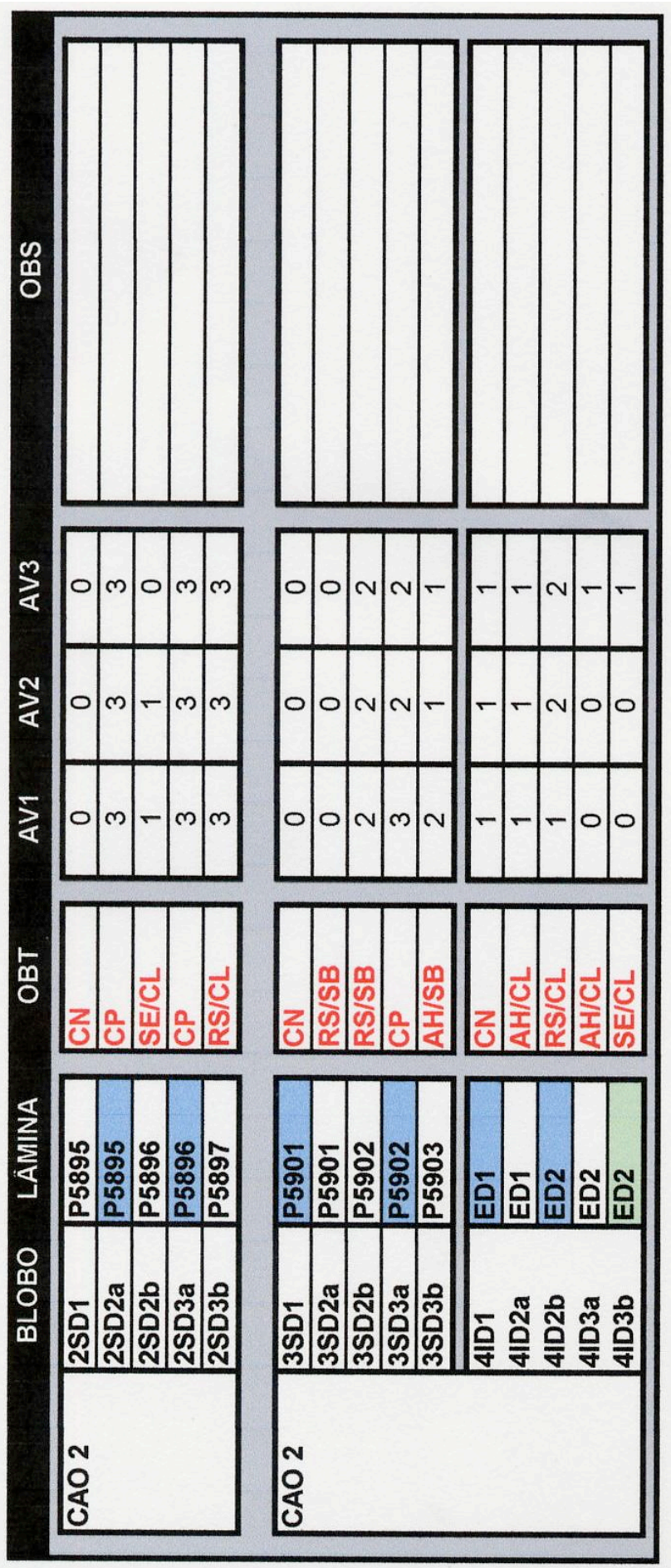


APÊNDICE D - Planilha das avaliações (Cão 3)

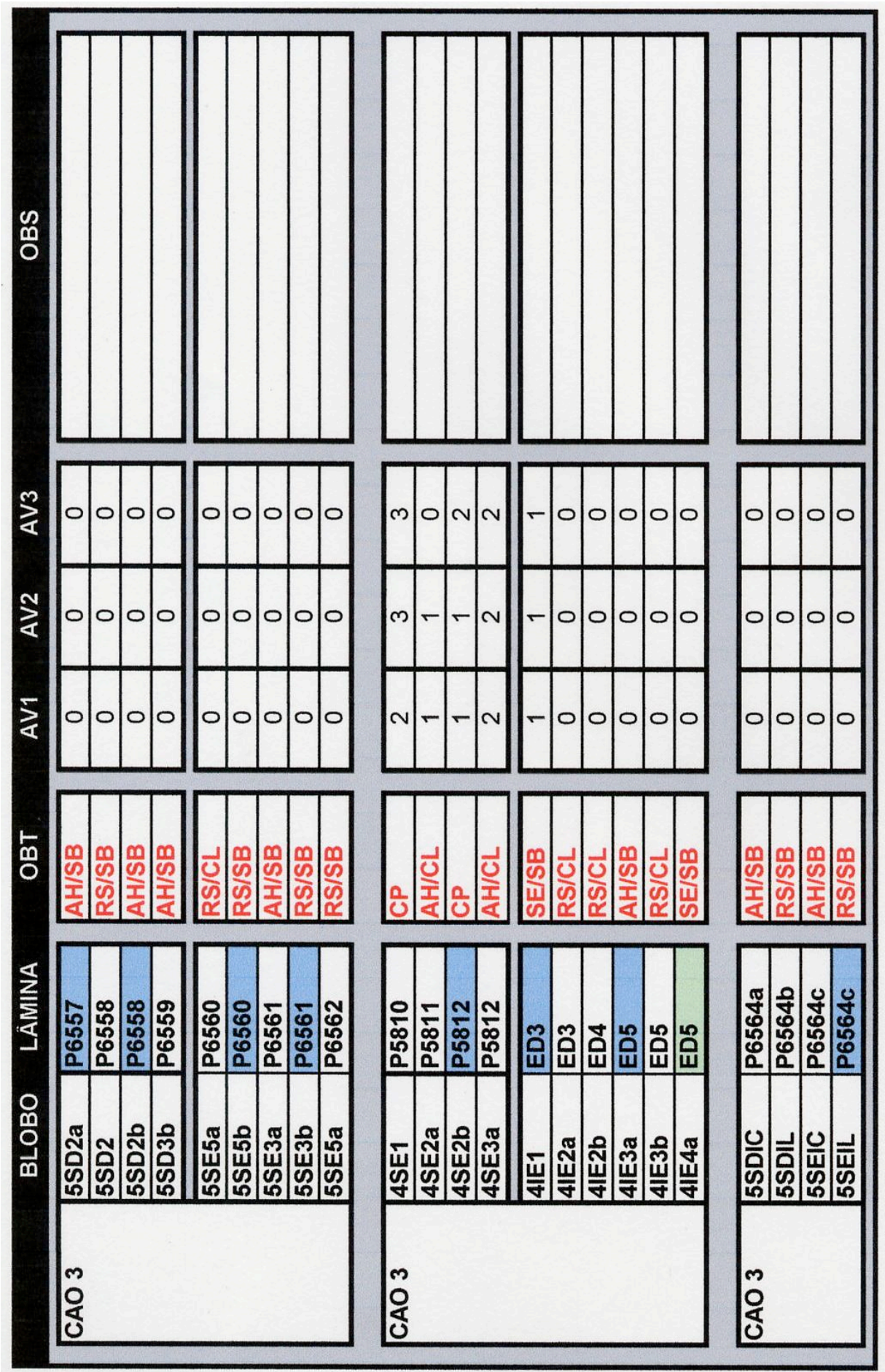


APÊNDICE E - Planilha das avaliações (Cão 4)

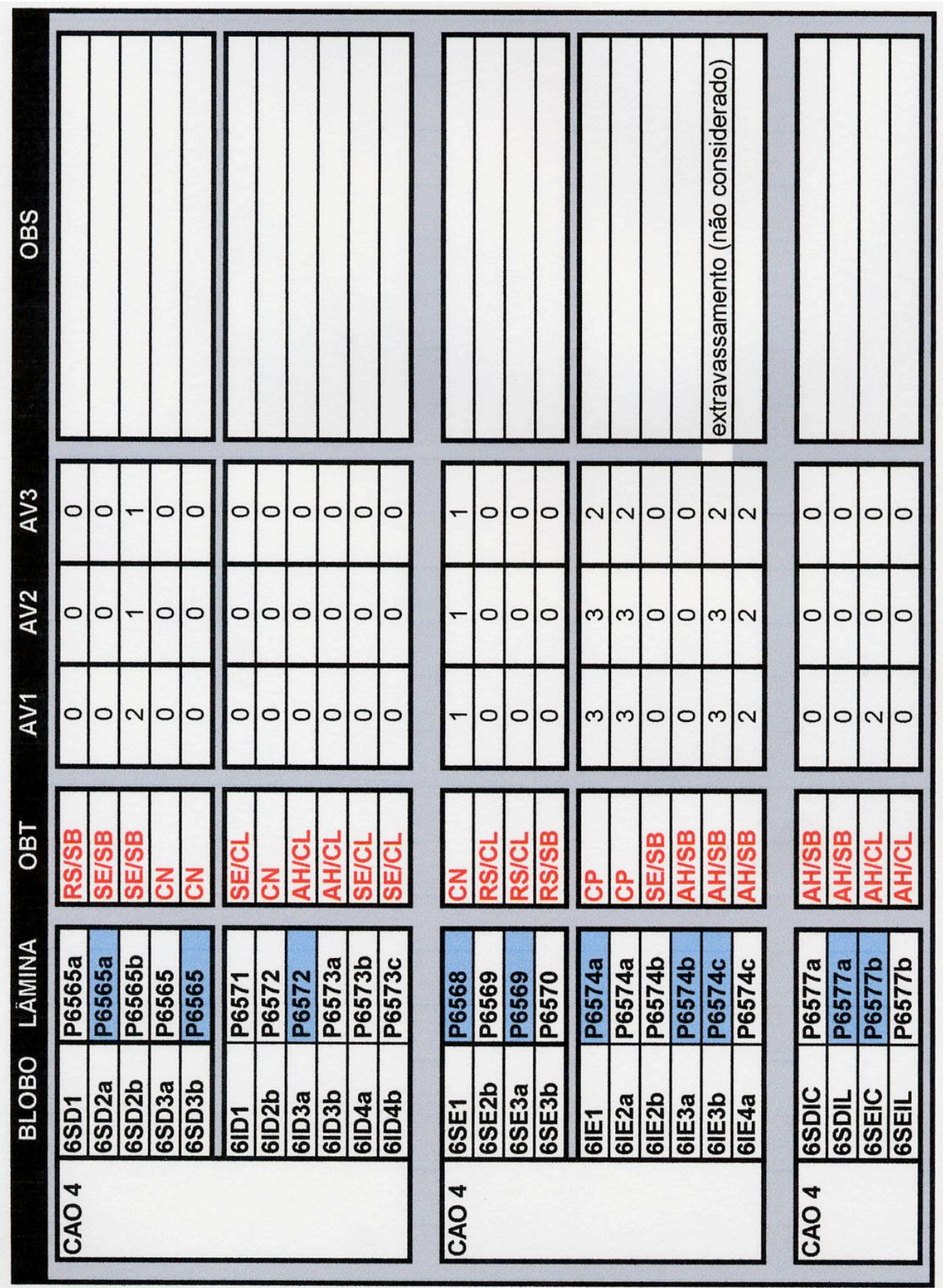


APÊNDICE F - Planilha das avaliações (Cão 5)

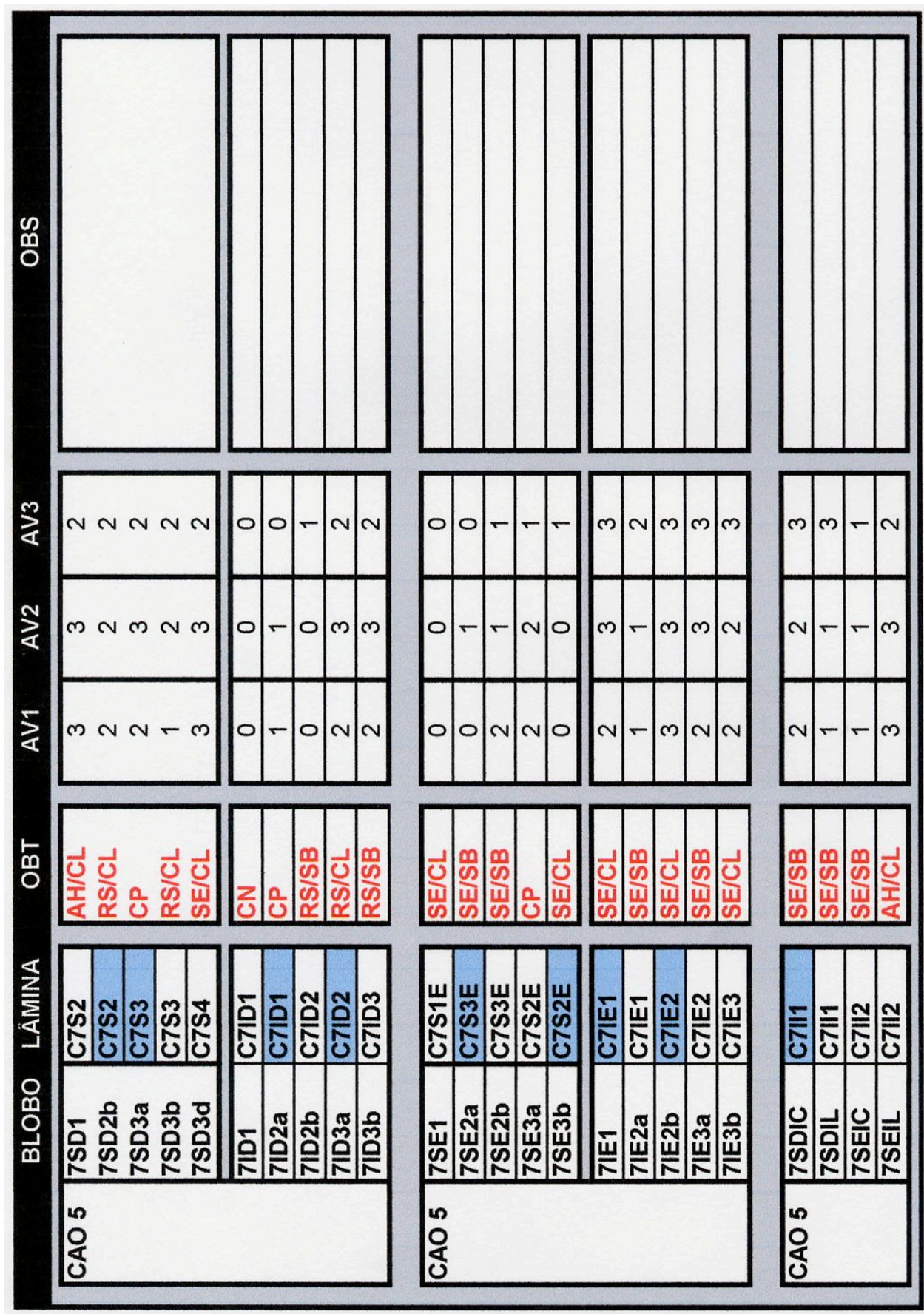

